\title{
DESIGN AND IMPLEMENTATION OF EIGHT-LEGGED ROBOTIC
} TRANSPORTER

\author{
A Thesis \\ presented to \\ the Faculty of California Polytechnic State University, \\ San Luis Obispo
}

\author{
In Partial Fulfillment \\ of the Requirements for the Degree \\ Master of Science in Mechanical Engineering \\ by \\ Jeremy David DePangher
}

September 2013 
(C) 2013

Jeremy David DePangher ALL RIGHTS RESERVED 
TITLE:

AUTHOR:

DATE SUBMITTED:

COMMITTEE CHAIR:

COMMITTEE MEMBER

COMMITTEE MEMBER:
Design and Implementation of Eight-Legged Robotic Transporter

Jeremy David DePangher

September 2013

Saeed Niku, PhD

Professor of Mechanical Engineering

John Ridgely, $\mathrm{PhD}$

Professor of Mechanical Engineering

Peter Schuster, $\mathrm{PhD}$

Professor of Mechanical Engineering 


\section{ABSTRACT \\ Design and Implementation of Eight-Legged Robotic Transporter Jeremy David DePangher}

This thesis contains the design, manufacturing, and testing of a functional eightlegged robotic transporter based on the concept design laid out in U.S. Patent 7,246,671. The device is intended to achieve three different sequences of motion: regular driving, obstacle climbing, and stair climbing. The prototype was carried through concept design, analysis, selection of materials and components, manufacturing, software development, and final assembly and testing. The device can be assembled under multiple configurations, which harbor certain advantages and disadvantages. The results of the testing encourage the continuation of a second iteration of this concept.

Keywords: U.S. Patent 7,246,671, functional, eight-legged, robotic, obstacle, stair, climbing, design, testing, sequence, prototype, configurations. 


\section{ACKNOWLEDGMENTS}

I would like thank my committee for their continued support of my project: Dr. Saeed Niku, my committee chair; Dr. John Ridgely; and Dr. Peter Schuster. These individuals aided me each step along the way, and for that I am very grateful.

My project would not have been possible without the financial support and encouragement of my sponsor, Mr. Michael Goren.

I would also like to acknowledge the technicians at the Mustang '60 machine shop for their help in manufacturing many of the parts necessary for the completion of this project.

Lastly, I would like to thank my family and friends for the motivation to see this project to completion. 


\section{TABLE OF CONTENTS}

LIST OF TABLES ........................................................................................ vii

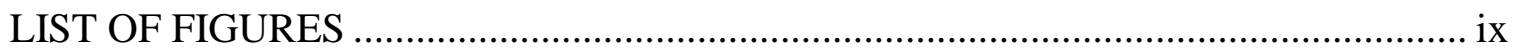

CHAPTER

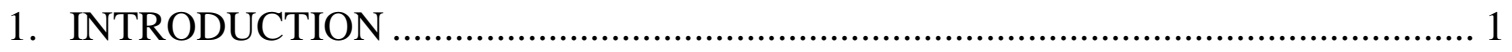

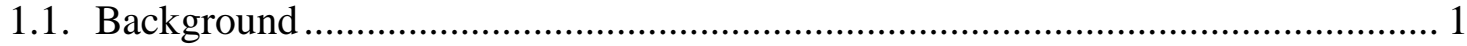

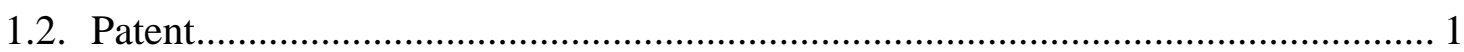

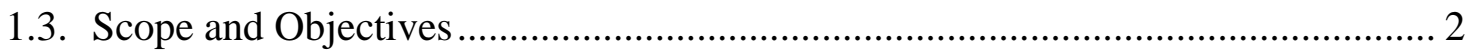

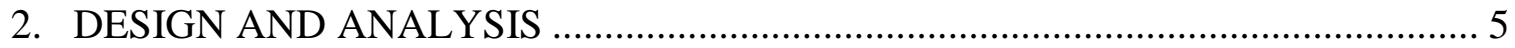

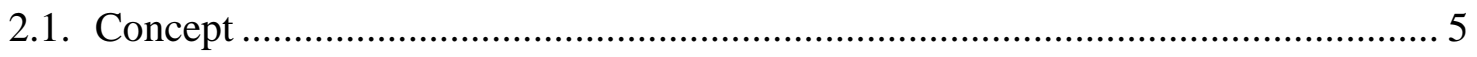

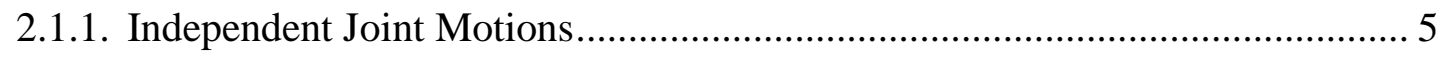

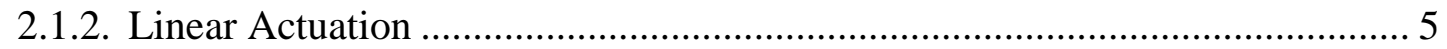

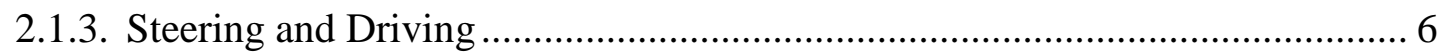

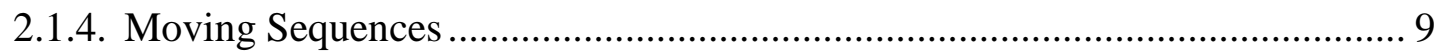

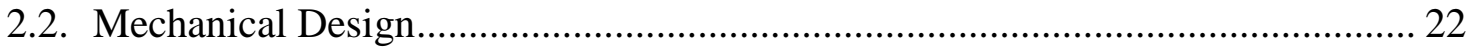

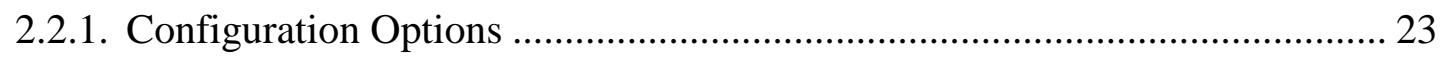

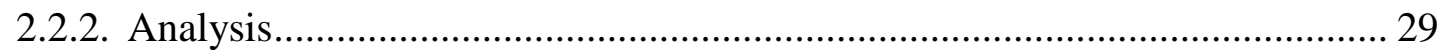

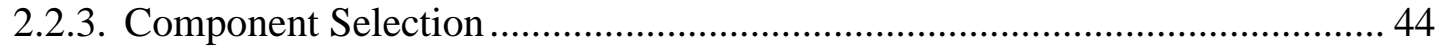

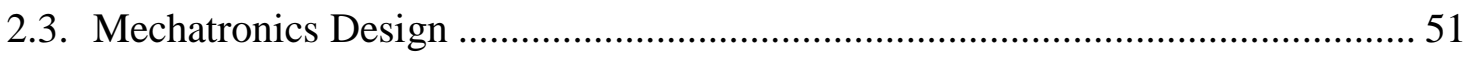

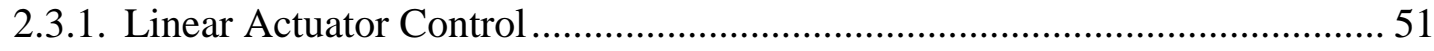

2.3.2. Driving and Steering Motor Control.......................................................... 53

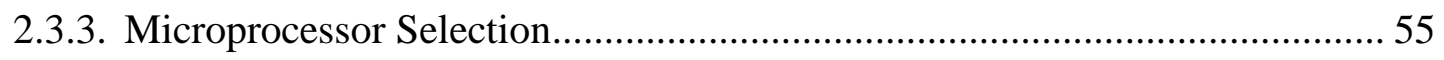

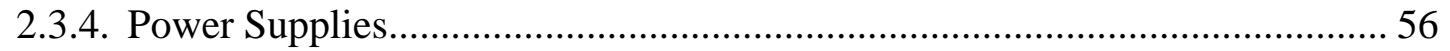

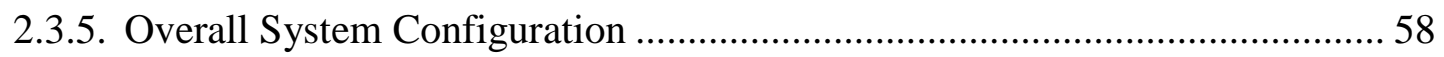

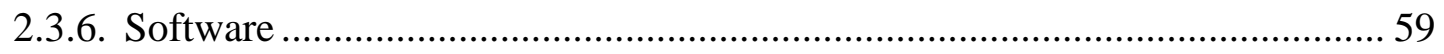

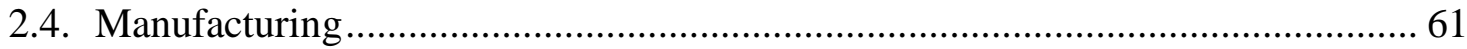

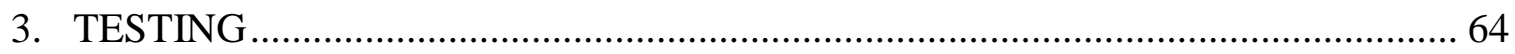

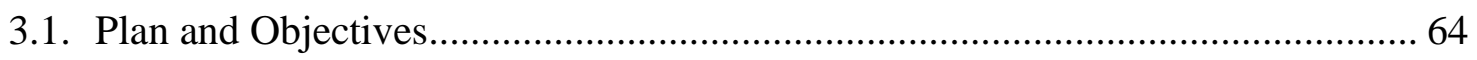

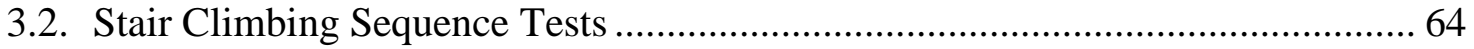




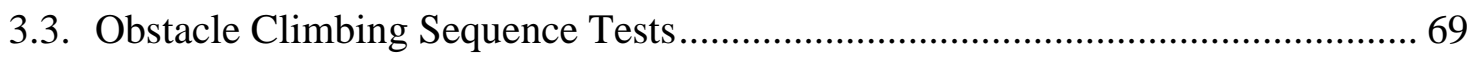

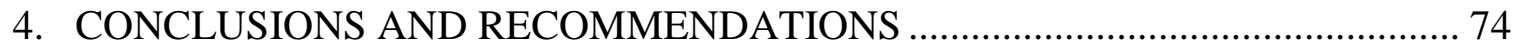

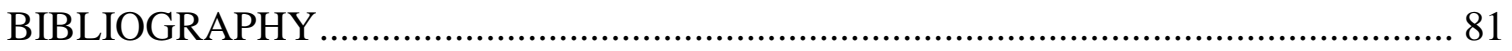
APPENDICIES

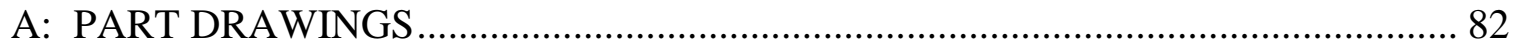

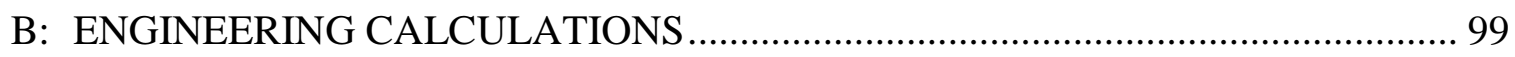

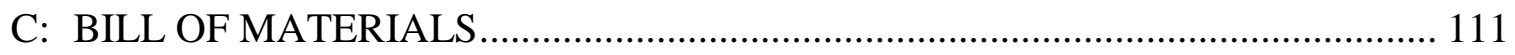

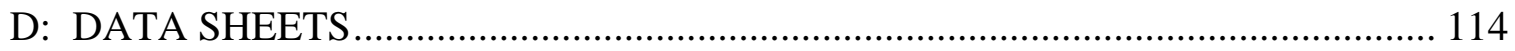

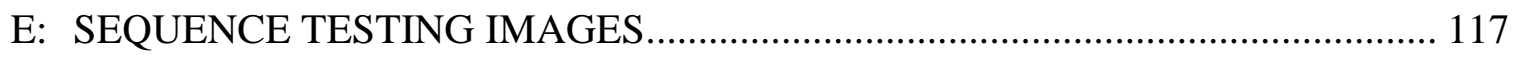

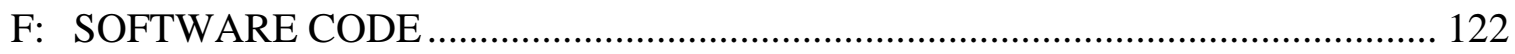




\section{LIST OF TABLES}

2.1. Configuration Options for Driving and Steering Motor Pairs ................................. 7

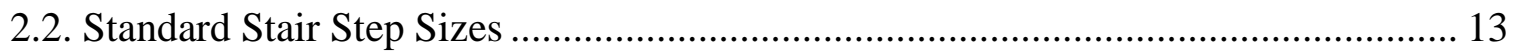

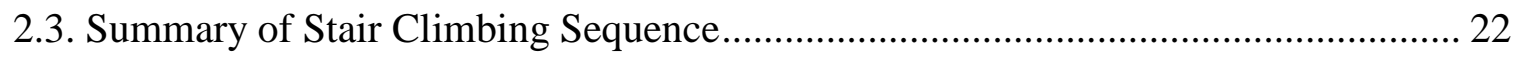

2.4. Variable Inputs for Driving Torque Calculations ............................................. 31

2.5. Inputs for Drive Motor Mounting Bracket Deflection.......................................... 34

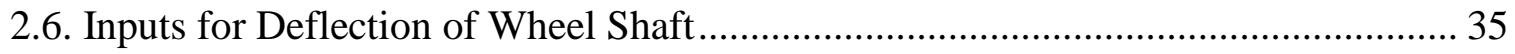

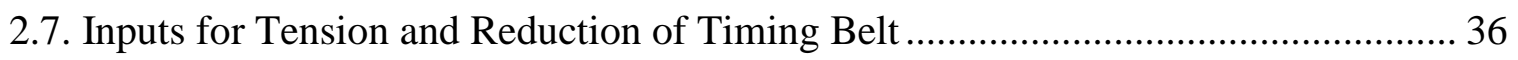

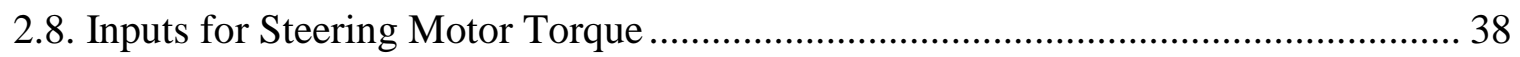

2.9. Inputs for Deflection of Steering Motor Mounting Plate ....................................... 39

2.10. Inputs for Horizontal Support Shaft Deflection .............................................. 40

2.11. Inputs for Wheel Shaft Press Fit ............................................................... 41

2.12. Inputs for Actuator Mounting Screw Stress.................................................. 42

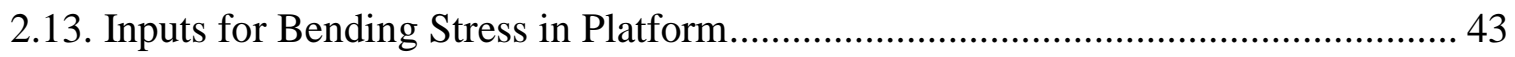

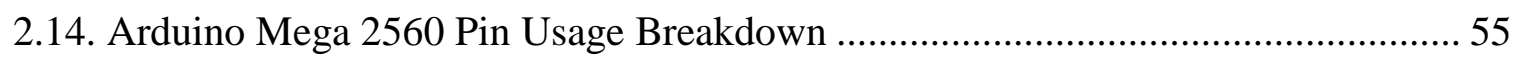

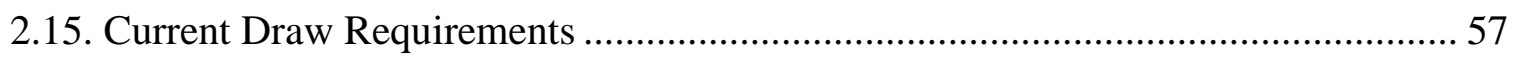

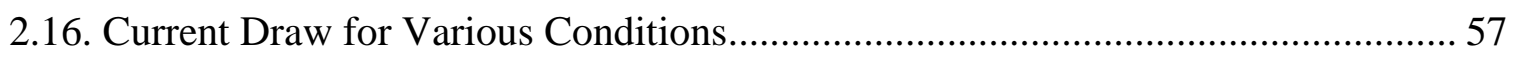

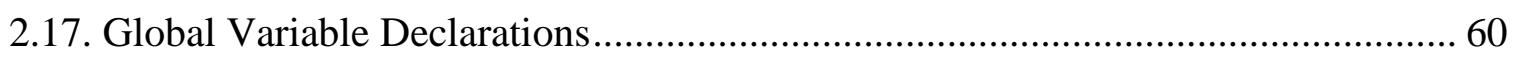

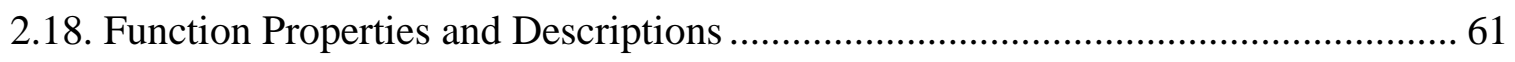

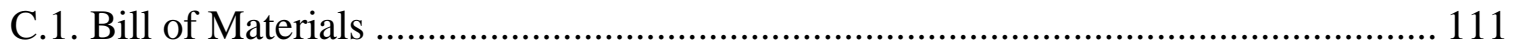




\section{LIST OF FIGURES}

1.1 - Concept Sketch Based on Patent Description........................................................ 4

2.1 - Conceptual Platform with Labeled Pairs ................................................................ 8

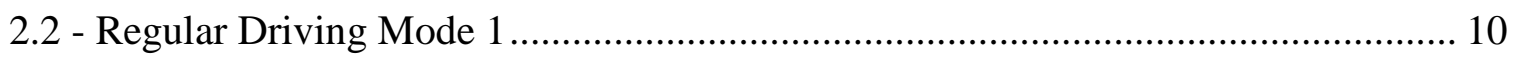

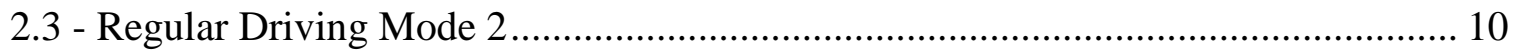

2.4 - Obstacle Climbing Sequence Stage 1 ................................................................ 11

2.5 - Obstacle Climbing Sequence Stage 2 ............................................................. 11

2.6 - Obstacle Climbing Sequence Stage 3a …………............................................ 12

2.7 - Obstacle Climbing Sequence Stage 3b ………….............................................. 12

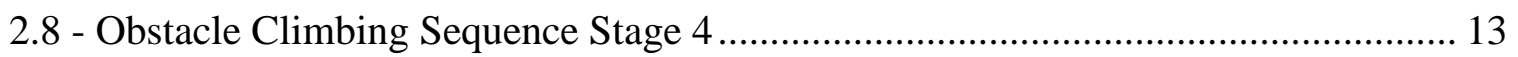

2.9 - Device with Critical Climbing Dimensions.......................................................... 14

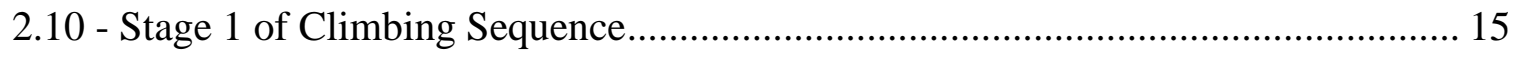

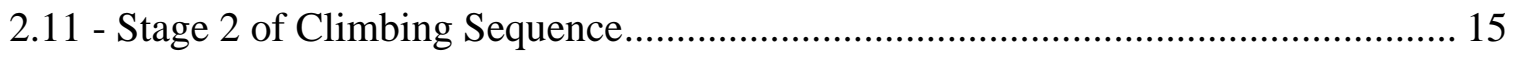

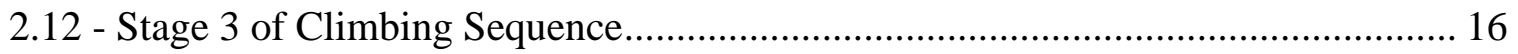

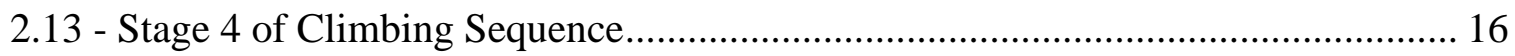

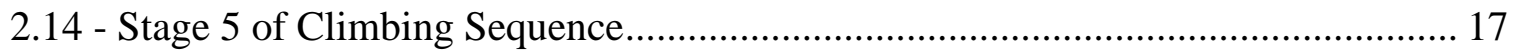

2.15 - Stage 6 of Climbing Sequence........................................................................ 18

2.16 - Stage 7 of Climbing Sequence........................................................................ 18

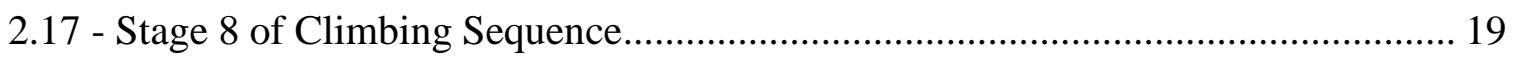

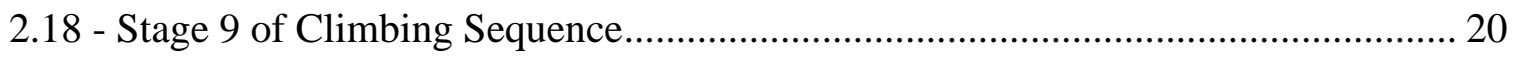

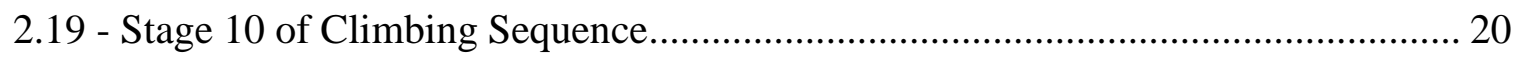

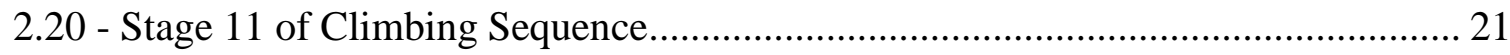

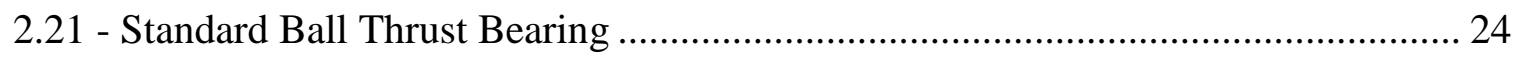

2.22 - Banded Ball Thrust Bearing …………………............................................. 24

2.23 - Turntable Bearing with Assembly ……………….......................................... 25

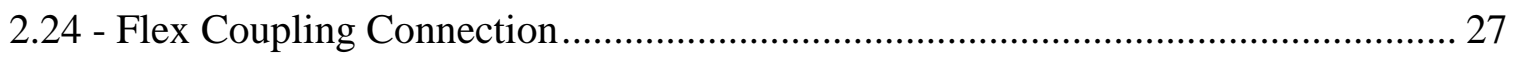

2.25 - Wheel Housing with Bearing Pillow Blocks and Wheel......................................... 28

2.26 - Actuator Tip Being Inserted Into Block to Complete Assembly........................... 29

2.27 - Diagram of Driving Motor Bracket Analysis .......................................................... 33

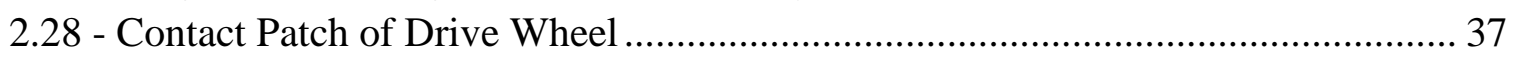

2.29 - Right Angle Geared Motor for Driving .............................................................. 45

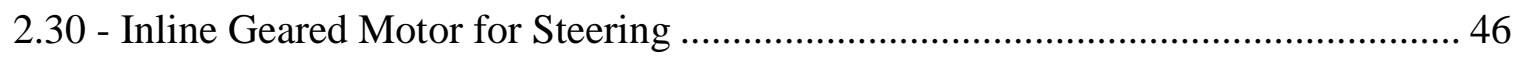

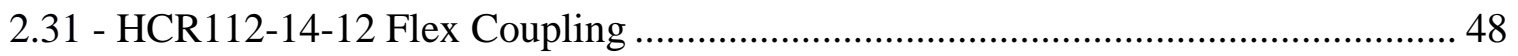

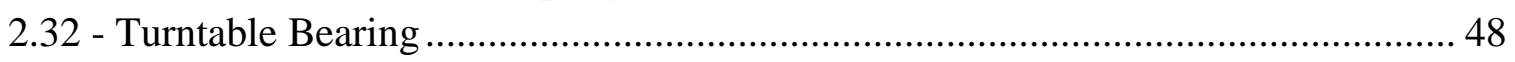

2.33 - Firgelli Automation FA-400-L-12-30 Linear Actuator ......................................... 49

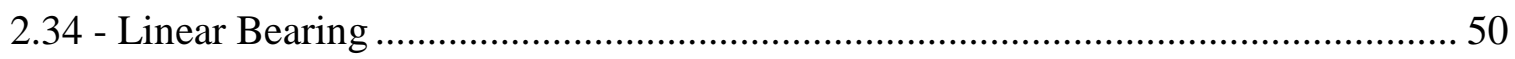

2.35 - Pololu VNH2SP30 Dual Motor Driver Board..................................................... 53 
2.36 - Pololu VNH5019 Single Motor Driver Board................................................ 54

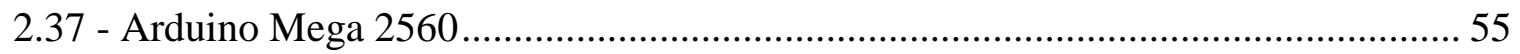

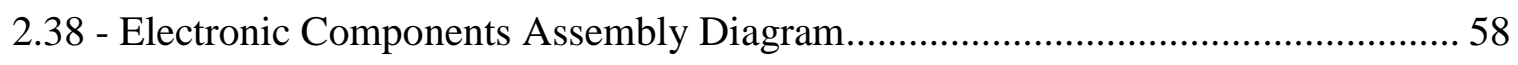

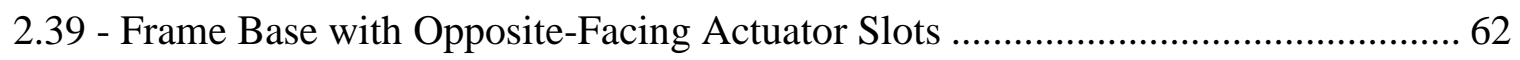

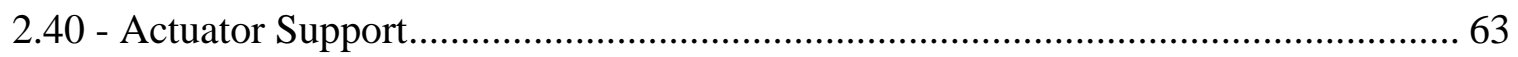

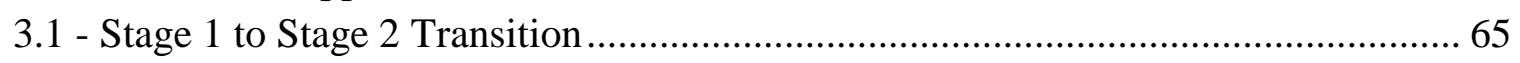

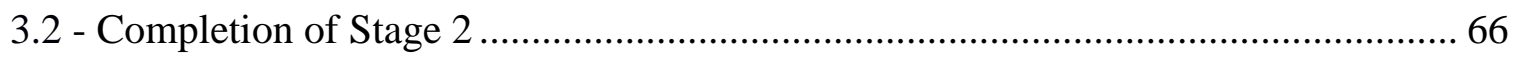

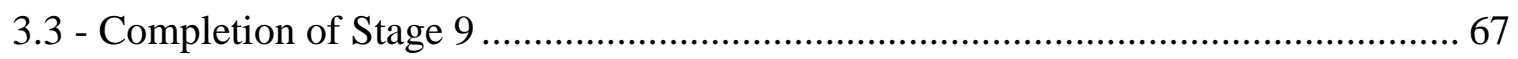

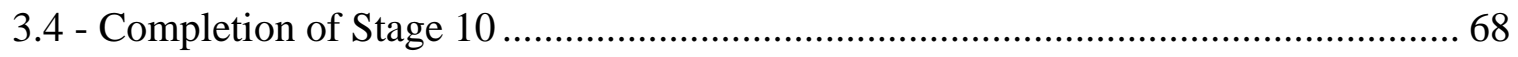

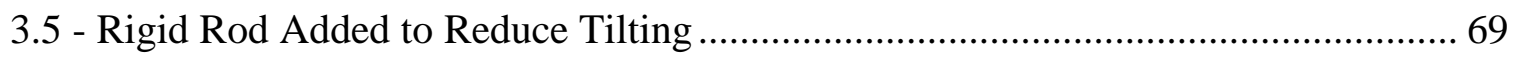

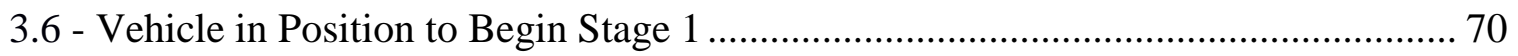

3.7 - Completion of Stage 1 .............................................................................. 70

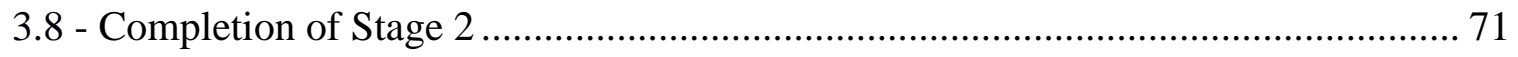

4.1 - Complete Solid Model of 8-Legged Robotic Transporter....................................... 74

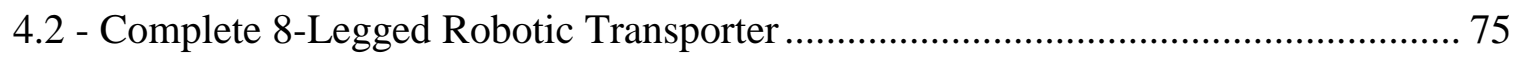

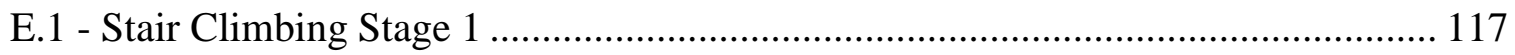

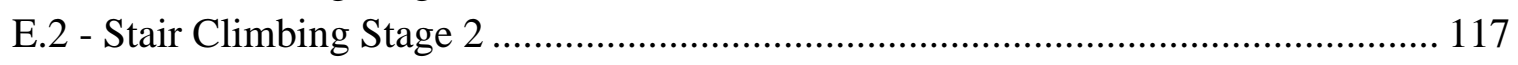

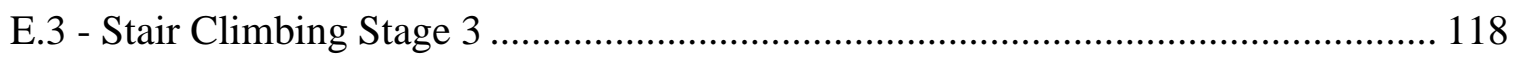

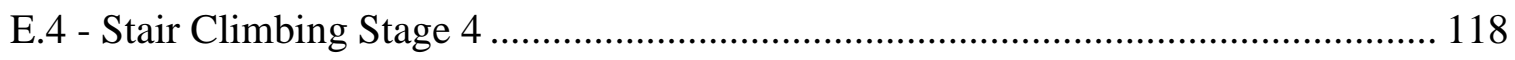

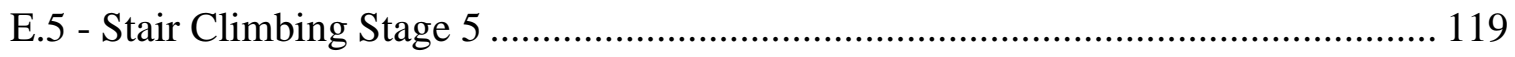

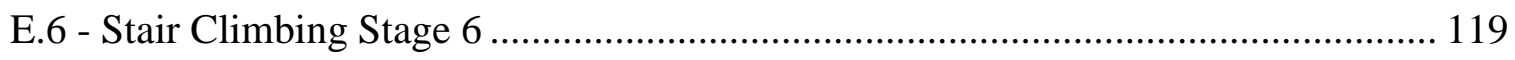

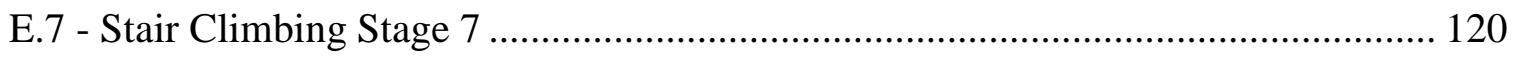

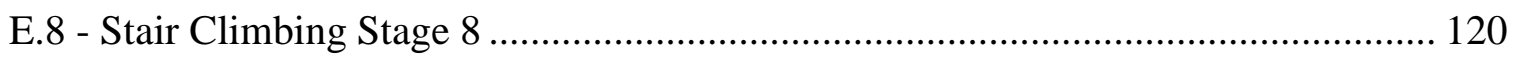

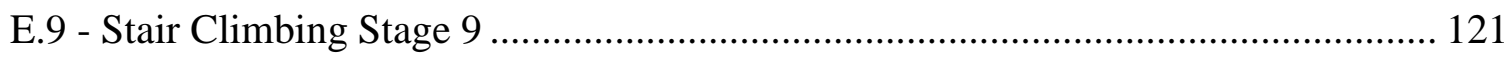

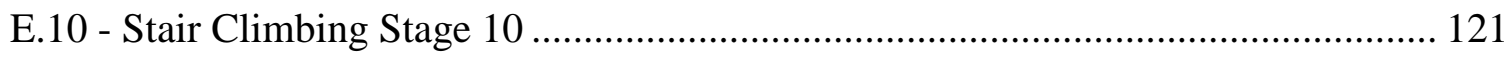




\section{INTRODUCTION}

\subsection{Background}

This thesis is concerned with the designing, manufacturing, and testing of a functional prototype based on the concept design laid out in U.S. Patent No. 7,246,671. This patent, entitled "Stair-climbing human transporter," is the sole inspiration for the body of work done in this thesis.

\subsection{Patent}

According to the patent language, the purpose of this invention is to "transport persons, robots or cargo, moving on a surface, over obstacles and for ascending and descending stairs" [1]. There are several aspects of this invention that not only make it unique from other transportation methods, but also advantageous in comparison.

First, "typically such vehicles cannot climb stairs while keeping their platform and rider level" [1]. Perhaps the most critical example of this is stairs. There currently is not a device that can travel upstairs while keeping its platform flat and also simultaneously meeting the next two requirements.

Second, a main advantage is that the device can transport persons or cargo with multiple different configurations of motion.

"while there are many vehicles that can transport multiple individuals and a payload, many such vehicles are not lightweight and capable of navigating or climbing over obstacles, climbing stairs and also of transporting more than one individual rapidly on common surfaces such as roads and sidewalks. " [1] 
This language points out two key factors at issue in current designs: weight of the vehicle, and having multiple modes of motion to accomplish climbing over obstacles as well as travel on flat ground with reasonable speed.

Third, most vehicles face some level of setback when obstacles are in their path. "Most common vehicles such as automobiles, motorcycles, wheelchairs and gurneys, place all of their points of ground contacts such as wheels on the ground all at the same time, such that when there is an obstacle in the road, such vehicles must run over such obstacle. Often this results in passengers either feeling bumps or having the entire platform or chassis incline rather than staying level." [1]

Being able to avoid obstacles entirely without having to run over them or tilt the platform to overcome them are desirable qualities that common transportation vehicles do not have.

These three factors are the most important features that were considered for this project. Each of these was carefully considered and later implemented in the design and creation of the device.

Under the Claims section of the patent, various descriptions are given of the components and how they interact with each other. While the scope of this project does not include every claim specified in the patent, each of the components that were designed in order to create a functional prototype were based on these claims.

\subsection{Scope and Objectives}

The scope of this thesis consists of extracting the description of the device's components and motions from the patent language, and creating a physical design based on these ideas. The following is a list of characteristics that must be included in the design for the functional prototype. The prototype must: 
- Be able to travel up a flight of stairs.

- Have eight vertical legs, four of which can move in a plane parallel to the ground via horizontal actuation of some sort. The other four must remain fixed to the platform.

- Have a platform upon which a weight can be rested to simulate a person or cargo.

- Be powered from its own on-board power supply.

- Stay level at all times.

For clarification, there were several features included in the patent which did not have to be represented in this first prototype. The prototype did not have to:

- Use sensors.

- Be wirelessly controlled.

- Be autonomous.

- Be made out of a specific type of material.

Using these specifications, a concept design could be formulated. The design phase, including calculations, selection of materials and components, and any necessary analysis, follows from the concept design. Once the critical portions of the design were decided, the relevant parts could be machined. The machined parts would be quality checked and assembled along with the electronic components. Once the electronics are fully integrated with the mechanical assembly, testing of the device's functions could commence. The testing is to ensure that not only the calculations and analytical predictions of the design were adequate, but also that the device met the specifications. Once it is verified that the prototype meets all the specifications, the project is complete. 
The final version of the prototype will look and function something like the diagram in Figure 1.1.

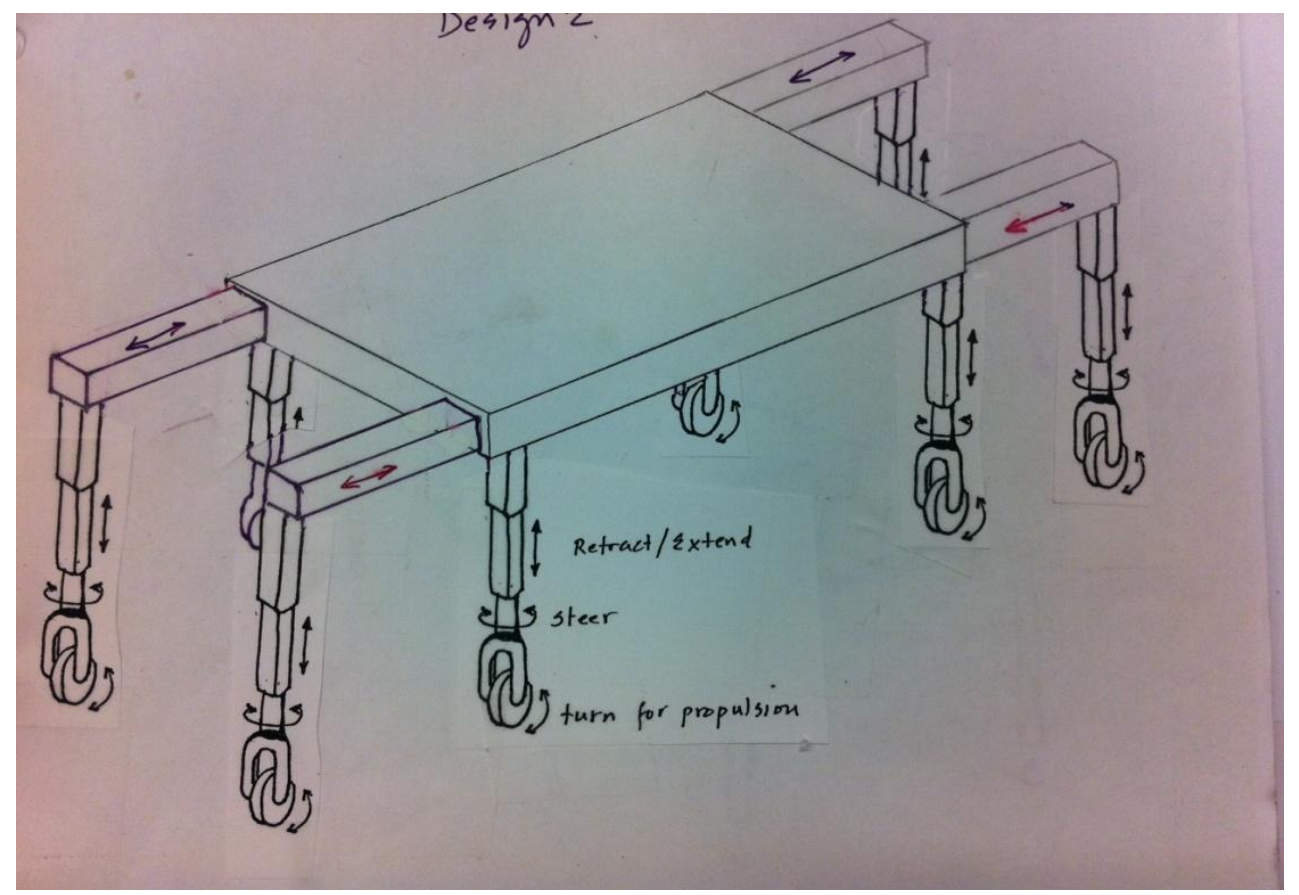

Figure 1.1 - Concept Sketch Based on Patent Description

Figure 1.1 shows that the prototype will have eight vertical legs which can each extend and retract. Four of these vertical legs will be attached to horizontal actuators that can extend and retract the vertical legs relative to the platform. Each vertical leg will have a wheel at its base, which can rotate in either a free or controlled manner. Each of the vertical legs must also be able to steer the wheel either via free or controlled motion. The platform at the center of the device will be flat and be able to carry cargo to simulate a load. 


\section{DESIGN AND ANALYSIS}

\subsection{Concept}

The general concept for the type of motion and types of components used to make that motion happen are described in the patent itself. However, in order to turn the general patent language into something that could function mechanically, there were several additional factors that had to be considered. These factors include:

- Determining the minimum number of independent joint motions

- How to accomplish the linear actuation

- How to accomplish the steering and driving of each of the vertical legs

\subsubsection{Independent Joint Motions}

There are twelve linear actuators - eight vertical and four horizontal. Each of these constitutes one potential joint of motion. At the tip of four of the vertical legs will be assemblies containing a steering and a driving motor. ${ }^{1}$ This constitutes an additional eight joints of motion for a total of twenty.

\subsubsection{Linear Actuation}

A component was needed to accomplish the raising and lowering of all eight vertical legs, as well as the extension and retraction of the fore and aft pairs of vertical legs relative to the platform. The type of linear actuation could be narrowed down to two choices. Either a fully assembled linear actuator component could be purchased, or a linear actuator could be built from smaller components. Due to time and manufacturing

\footnotetext{
${ }^{1}$ Reasons for only four of the legs containing motorized steering and driving are discussed 2.1.3.

${ }^{2}$ Discussion of the specific choice of the type of actuator is continued in 2.2. 
constraints, the former option was chosen. In this way, the eight vertical legs in addition to the four horizontal actuators would each be controlled by a linear actuator, electronically controlled by the microprocessor unit. ${ }^{2}$

\subsubsection{Steering and Driving}

The choice of having four pairs of vertical legs with steering and driving motors is not arbitrary. There are several possible configurations for which vertical legs have steering and driving motors. Theoretically, the number configurations of steering and driving motors could range all the way from all four pairs having steering and driving motors to just one pair having them. In addition to the number of pairs of legs with motors, any combination of configurations is also possible. For example, the front and back vertical pairs could have driving and steering motors while the middle two pairs do not. All of these considerations result in a large number of possible configurations, not all of which are necessary to consider for the actual design. An approach was undertaken to reduce the number of configurations that would need to be tested. The number and configuration of pairs of legs with motors is determined by the required functionality of the prototype. Since the prototype must accomplish regular driving on flat surfaces, climbing over obstacles, and climbing up stairs, the pairs must be chosen in order to satisfy each of these challenges.

- In the case of regular driving on flat surfaces, the platform could be modeled like a two-wheel drive car. Regular turning and driving can be accomplished with

\footnotetext{
${ }^{2}$ Discussion of the specific choice of the type of actuator is continued in 2.2.
} 
motors on just one pair of legs. Since this would mean that the other pair contacting the ground would be free, the motorized pair would need to be in the front if driving forward, and in the back if driving backwards. Caster wheels, which are free in both driving and steering, could not lead the motion.

- Climbing over obstacles would require at most motors on two pairs of legs. This is because there is never an instance when there would be more than two pairs of legs not touching the ground. Given all combinations of pairs that are contacting or not contacting the ground at any given time, only two pairs of vertical legs would need steering and driving motors.

- Climbing up stairs is a more complicated process that implements all the available joints of motion in the system. But even after analysis of each of the stages of motion, at any given time at most only two pairs of legs would be utilizing their steering and driving motors to move the device. ${ }^{3}$

These considerations allow the design to be simplified to only six possible configurations involving motors on only two pairs of legs. Table 2.1 shows all possible configurations. Figure 2.1 labels each pair on the platform for reference.

Table 2.1. Configuration Options for Driving and Steering Motor Pairs

\begin{tabular}{|c|c|c|c|c|}
\hline Configuration & Pair 1 (Fore) & Pair 2 & Pair 3 & Pair 4 (Aft) \\
\hline 1 & $\checkmark$ & $\checkmark$ & - & - \\
\hline 2 & $\checkmark$ & - & $\checkmark$ & - \\
\hline 3 & $\checkmark$ & - & - & $\checkmark$ \\
\hline 4 & - & $\checkmark$ & $\checkmark$ & - \\
\hline 5 & - & $\checkmark$ & - & $\checkmark$ \\
\hline 6 & - & - & $\checkmark$ & $\checkmark$ \\
\hline
\end{tabular}

\footnotetext{
${ }^{3}$ See 2.1.4.
} 


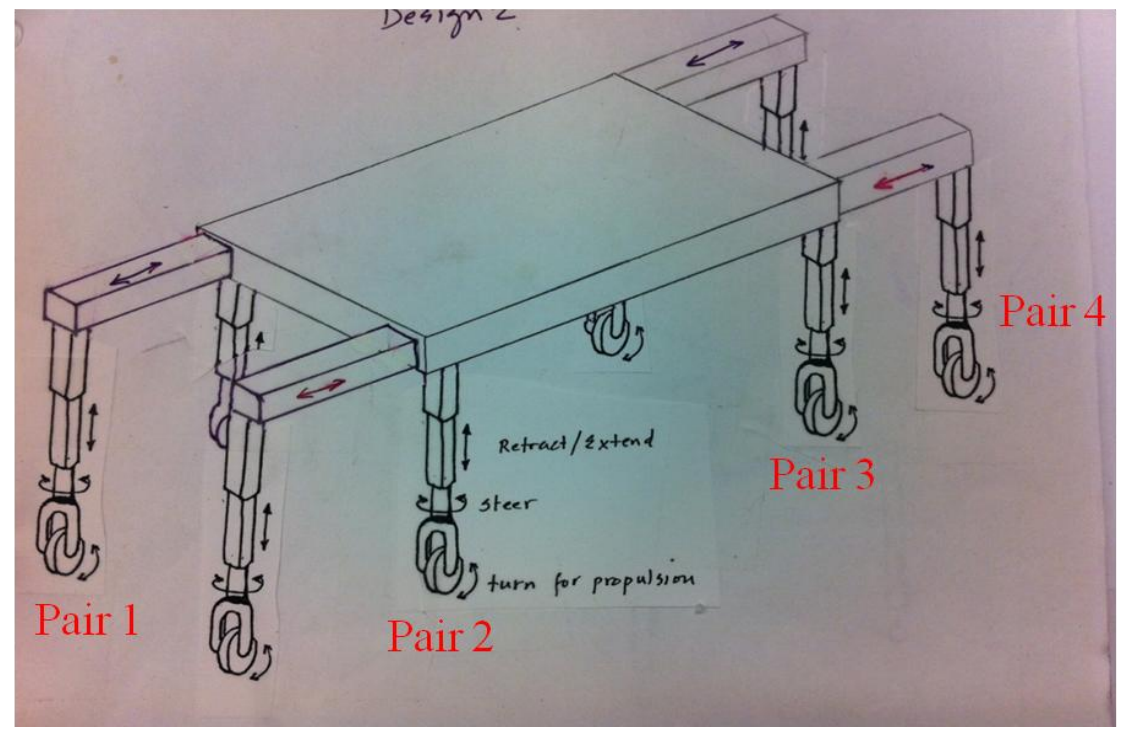

Figure 2.1 - Conceptual Platform with Labeled Pairs

The best configuration is ultimately determined by testing. However, basic analysis reveals that configurations 3 and 4 are insufficient. During a regular driving sequence on flat ground, the default would be to have pairs 2 and 3 on the ground with pairs 1 and 4 lifted up. ${ }^{4}$ In order for the device to move at all, at least one of Pairs 2 or 3 must have motors. This eliminates configuration 3 . While climbing over obstacles, there are foreseeable instances when 2 and 3 must be lifted up to traverse the obstacle, and 1 or 4 must drive forward or reverse in order to put 2 and 3 back on the ground. This eliminates Configuration 4. Configurations 1, 2, 5, and 6 remain as possible configurations with which the device can operate.

Even though these four remaining configurations could work in theory, further inspection shows that Configurations 1 and 6 create unnecessary disadvantages. During

\footnotetext{
${ }^{4}$ Having Pairs 2 and 3 on the ground during regular driving would provide the most balance in the system, since these pairs are only creating transverse loads, not transverse and bending loads.
} 
the stair climbing sequence, there would be times where the two front pairs are on the stairs and the two back pairs are on the ground. One of the front pairs and one of the back pairs should have motorized wheels that can brake in place to keep the device from slipping. Considering this as a safety precaution, Configurations 1 and 6 are not ideal. This leaves Configurations 2 and 5 to test. Testing each of these remaining configurations would ultimately determine which one is optimized for all conditions. ${ }^{5}$ In order to test these two configurations, however, the legs would have to be designed so that the components could be easily interchanged.

\subsubsection{Moving Sequences}

As previously mentioned, the three major applications of this device will be to 1) travel on flat ground, 2) climb over obstacles, 3) climb up and down stairs. The most frequent usage of the vehicle will be on flat ground, and this application is discussed first. Climbing over obstacles and climbing up and down stairs are secondary applications that will be discussed next.

The primary application of the device will be to travel on flat ground. When the vehicle is travelling this way, there are two likely modes of operation. The first one has Pairs 2 and 3 on the ground while Pairs 1 and 4 are raised. In order for this mode to be feasible as a regular driving mode, a motorized pair would have to be put on Pair 2. This configuration is named Mode 1. It is sketched in Figure 2.2.

\footnotetext{
${ }^{5}$ See 3 for a determination of the final configuration.
} 


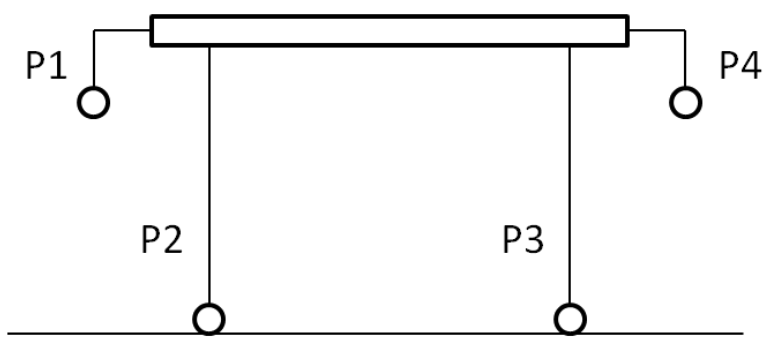

Ground

Figure 2.2 - Regular Driving Mode 1

The second mode of operation has Pairs 1 and 4 on the ground while Pairs 2 and 3 are raised. This mode, Mode 2, is less common because during regular driving there is no necessity for Pairs 1 and 4 to be controlling the motion and therefore inducing unnecessary bending in their horizontal actuators. ${ }^{6}$ Mode 2 is shown in Figure 2.3.

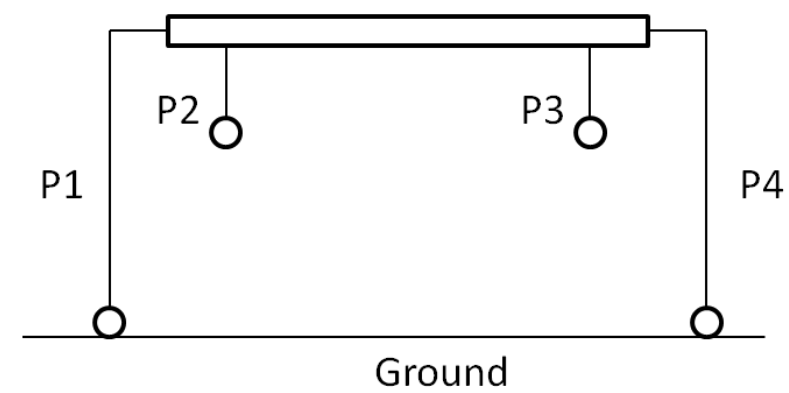

Figure 2.3 - Regular Driving Mode 2

The next major application of the device is to traverse obstacles. A brief sequence is laid out in this section to demonstrate how this will be accomplished. Stage 1 involves extending Pair 1 over the obstacle, while keeping the rest of the pairs in place. Figure 2.4 shows Stage $1 .^{7}$

\footnotetext{
${ }^{6}$ Even if the horizontal actuators are completely retracted, the fact that Pairs 1 and 4 are farther away than Pairs 2 and 3 from the center of gravity means that there will be additional stress on the platform. If this can be avoided, it should be.

${ }^{7}$ All arrows in Figures $2.3-2.18$ indicate the direction of motion that took place in order for the joint to arrive at that position. For example, an up arrow on a vertical actuator means that the actuator retracted to
} 


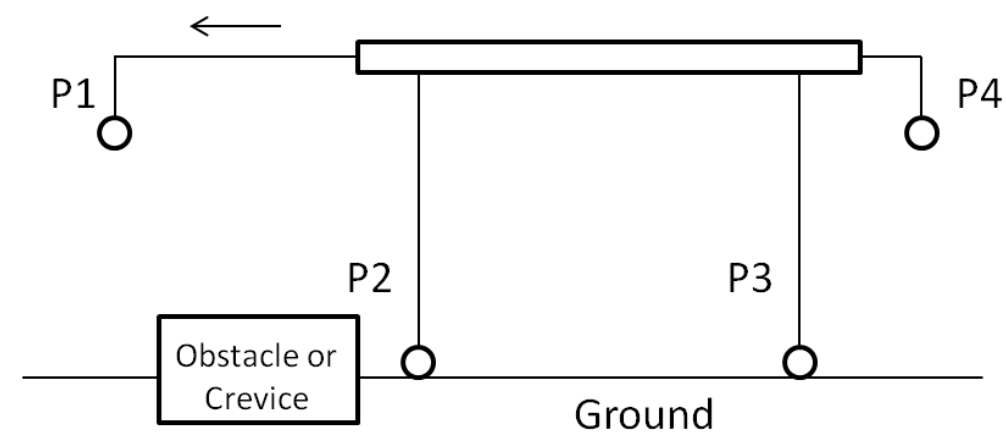

Figure 2.4 - Obstacle Climbing Sequence Stage 1

Once Pair 1 is extended over the obstacle, Pairs 1 and 4 must be lowered to the ground so that Pairs 2 and 3 can traverse the space over the obstacle. Stage 2 is shown in Figure 2.5.

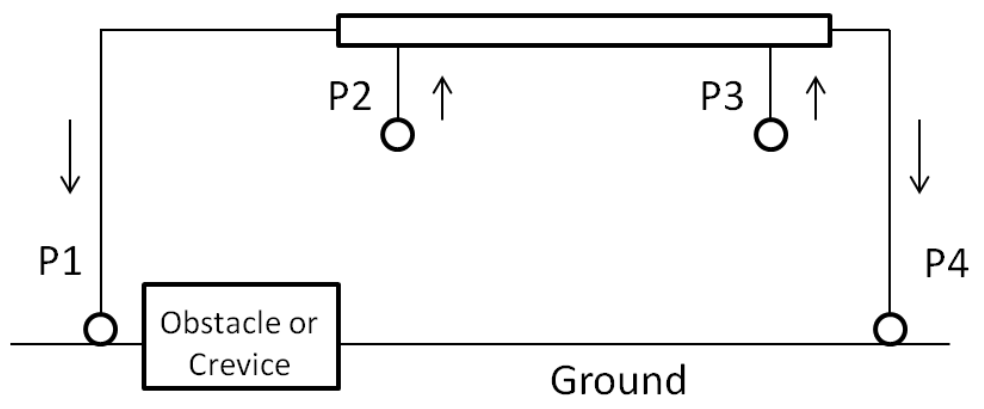

Figure 2.5 - Obstacle Climbing Sequence Stage 2

Stage 3 involves carrying the platform over the obstacle. This can most easily be accomplished by rolling Pairs 1 and 4 forward as far as possible. If necessary, depending upon the size of the obstacle, extension of the horizontal actuators might be required for extra distance. Stage 3 is shown in Figure 2.6.

get to that position. It does not indicate the motion of the next stage. Labels such as "P1" refer to the pair of actuators, such as "Pair 1," being discussed in the text. 


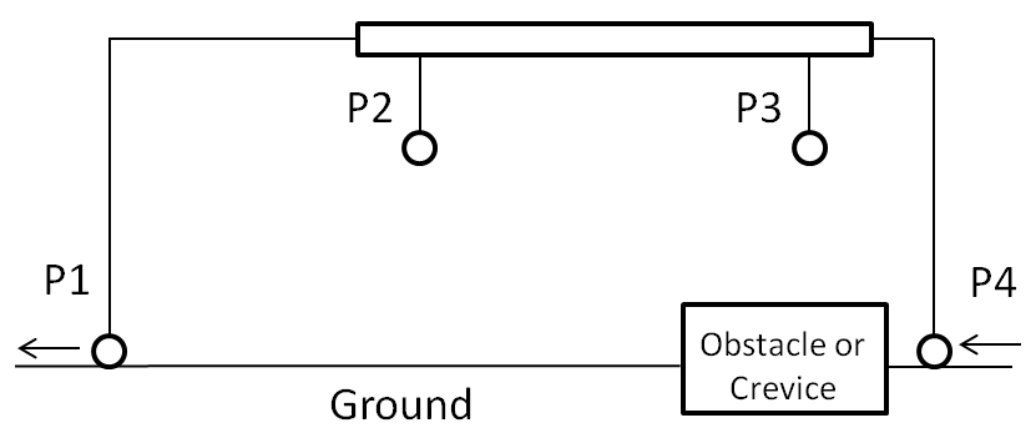

Figure 2.6 - Obstacle Climbing Sequence Stage $3 a$

Figure 2.6 shows that in order for the platform to completely traverse the obstacle, Pair 4's horizontal actuators must extend past the obstacle. Figure 2.7 demonstrates what is, in this case, a necessary second part to Stage 3 .

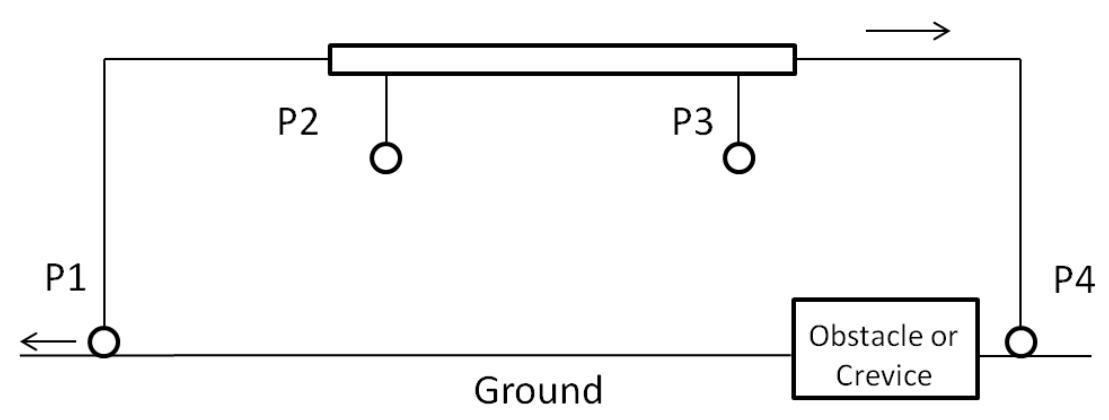

Figure 2.7 - Obstacle Climbing Sequence Stage $3 b$

In order to complete the sequence, Pairs 2 and 3 must lower to the ground and Pairs 1 and 4 must return to their original raised position. Figure 2.8 shows Stage 4 , the final stage. After Stage 4, the device will begin driving on flat ground again. 


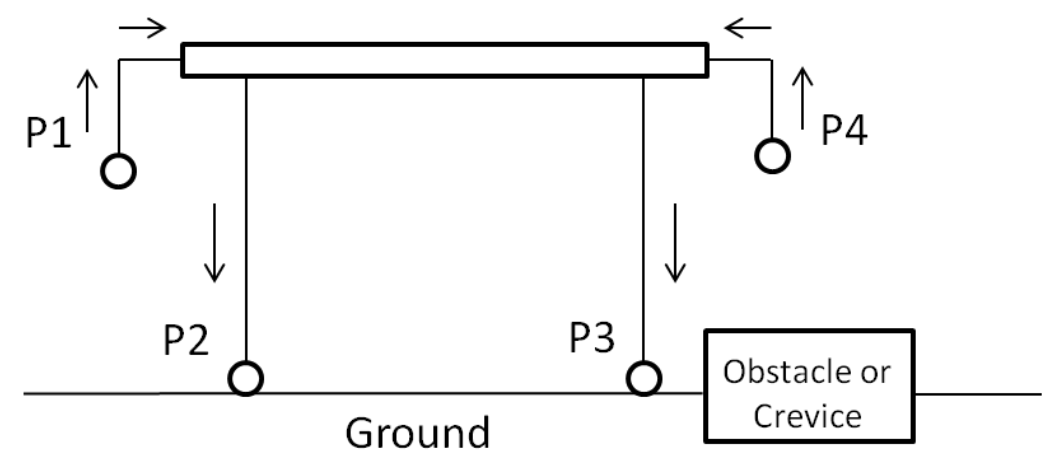

Figure 2.8 - Obstacle Climbing Sequence Stage 4

The final application of the device is to climb up a full flight of stairs. Because stairs generally have certain standard dimensions, the platform would need to be designed in a way that would allow it to climb any set of stairs while keeping the platform itself level with the ground. Using average stair riser and tread sizes, the dimensions for the length of the platform as well as the actuator stroke lengths could be determined. Table 2.2 shows these average lengths.

\section{Table 2.2. Standard Stair Step Sizes}

\begin{tabular}{|c|c|}
\hline & Dimension (in) \\
\hline Riser & 8 \\
\hline Tread & 11 \\
\hline
\end{tabular}

The length of each linear actuator is determined by its stroke length. If a larger stroke length is desired, then a longer actuator is required. In order for the actuators to be in-line with each other and not overhang the edge of the platform, the actuators had to be kept at a maximum stroke length of $18 " .8$ This meant that the horizontal pair could extend to the second step. Because of the large increase in cost for actuators of stroke lengths

\footnotetext{
${ }^{8}$ As compared to the opposing horizontal actuators being offset or placed on top of each other.
} 
over 30 ", it was decided early on that the prototype would be demonstrated using a specially fabricated staircase with the same length tread but half-scaled risers. As will be described in the following diagrams, this riser height of 4" would allow the maximum height dimension (28") to be reached with a 30 " stroke linear actuator.

Analysis of each stage of the motion of the device up a flight of stairs was the key to determining certain dimensions. Figure 2.10 through Figure 2.20 describe the eleven stage process involved in the device travelling from flat ground to being completely on a set of stairs.

There are a few dimensions that are important to consider for all of the following diagrams. First, the length of the platform is 48". Second, there are 5" between Pair 2 and its closest edge, and Pair 3 and its closest edge. Third, the wheels and their housings at the base of each leg are approximately 10" tall, which makes the potential height of the platform $30 "+10 " \approx 40$ ". Figure 2.9 shows these dimensions in a two-dimensional sketch of the platform.

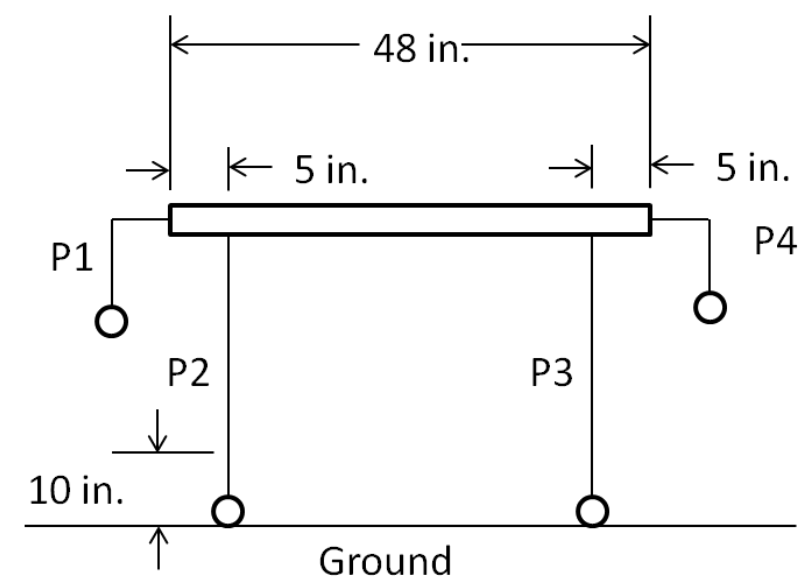

Figure 2.9 - Device with Critical Climbing Dimensions

\section{$\underline{\text { Stage } 1}$}




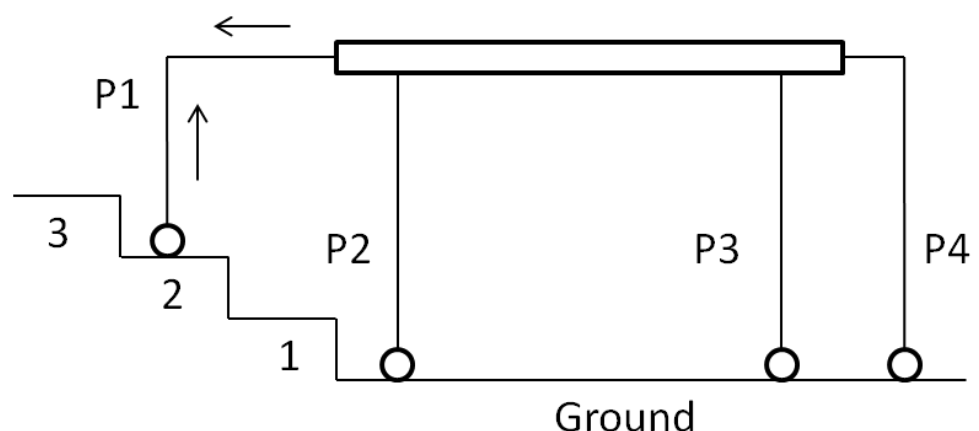

Figure 2.10 - Stage 1 of Climbing Sequence

The first stage of motion involves moving Pair 1 from the ground to the second stair. ${ }^{9}$ This involves retracting Pair 1's vertical actuators and extending its horizontal ones. The maximum distance between Pair 1 and Pair 2 is 23"; 18" of stroke plus 5" from Pair 2 to the edge of the platform where the stroke begins. To position Pair 1 at the center of stair 2, the actuator must extend a minimum of $13.5{ }^{\prime 10}$

\section{$\underline{\text { Stage } 2}$}

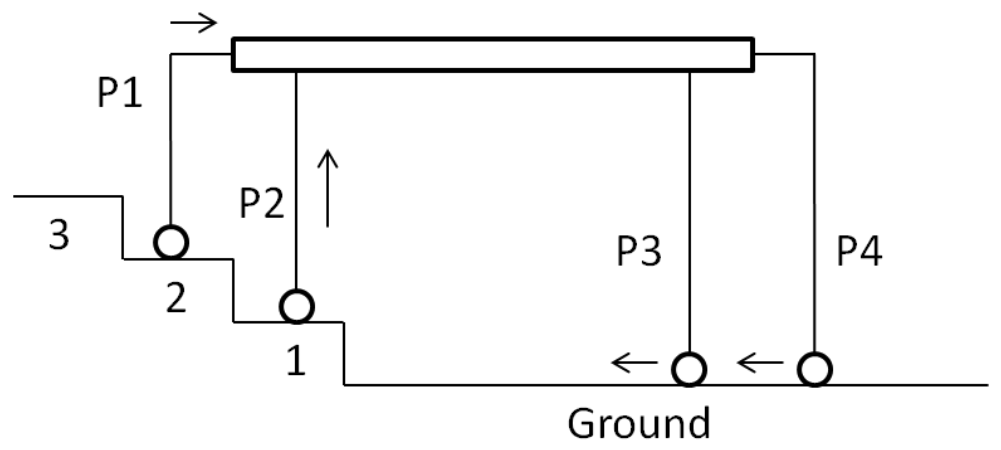

Figure 2.11 - Stage 2 of Climbing Sequence

\footnotetext{
${ }^{9}$ The first ten diagrams show Pair 4 touching the ground. While this is not necessary until Stage 8 , it is shown simply for consistency. Lowering Pair 4 in preparation for a stair climbing sequence would also save time, since Pair 4 must contact the ground during the sequence.

${ }^{10}$ This minimum distance assumes the wheels of Pair 2 are touching the base of the first step. The distance between the edge of the wheels on Pair 2 and the edge of the platform is 3 ". This is overhang over the first step, so by subtracting this from one and a half times the tread length (16.5") gives 13.5".
} 
The transfer of Pair 2 from the ground to stair 1 requires three motions. First, Pair 2 must retract. Second, the horizontal actuators connected to Pair 1 must also retract. ${ }^{11}$ Third, the wheels on Pairs 3 and 4 must roll forward.

\section{$\underline{\text { Stage } 3}$}

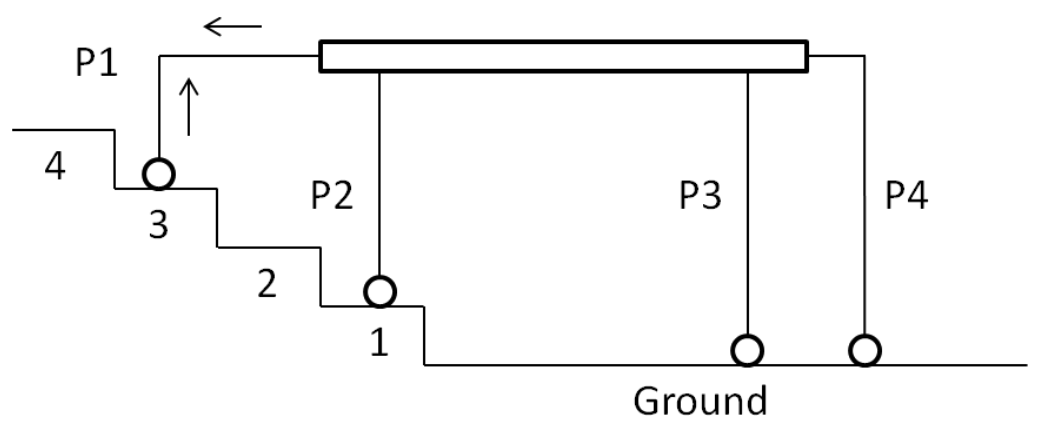

Figure 2.12 - Stage 3 of Climbing Sequence

Stage 3 is essentially Stage 1 repeated. Pair 1 must move from stair 2 to stair 3 to clear the way for Pair 2 to move from stair 1 to stair 2 . At this point, the only motion required to achieve Stage 3 is the retraction of the vertical actuators of Pair 1 while also extending the horizontal actuators of Pair 1.

$\underline{\text { Stage } 4}$

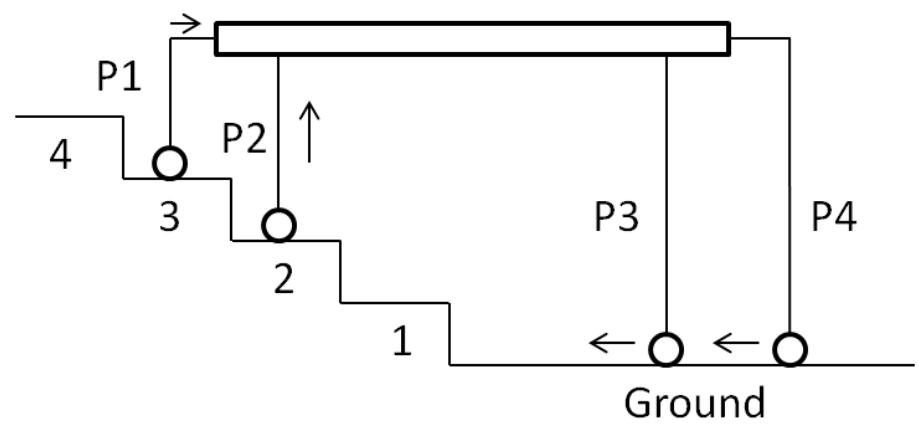

Figure 2.13 - Stage 4 of Climbing Sequence

\footnotetext{
${ }^{11}$ A third motion is required if Pairs 3 and 4 do not have caster wheels. They must drive forward simultaneous with Pair 2's horizontal retraction in order to keep Pairs 3 and 4's wheels from dragging on the ground.
} 
Stage 4 is closely related to Stage 2 . Pair 2 must move from stair 1 to stair 2 . This is accomplished by the retraction of Pair 2 and the retraction of Pair 1's horizontal actuators. ${ }^{12}$ The wheels on Pairs 3 and 4 will bring the backside of the platform forward.

\section{$\underline{\text { Stage } 5}$}

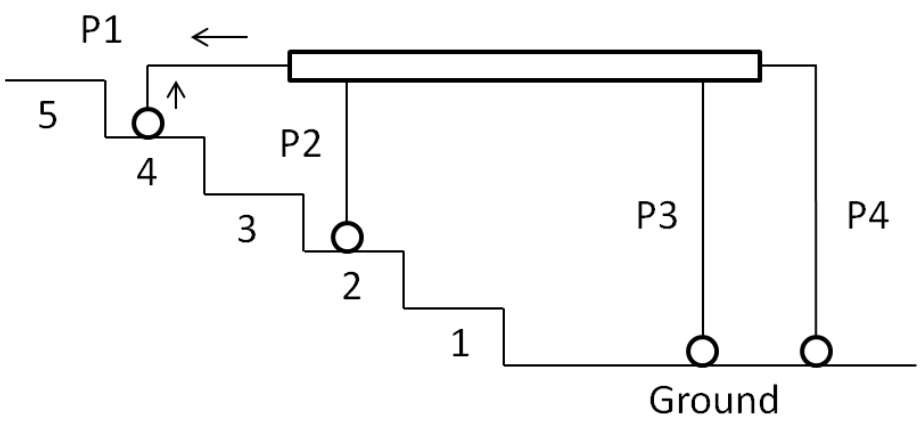

Figure 2.14 - Stage 5 of Climbing Sequence

Stage 5 is similar to Stage 3. Pair 1 must again move up one stair - this time from 3 to 4 . This is accomplished by retracting Pair 1's vertical actuators and extending its horizontal ones. While Pair 1's vertical actuators have almost retracted to zero position, it hasn't quite reached zero which means that Pairs 3 and 4 do not have to extend their vertical actuators during this stage.

\section{Stage 6}

\footnotetext{
${ }^{12}$ The same issue with the caster wheels also arises in this case. See Note 7.
} 


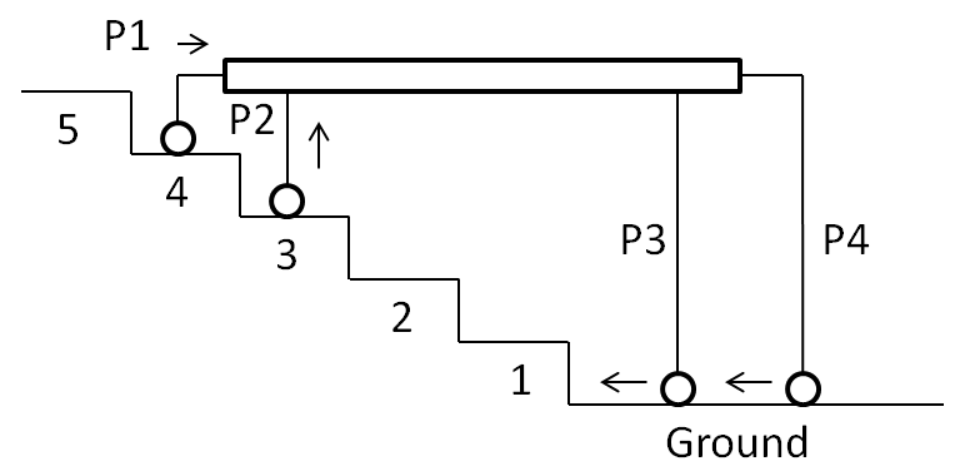

Figure 2.15 - Stage 6 of Climbing Sequence

Stage 6 is similar to Stage 4. Pair 2 must move from stair 2 to stair 3 . This is accomplished again by retracting Pair 3, and retracting Pair 4's horizontal actuators. The wheels on Pairs 3 and 4 must again roll forward.

\section{$\underline{\text { Stage } 7}$}

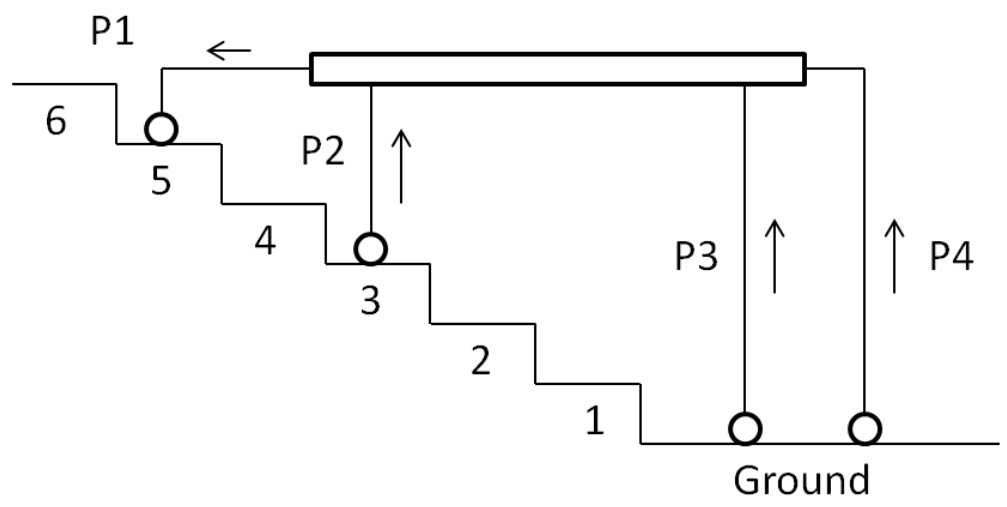

Figure 2.16 - Stage 7 of Climbing Sequence

Stage 7 is similar to Stage 5 but there are now a couple of key differences. Pair 1 must move to the next step, but in order to accomplish this two additional motions must occur. The vertical legs of Pairs 2, 3, and 4 must all extend to account for the additional 4" for Pair 1 to get to stair 5. At this point the vertical actuators for Pairs 3 and 4 are extended approximately $14 "$.

$\underline{\text { Stage } 8}$ 


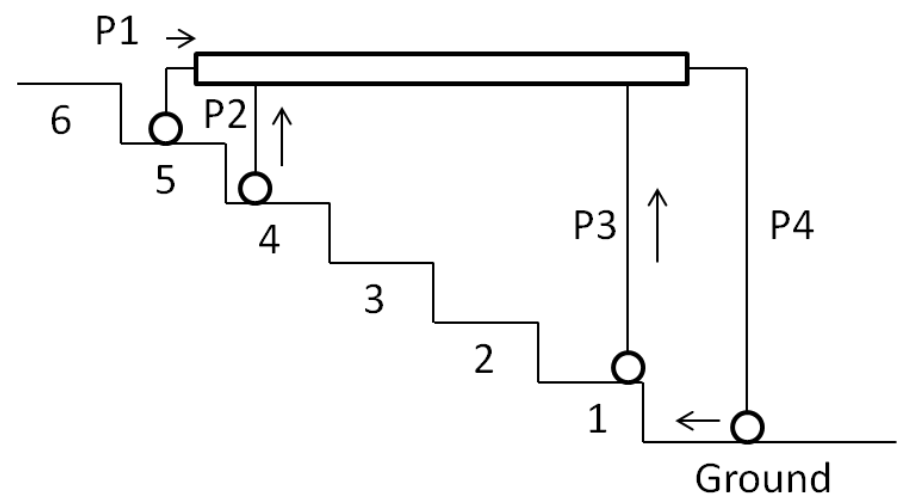

Figure 2.17 - Stage 8 of Climbing Sequence

Stage 8 begins the pattern that will occur for the remainder of the flight of stairs. Instead of just moving Pair 2 up one stair, both Pair 2 and Pair 3 will move up one stair simultaneously. This is accomplished by retracting both Pairs 2 and 3 to fit onto the next stair. In order to position them horizontally, however, Pair 1's horizontal actuators must retract, thus bringing the platform forward. It is also important to note that since there are 38" between Pairs 2 and 3, their vertical legs will no longer be able to be positioned at the center of the stair. This is acceptable for two reasons. First, the contact patches (and also the center of gravity) of the wheels are completely on the stair. Second, Pairs 1 and 4 would provide support for the vehicle even if Pair 3 were to slip off its step.

$\underline{\text { Stage } 9}$ 


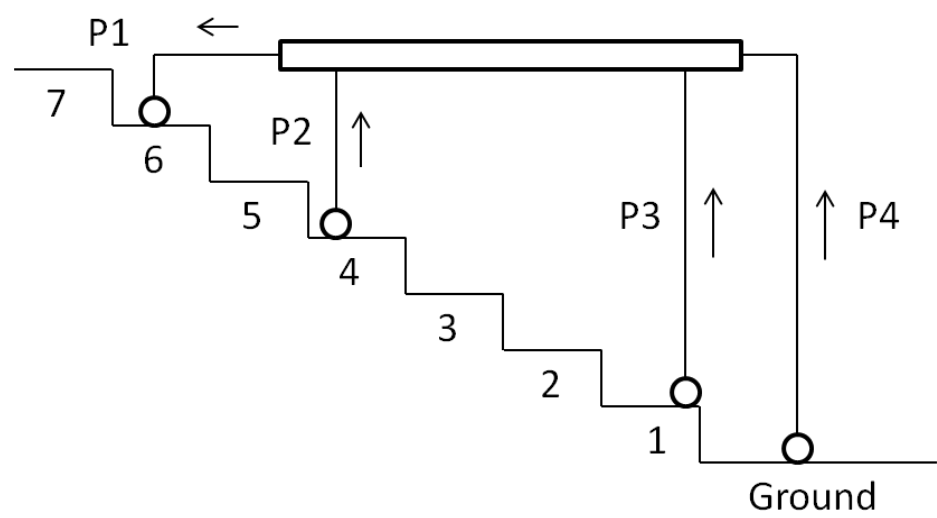

Figure 2.18 - Stage 9 of Climbing Sequence

Stage 9 is almost identical to Stage 7. Pair 1 must move its leg up one stair. But again Pairs 2, 3 and 4 must extend their vertical actuators to account for this additional 4" by Pair 1 moving up a stair.

$\underline{\text { Stage } 10}$

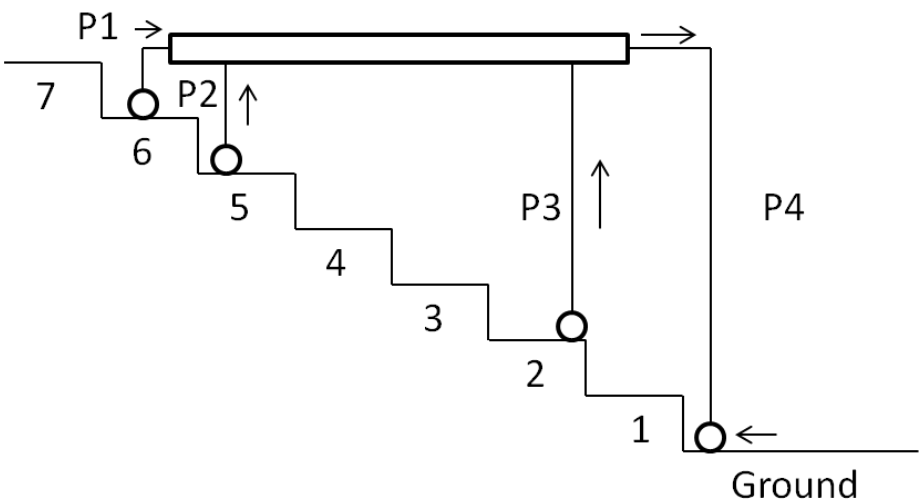

Figure 2.19 - Stage 10 of Climbing Sequence

Stage 10 is similar to Stage 8 . Both Pairs 2 and 3 will move up 1 step simultaneously. This is achieved by Pairs 2 and 3 retracting 4" while Pair 1 retracts its horizontal actuator to move the platform forward. Pair 4's horizontal actuators will likely have to extend slightly at this point. Pair 4 has reached $y_{\max }=28$ ". At every even stage from this point forward, Pair 4 must extend to $\mathrm{y}_{\max }$. 


\section{$\underline{\text { Stage } 11}$}

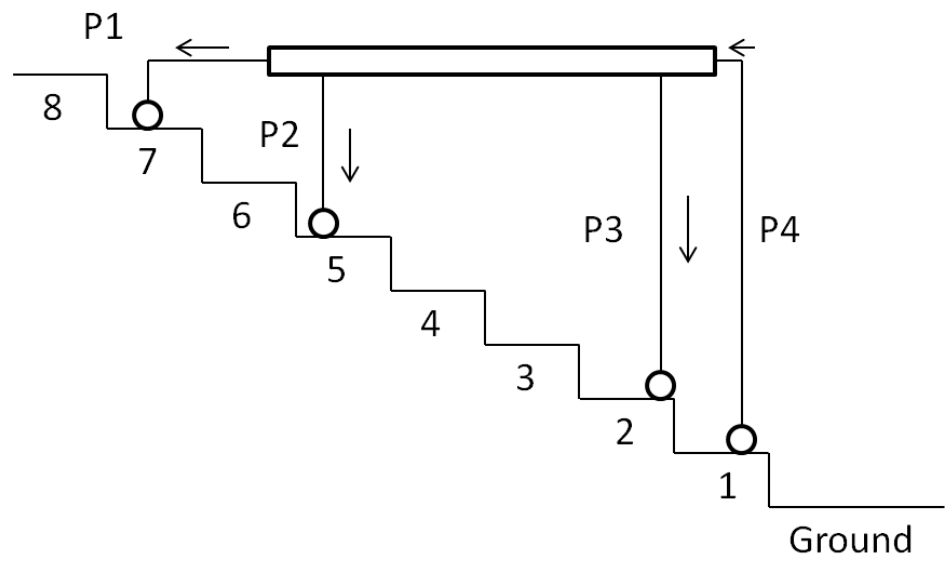

Figure 2.20 - Stage 11 of Climbing Sequence

Stage 11 now combines the motion of both Pairs 1 and 4 . This can be accomplished because the platform is now fully on the stairs, making its pattern of motion repeatable every 2 stages. Pair 2 and 3 will extend, while Pair 4's horizontal actuators retract to put it on the new stair. Simultaneously Pair 1 will extend its horizontal actuators to place it on the $7^{\text {th }}$ stair.

Now that the platform is entirely on the stairs, Stages 10 and 11 will be repeated until the platform reaches the top of the stairs. At this point, Pairs 3 and 4 will do the inverse of what Pairs 1 and 2 did for the first several stages. With Pairs 1 and 2 on the top of the staircase, Pairs 3 and 4 must simply alternate one stair at a time until they have also reached the top. 
In summary, each stage requires specific joints to move to locate the device at the correct position. Table 2.3 illustrates the results of each stage.

Table 2.3. Summary of Stair Climbing Sequence

\begin{tabular}{|c|c|c|c|c|}
\hline Stage & Pair 1 & Pair 2 & Pair 3 & Pair 4 \\
\hline 1 & Stair 2 & Ground & Ground & Ground \\
\hline 2 & Stair 2 & Stair 1 & Ground & Ground \\
\hline 3 & Stair 3 & Stair 1 & Ground & Ground \\
\hline 4 & Stair 3 & Stair 2 & Ground & Ground \\
\hline 5 & Stair 4 & Stair 2 & Ground & Ground \\
\hline 6 & Stair 4 & Stair 3 & Ground & Ground \\
\hline 7 & Stair 5 & Stair 3 & Ground & Ground \\
\hline 8 & Stair 5 & Stair 4 & Stair 1 & Ground \\
\hline 9 & Stair 6 & Stair 4 & Stair 1 & Ground \\
\hline 10 & Stair 6 & Stair 5 & Stair 2 & Ground \\
\hline 11 & Stair 7 & Stair 5 & Stair 2 & Stair 1 \\
\hline
\end{tabular}

In order to travel down a flight of stairs, the sequence must simply do the reverse of what it did to climb up the stairs. This time, instead of Pair 1 retracting its vertical actuators and extending its horizontal ones, it will extend its vertical actuators and extend its horizontal ones. The device can then sequentially lower Pair 2 to reach the top step, just as Pair 2 was raised to reach the first step in the ascension sequence. The pattern continues until the platform has reached the bottom of the stairs.

\subsection{Mechanical Design}

There were four stages involved in the mechanical design of the device. First, the conceptual design had to be broken down into parts and assemblies that could accomplish the required functionality. Second, analysis was conducted to prove that each of these designed parts would be feasible and operate correctly. Third, components were selected 
based on the analysis. Fourth, a solid model was constructed which could be used to create drawings for the manufacturing phase.

\subsubsection{Configuration Options}

The device can be broken down into two main categories: the vertical legs and the frame. There are two different versions of the vertical legs - one with drive and steering motors and the other without either. The more complex version contains the drive and steering motors, and therefore required the most careful analysis and consideration. The complex vertical leg had to accomplish two goals: 1) rotate the base of the leg assembly relative to the actuator tip, and 2) rotate the wheel in contact with the ground.

1) The rotation of the leg base could be accomplished by installing a bearing. The two types of bearings that were considered were turntable bearings (e.g. a lazy susan bearing) and banded ball thrust bearings. Choosing a ball bearing would have increased the complexity of the design without adding any comparative benefits. The bearing needed to survive a thrust load, because the leg itself would not always be in contact with the ground. Without the band to keep the inner race and outer race from separating, a regular ball bearing would have fallen apart the moment the leg lifted off the ground. Figure 2.21 shows a section view of the standard ball thrust bearing, which demonstrates the lack of feasibility without the band. Figure 2.22 shows a generic banded ball thrust bearing. 


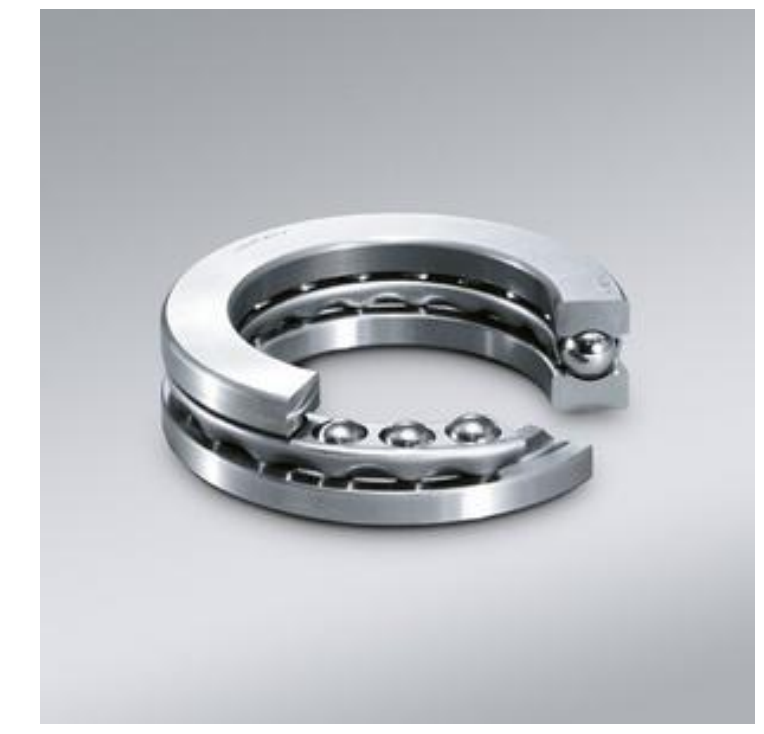

Figure 2.21 - Standard Ball Thrust Bearing ${ }^{13}$

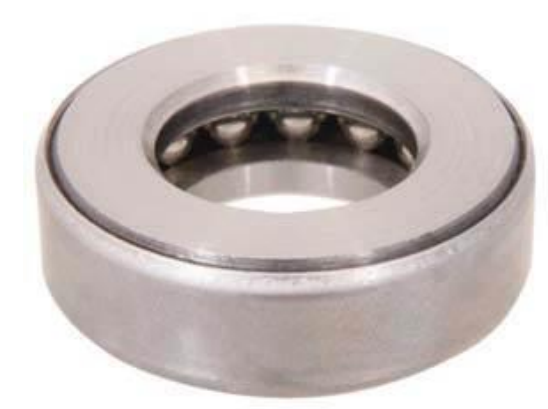

\section{Figure 2.22 - Banded Ball Thrust Bearing ${ }^{14}$}

The main disadvantage of the banded ball thrust bearing is the need for a press fit to assemble the components together. This would require circular components to fit inside the inner race, which limits the flexibility for selecting the size and shape of materials in the assembly. While the banded ball thrust bearing has disadvantages for this application, a turntable bearing

\footnotetext{
13 “Thrust Ball Bearings". NSK Products. http://www.nskeurope.de/cps/rde/xchg/eu_de/hs.xsl/thrust-ballbearings.html. 03 Aug. 2013.

14 "Banded Assembly Ball Thrust Bearing". Reid Supply Company. http://www.reidsupply.com/sku/INA430/. 03 Aug. 2013.
} 
could survive in both tension and compression and has the advantage of being low cost. Another key advantage of the turntable bearing is that it has convenient locations for attaching the other parts of the assembly. Ultimately, the turntable bearing was chosen because it could handle the loading conditions of the leg, was low cost, and could be easily integrated into the assembly. Figure 2.23 shows how the turntable bearing operates within the assembly.

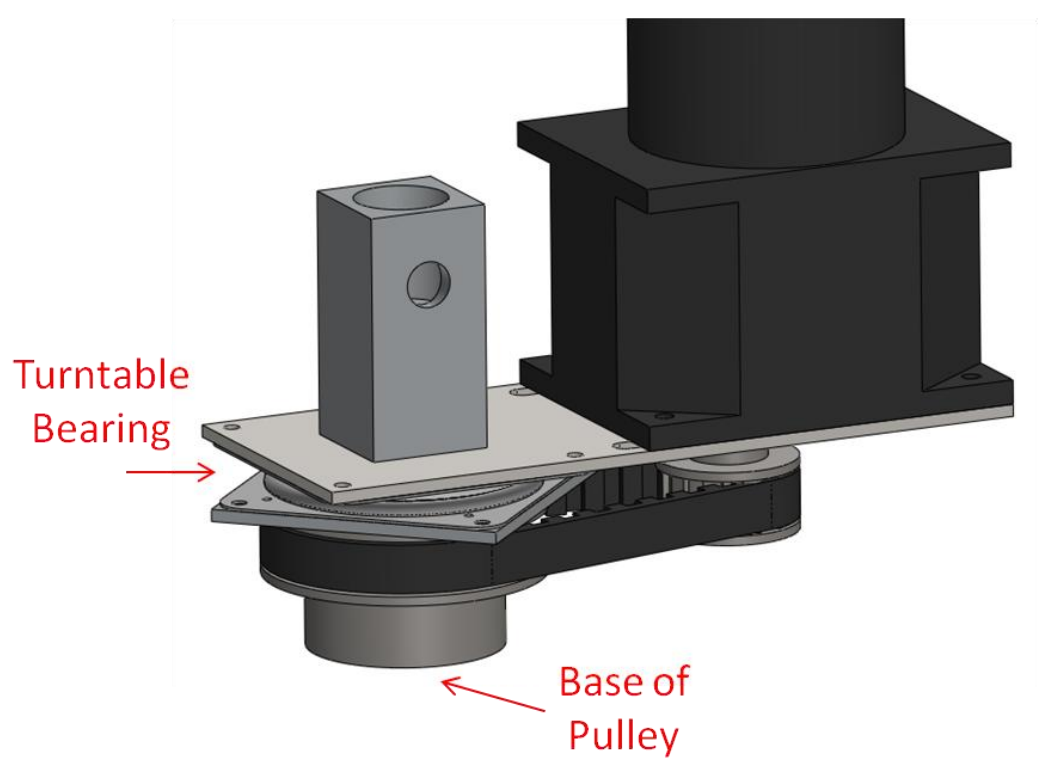

Figure 2.23 - Turntable Bearing with Assembly

2) The rotation of the wheel could be accomplished by either using a direct connection between the motor shaft and the wheel, or through a power train. Each has a key disadvantage at the outset. Direct attachment requires that the motor spin speed and torque are the correct amount without being able to adjust with a gear reduction or some other power train method. The power train option is more complex and thus requires more components. Because 
cost was a consideration for every aspect of the design and manufacturing, a solution had to be found that could allow for the selection of low cost motors. Eventually cost drove the decision for the direct attachment method. ${ }^{15}$

The selection of direct attachment for the drive mechanism requires a bracket to attach the motor to the rest of the leg base. This could be accomplished with a U-shaped metal bracket with the motor attached on one side and the leg attached on the other. With direct attachment, care had to be taken to ensure that the motor shaft and wheel shaft were correctly aligned. Ensuring alignment via manual machining methods only would be very difficult, so the decision was made to install a flex-coupling between the two shafts. This would eliminate the negative effects of any small amount of parallel misalignment between the two shafts. Figure 2.24 shows the motor, U-bracket, wheel shaft, and flex coupling portion of the assembly.

\footnotetext{
${ }^{15}$ See 2.2.3.
} 


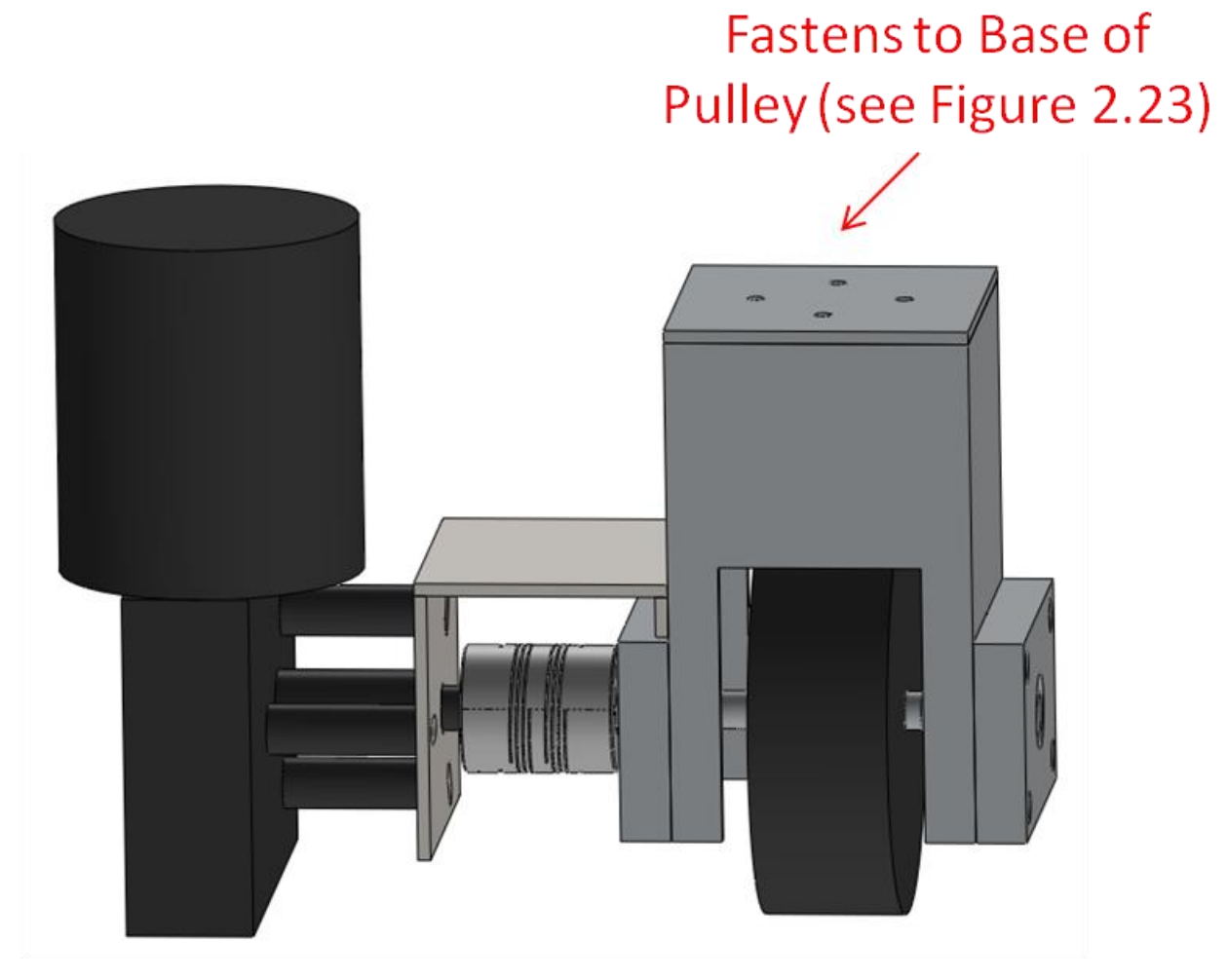

Figure 2.24 - Flex Coupling Connection

The wheel shaft was attached to bearings on each end. Banded ball thrust bearings were selected because, during operation, the shaft could experience forces parallel to the axis of rotation. As discussed before, a regular ball bearing cannot protect against a thrust load. These bearings were installed inside their own pillow blocks, which were fastened to a wheel housing. The wheel housing needed to be shaped in such a way as to allow the wheel to fit inside while simultaneously allowing for easy fastening to each of the pillow blocks, as well as the rest of the assembly above it. Figure 2.25 shows how the selection of square tubing made sense to meet these requirements. 


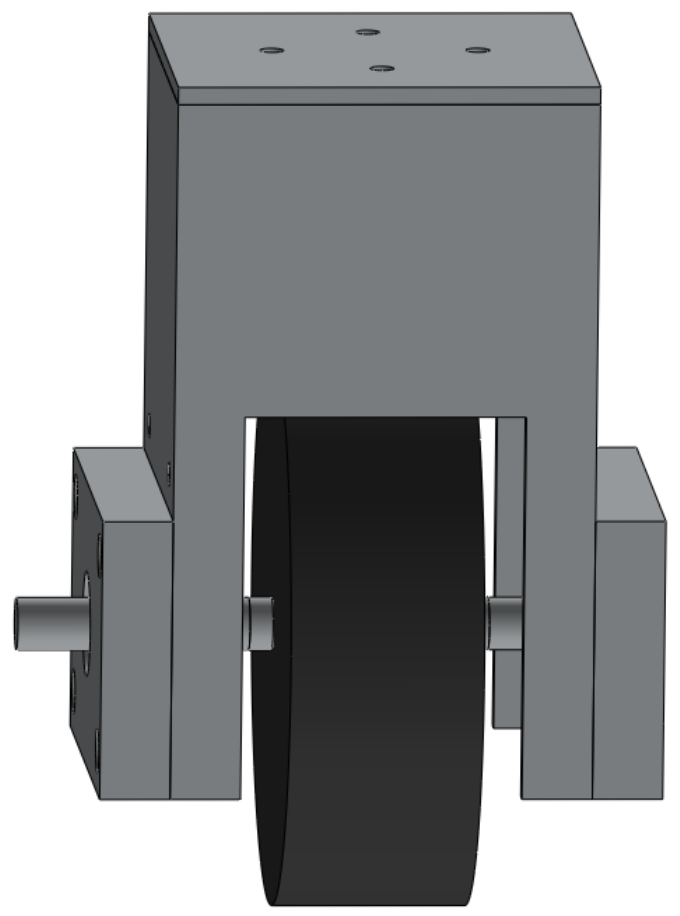

Figure 2.25 - Wheel Housing with Bearing Pillow Blocks and Wheel

Figure 2.25 also shows a cap attached on top of the wheel housing to allow for attachment to the steering drive mechanism (Figure 2.23) on the upper part of the leg.

The last configuration decision was how to attach the actuator tip to the assembly below it. At this point in the design several different linear actuator types had been examined, and one with a circular tip had been selected. ${ }^{16}$ This meant that there needed to be a part that could attach to the tip but also attach to the plate connected to the turntable bearing below. The simplest design to accomplish this was a square aluminum rod with a circular slot on top. There would also be a hole running through the side of the rod that a

\footnotetext{
${ }^{16}$ See 2.2.3.
} 
bolt could fit through. The actuator tip came with a $12 \mathrm{~mm}$ hole to allow for this sort of fastening. Figure 2.26 shows how the actuator tip is integrated with the leg base.

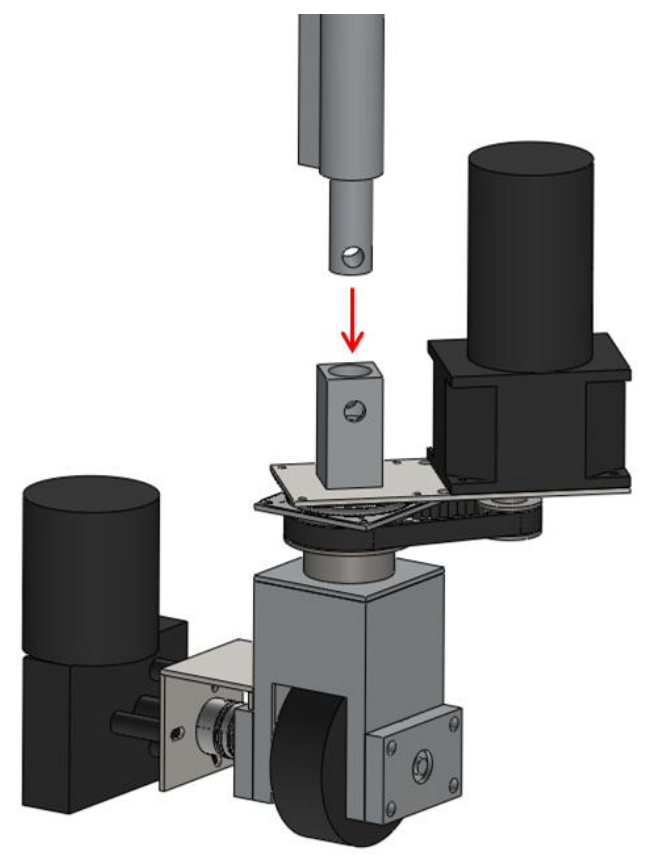

Figure 2.26 - Actuator Tip Being Inserted Into Block to Complete Assembly

If the tube inside the actuator does not rotate, then the steering motor would stay in place as it caused the pulley to rotate the drive mechanism below it. In this way, the only rotating components would be everything below the steering motor mounting plate.

\subsubsection{Analysis}

Engineering analysis was conducted for components that were directly related to certain specifications or needed to meet some threshold in order for the device to function. The mechanical design analysis includes:

1) Drive motor torque

2) Deflection of drive bracket 
3) Deflection of wheel shaft

4) Tension and reduction of timing belt

5) Steer motor torque

6) Deflection of steering plate

7) Horizontal support shaft deflection

8) Allowable torque of wheel shaft press fit

9) Tension in linear actuator mounting screws

10) Bending stress and deflection of platform

While all of these calculations are included in Appendix B, there were several considerations and assumptions in the calculations that require discussion. All of the equations discussed in this section were taken from Shigley's Mechanical Engineering Design, $9^{\text {th }}$ Edition [3] unless otherwise specified.

1) The torque requirements for the drive motor were based on known equations for ground vehicle dynamics [3]. The analysis was conducted by taking the variable inputs and placing them sequentially into six key equations. These equations are as follows:

$$
\begin{gathered}
R R=G V W \cdot f \\
G R=G V W \cdot \sin (\alpha) \\
F A=G V W \cdot \frac{V_{\text {max }}}{32.2 \cdot a_{\text {time }}} \\
T E=R R+G R+F A \\
T_{w}=T E \cdot R \cdot R F \\
M T T=W_{d} \cdot \mu \cdot R
\end{gathered}
$$


Table 2.4 shows each variable involved in the calculations and its corresponding value for this application.

Table 2.4. Variable Inputs for Driving Torque Calculations

\begin{tabular}{|l|c|c|}
\hline \multicolumn{1}{|c|}{ Input } & Symbol & Value \\
\hline Gross Vehicle Weight & GVW & $240 \mathrm{lb}$ \\
\hline Weight on each drive wheel & $\mathrm{W}_{\mathrm{d}}$ & $60 \mathrm{lb}$ \\
\hline Radius of wheel & $\mathrm{R}$ & $2 \mathrm{in}$ \\
\hline Desired top speed & $\mathrm{V}_{\max }$ & $1.76 \mathrm{ft} / \mathrm{s}(1.2 \mathrm{mph})$ \\
\hline Desired acceleration time & $\mathrm{a}_{\text {time }}$ & $2 \mathrm{sec}$. \\
\hline Max incline angle & $\alpha$ & 0 \\
\hline Resistance factor & $\mathrm{RF}$ & 1.15 \\
\hline Frictional coefficient & $\mu$ & 0.4 (rubber and concrete) \\
\hline Worst working surface & $\mathrm{f}$ & 0.015 (concrete, fair) \\
\hline
\end{tabular}

The gross vehicle weight was determined by making a rough weight estimate for each component. The weight on each drive wheel is simply the total weight divided by four, since there will be at least four wheels in contact with the ground at all times. The radius of the wheel was chosen to be 2 " because the bottom of the drive motor would have come in contact with the ground had a radius of 1.5 " been chosen. 2 " is the next standard wheel size that gives adequate space. The estimated vehicle speed of $3 \mathrm{mph}$ was initially chosen based on a reasonable estimate of an average person walking. It was later reduced to $1.2 \mathrm{mph}$ for the speed output of the drive motors that were selected. Although future designs will potentially want to consider making the device faster, the prototype was concerned only with getting a minimal amount of motion to prove functionality. The desired acceleration time was selected to accelerate to $1.2 \mathrm{mph}$ from a standstill in 2 
seconds. ${ }^{17}$ The max incline angle was assumed to be zero since the demonstration of the prototype will only occur on flat ground (or in the case of stairs, motion parallel to the flat ground). Most of the time this device will be travelling on concrete, so an intermediate value of "fair" was chosen. The value of "fair" falls between "poor" and "good," which are both measurements of the quality of the traction on the concrete. "Fair" corresponds to a numerical value of 0.015 , where all values of concrete typically range between 0.01 and 0.02 [2]. The final equation, which calculates the maximum tractive torque (MTT), was used as a check to ensure that the wheel would not slip on the ground's surface during operation. If it could be shown that value of MTT is greater than the value of the drive torque for one wheel $\left(\mathrm{T}_{\mathrm{w}}\right)$, then the wheels would not slip. MTT was calculated to be $48 \mathrm{in}-\mathrm{lb}$, while the drive torque was calculated to be $26.1 \mathrm{in}-\mathrm{lb}$. Therefore, the wheels would not slip during operation.

2) The deflection in the drive motor mounting bracket was critical in determining the thickness of material in the bracket required in order to keep the motor from contacting the ground. The portion of the bracket parallel to the ground was modeled as a cantilever beam with an end load and end moment. The end load is simply the weight of the motor, while the end moment is caused by the fact that the center of gravity of the motor is not in line with the end of the bracket. Figure 2.27 shows a diagram of the system.

\footnotetext{
${ }^{17}$ The acceleration time was discovered to be much less during testing. This was because the motors spun up to full speed without any motion control. Some reasonable estimate still had to be given for the sake of the torque calculations, however.
} 


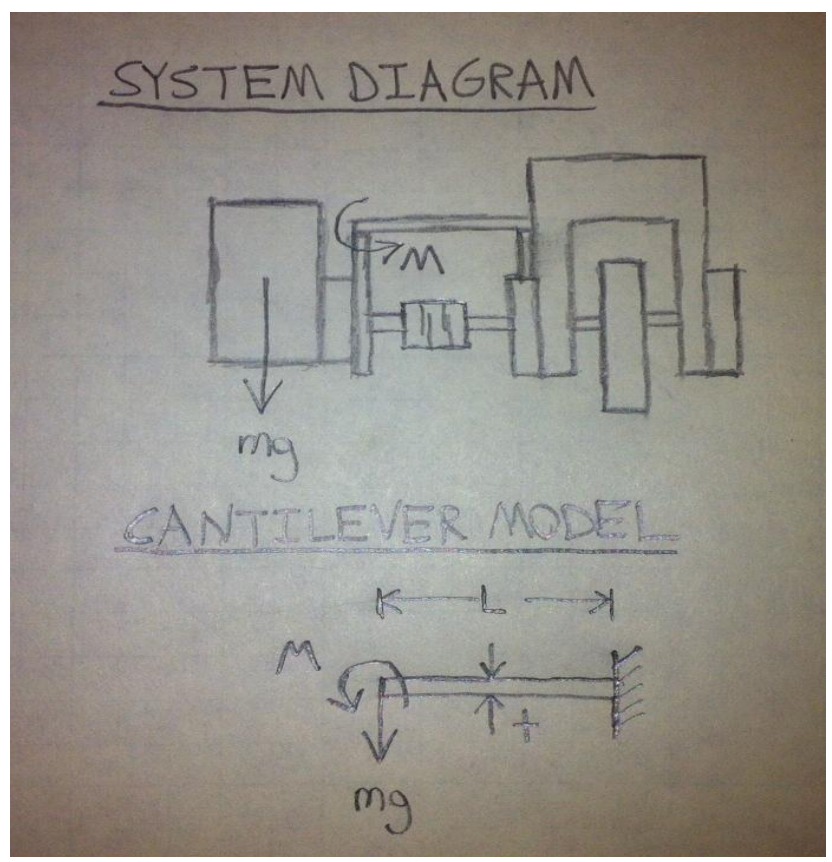

Figure 2.27 - Diagram of Driving Motor Bracket Analysis

There were three key equations used to calculate the deflection. They are shown as follows:

$$
\begin{gathered}
y_{M}=\frac{M L^{2}}{2 E I} \\
y_{F}=\frac{F L^{3}}{3 E I} \\
y_{t o t}=y_{M}+y_{F}
\end{gathered}
$$

The first equation calculates the deflection at the tip of the bracket due to the moment caused by the weight of the motor. The second equation calculates the deflection due to the weight of the motor itself. These are summed up in the final equation to give the total deflection caused by the driving motor. 
The equations for deflection required several inputs, which are all included in Table 2.5.

Table 2.5. Inputs for Drive Motor Mounting Bracket Deflection

\begin{tabular}{|l|c|c|}
\hline \multicolumn{1}{|c|}{ Input } & Symbol & Value \\
\hline Width of plate & $\mathrm{b}$ & $3 \mathrm{in}$. \\
\hline Length of plate & $\mathrm{L}$ & $2.5 \mathrm{in}$. \\
\hline Young's Modulus of steel & $\mathrm{E}$ & $30 \mathrm{e} 6 \mathrm{psi}$ \\
\hline Moment caused by motor weight & $\mathrm{M}$ & $14 \mathrm{in}-\mathrm{lb}$ \\
\hline Weight of motor & $\mathrm{F}$ & $7 \mathrm{lb}$ \\
\hline Thickness of plate & $\mathrm{t}$ & $0.125 \mathrm{in}$. \\
\hline
\end{tabular}

The main parameter for these equations is the plate thickness. Thicknesses of $1 / 16 "$ and $1 / 8$ " were inputted into the equations to determine deflection. A $1 / 16$ " plate thickness would cause 0.0438 " of vertical deflection at the tip. This is acceptable considering that there is approximately 0.5 " between the base of the motor and the ground. Since $1 / 8$ " steel plating was already available, however, this size was selected for the assembly. A $1 / 8$ " plate would result in 0.005 " of vertical deflection.

3) Deflection of the wheel shaft was determined by modeling the shaft as a simply supported beam with a weight in the middle (equal to $1 / 4$ of the weight of the entire device). The only equation required for this calculation was the equation for the deflection of a simply supported beam with a center load. This equation is:

$$
y=\frac{F L^{3}}{48 E I}
$$


The inputs for this equation are listed in Table 2.6.

Table 2.6. Inputs for Deflection of Wheel Shaft

\begin{tabular}{|l|c|c|}
\hline \multicolumn{1}{|c|}{ Input } & Symbol & Value \\
\hline Diameter of wheel shaft & $\mathrm{d}$ & $0.375 \mathrm{in}$. \\
\hline Length of shaft between supports (bearings) & $\mathrm{L}$ & $4 \mathrm{in}$. \\
\hline Young's Modulus of steel & $\mathrm{E}$ & $10.4 \mathrm{e} 6 \mathrm{psi}$ \\
\hline Weight on each wheel & $\mathrm{F}$ & $60 \mathrm{lb}$ \\
\hline
\end{tabular}

With a minimum ${ }^{18}$ shaft thickness of $0.375^{\prime \prime}$, the resulting deflection was 0.008". This is essentially negligible and would not result in contact between the wheel and its housing.

4) The effective tension and desired pulley reduction would determine the correct pulley and timing belt sizes. In order to determine these values, five equations had to be used. These equations calculate the pitch diameters of each pulley, the length of the timing belt, the torque seen by the motor after the pulley reduction, and lastly the effective tension itself. These five equations are as follows [4]:

$$
\begin{gathered}
d_{1}=\frac{p z_{p 1}}{\pi} \\
d_{2}=\frac{p z_{p 2}}{\pi} \\
L=2 C+\frac{\pi d_{1}}{2}+\frac{\pi d_{2}}{2} \\
T_{1}=\frac{T_{\max }}{n} \\
T_{e}=\frac{2 T_{1}}{d_{1}}
\end{gathered}
$$

\footnotetext{
18 The shaft was stepped to account for the difference between the wheel's hole and the bore diameter of the bearings. The smaller of the two diameters was selected for calculations.
} 
The required inputs for these equations are shown in Table 2.7.

Table 2.7. Inputs for Tension and Reduction of Timing Belt

\begin{tabular}{|l|c|c|}
\hline \multicolumn{1}{|c|}{ Input } & Symbol & Value \\
\hline Center distance & $\mathrm{C}$ & $3.5 \mathrm{in}$. \\
\hline L-series timing belt pitch & $\mathrm{p}$ & $0.375 \mathrm{in}$. \\
\hline Number of teeth of driving pulley & $\mathrm{z}_{\mathrm{p} 1}$ & 10 \\
\hline Number of teeth of driven pulley & $\mathrm{z}_{\mathrm{p} 2}$ & 22 \\
\hline Belt width & $\mathrm{b}$ & $0.5 \mathrm{in}$. \\
\hline Max required torque to steer & $\mathrm{T}_{\max }$ & $25.5 \mathrm{in}-\mathrm{lb}$ \\
\hline Pulley ratio & $\mathrm{n}$ & 2.2 \\
\hline Max allowable tension for L-series belt & $\mathrm{T}_{1 \mathrm{all}}$ & $100 \mathrm{in}-\mathrm{lb}$ \\
\hline
\end{tabular}

Using the center to center distance and calculated pitch diameters, the required belt length was determined to be 13.0 ”. Using the driving torque, number of teeth, and pulley geometry, the effective tension of the system was calculated to be $19.4 \mathrm{lb}$. [4]. The maximum allowable tension in an L-series timing belt is $100 \mathrm{lb}$, so the selection of a $130 \mathrm{~L} 050^{19}$ timing belt was adequate. Slots were included in the steering motor mounting bracket to allow for belt tensioning.

5) The required steering motor torque was determined by estimating the contact patch radius and using it as the moment arm to determine the frictional torque. If the applied torque from the motor could be shown to be greater than the frictional torque, then steering would be successful. A few key assumptions were made for these calculations. First, a test was done to determine the size and shape of the contact patch. An epoxy patch was painted onto a section of the bottom wheel.

\footnotetext{
${ }^{19}$ The first three digits " 130 " represent length to one decimal place. "L" stands for L-series. " 050 " stands for 0.5 " belt width. The pitch of this L-series belt is 0.375 ".
} 
The bottom of the wheel was pressed down against a piece of paper and then lifted up. This was done several times to get a consistent contact patch size. The assumption made here was that the contact patch was a circle, which doesn't diverge much from the actual epoxy mark itself. ${ }^{20}$ Figure 2.28 shows one of the contact patch marks.

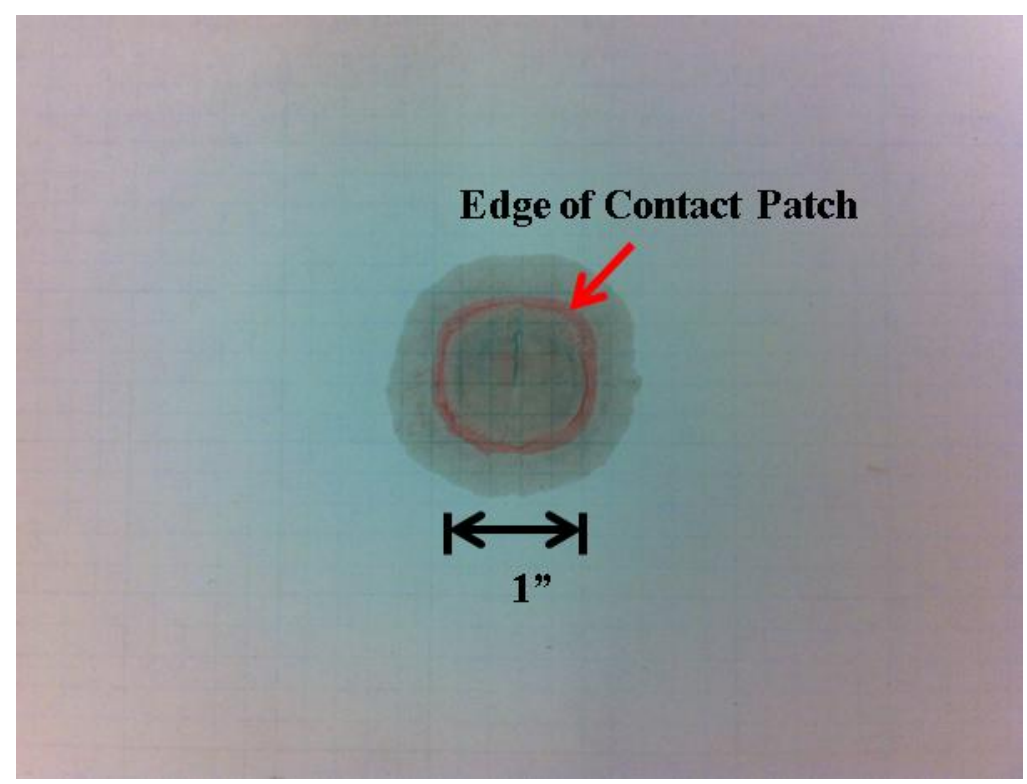

Figure 2.28 - Contact Patch of Drive Wheel

Second, the steering conditions assume that the vehicle is not also driving. While this assumption will produce a larger amount of torque to overcome the friction (since the required steering torque is less when the vehicle is in motion), this assumption will produce the worst-case torque that the motor must surpass. Third, the coefficient of friction between hard rubber and cement in dry conditions is 0.85 [5].

\footnotetext{
${ }^{20}$ In the event that the contact patch is not circular, one could calculate an average radius and use that for the frictional torque equations.
} 
There were two main equations used to calculate the steering torque. The first equation is:

$$
F_{f}=\mu N
$$

This equation gives the frictional force between the wheel and the ground. The second equation calculates the frictional torque.

$$
T_{f}=F_{f} r
$$

As shown in the second equation, the frictional torque is found by multiplying the radius of the contact patch by the frictional force between the ground and the wheel. The inputs needed for these equations are listed in Table 2.8.

Table 2.8. Inputs for Steering Motor Torque

\begin{tabular}{|l|c|c|}
\hline \multicolumn{1}{|c|}{ Input } & Symbol & Value \\
\hline Coefficient of friction between dry concrete and hard rubber & $\mu$ & 0.85 \\
\hline Weight on each wheel & $\mathrm{w}$ & $60 \mathrm{lb}$ \\
\hline Radius of contact patch & $\mathrm{r}$ & $0.5 \mathrm{in}$. \\
\hline
\end{tabular}

The largest frictional torque for a wheel to overcome on cement was determined to be $25.5 \mathrm{in}-\mathrm{lb}$. A steering motor and gear reduction with at least this much continuous torque would be required for full functionality.

6) The deflection of the steering motor mounting plate is critical because too much bending would result in the edge with the steering motor to contact the top of the drive motor. The system was modeled as a cantilever beam (the mounting plate) with an end load (the motor), since worst case deflection would be seen at the very tip of the mounting plate. The equation for the deflection of a cantilever beam with an end load is: 


$$
y=\frac{F L^{3}}{3 E I}
$$

The inputs required for this calculation are included in Table 2.9.

Table 2.9. Inputs for Deflection of Steering Motor Mounting Plate

\begin{tabular}{|l|c|c|}
\hline \multicolumn{1}{|c|}{ Input } & Symbol & Value \\
\hline Weight of steering motor & $\mathrm{F}$ & $8 \mathrm{lb}$ \\
\hline Cantilever length & $\mathrm{L}$ & $4 \mathrm{in}$. \\
\hline Young's Modulus of steel & $\mathrm{E}$ & $30 \mathrm{e} 6 \mathrm{psi}$ \\
\hline Width of plate & $\mathrm{b}$ & $3 \mathrm{in}$. \\
\hline Height (thickness) of plate & $\mathrm{h}$ & $0.125 \mathrm{in}$. \\
\hline
\end{tabular}

The results indicate that there will be at most 0.012 " of deflection. This is acceptable as it does not exceed the maximum allowable deflection of 0.88 ", which is based on the spacing between the plate and the drive motor.

7) The deflection of the horizontal support shaft (one in parallel with each horizontal actuator) is important to determine the angle at which Pair 1 and Pair 4's vertical actuators contact the ground. The deflection was calculated in two stages. First, each shaft was modeled as a cantilever beam with an end load equivalent to $1 / 4$ the weight of the platform. The length of the beam is the maximum stroke length of the horizontal actuators (18"). The deflection at the tip is the portion of the deflection only due to the bending in the aluminum rods. In order to acquire the actual deflection of the tip, the deflection and angle at the edge of the platform would have to be added. There were four key equations necessary to calculate the deflection and angle due to both the aluminum and the platform itself. These equations are: 


$$
\begin{gathered}
y_{a}=\frac{F a^{2}}{3 E I} \cdot(L+a) \\
\theta_{a}=\frac{F a^{2}}{2 E I} \\
y_{p}=\frac{2 M L_{p}^{2}}{16 E_{p} I_{p}} \\
\theta_{p}=\frac{M L_{p}}{2 E_{p} I_{p}}
\end{gathered}
$$

The inputs required to calculate the deflections and angles are shown in

Table 2.10.

Table 2.10. Inputs for Horizontal Support Shaft Deflection

\begin{tabular}{|l|c|c|}
\hline \multicolumn{1}{|c|}{ Input } & Symbol & Value \\
\hline Force seen by each shaft & $\mathrm{F}$ & $60 \mathrm{lb}$ \\
\hline Moment arm of horizontal extension & $\mathrm{a}$ & $18 \mathrm{in}$. \\
\hline Center distance between linear bearings & $\mathrm{L}$ & $6.88 \mathrm{in}$. \\
\hline Total length of platform & $\mathrm{L}_{\mathrm{p}}$ & $48 \mathrm{in}$. \\
\hline Young's Modulus of aluminum & $\mathrm{E}$ & $10.4 \mathrm{e} 6 \mathrm{psi}$ \\
\hline Young's Modulus of platform (plywood) & $\mathrm{E}_{\mathrm{p}}$ & $1.01 \mathrm{e} 6 \mathrm{psi}$ \\
\hline Outer diameter of support shaft & $\mathrm{d}_{\mathrm{o}}$ & $1 \mathrm{in}$. \\
\hline Inner diameter of support shaft & $\mathrm{d}_{\mathrm{i}}$ & $0.5 \mathrm{in}$. \\
\hline
\end{tabular}

The total deflection, acquired by adding $\mathrm{y}_{\mathrm{a}}$ and $\mathrm{y}_{\mathrm{p}}$ together, comes out to be $0.346 "$. This means that the vertical legs will be contacting the ground at an angle equal to the sum of $\theta_{\mathrm{a}}$ and $\theta_{\mathrm{p}}$, or $1.2^{\circ}$.

8) The torque allowed by the wheel shaft press fit was determined by calculating the minimum interference fit such that the hard rubber wheel and solid aluminum shaft would not slip relative to each other. The inner diameter of the hard rubber wheel was known to be 0.404 in., and the diameter of the aluminum shaft could 
be sized to allow for sufficient diametral interference. The allowable torque needs to exceed the drive torque of 26.1 in-lb. Two equations, one for the pressure in the fit and one for the allowable torque, were used. These are:

$$
\begin{gathered}
p=\frac{\delta}{\frac{d}{E_{o}} \cdot\left(\frac{d_{o}^{2}+d^{2}}{d_{o}^{2}-d^{2}}+v_{o}\right)+\frac{d}{E_{i}} \cdot\left(\frac{d^{2}+d_{i}^{2}}{d^{2}-d_{i}^{2}}+v_{i}\right)} \\
T_{\text {all }}=\frac{\pi f p L d^{2}}{2}
\end{gathered}
$$

The inputs required for these two equations are shown in Table 2.11.

\section{Table 2.11. Inputs for Wheel Shaft Press Fit}

\begin{tabular}{|l|c|c|}
\hline \multicolumn{1}{|c|}{ Input } & Symbol & Value \\
\hline Nominal diameter of wheel shaft & $\mathrm{d}$ & $0.401 \mathrm{in}$. \\
\hline Outside diameter of wheel & $\mathrm{d}_{\mathrm{o}}$ & $4 \mathrm{in}$. \\
\hline Inside diameter of shaft & $\mathrm{d}_{\mathrm{i}}$ & 0 \\
\hline Poisson's Ratio for aluminum & $\mathrm{v}_{\mathrm{i}}$ & 0.333 \\
\hline Poisson's Ratio for hard rubber & $\mathrm{v}_{\mathrm{o}}$ & 0.5 \\
\hline Young's Modulus for hard rubber & $\mathrm{E}_{\mathrm{o}}$ & $14.5 \mathrm{e} 3 \mathrm{psi}$ \\
\hline Young's Modulus for aluminum & $\mathrm{E}_{\mathrm{i}}$ & $10.4 \mathrm{e} 6 \mathrm{psi}$ \\
\hline Coefficient of friction between aluminum and hard rubber & $\mathrm{f}$ & 1 \\
\hline Length of interference fit & $\mathrm{L}$ & $1.6 \mathrm{in}$. \\
\hline Minimum required torque & $\mathrm{T}_{\text {all }}$ & $25.5 \mathrm{in}-\mathrm{lb}$ \\
\hline
\end{tabular}

A minimum diametral interference fit of 0.00265 " was calculated based on these parameters. A diametral interference fit of 0.003 " was chosen for ease of machining.

\footnotetext{
${ }^{21}$ The torque was known from previous calculations. Simultaneously solving both equations would give solutions for $\mathrm{p}$ and $\delta$.
} 
9) The vertical actuators would have to be mounted to the vertical connector blocks using the three screw holes near the tip. The tensile force that these screws would see is equal to $1 / 4$ the weight of the platform minus the weight of each wheel assembly. In order to include a safety factor, the tensile force was assumed to be $1 / 4$ of the weight of the device without subtracting the wheel assembly weight. The allowable tensile stress in each screw (made of 18-8 stainless steel) is $42.1 \mathrm{ksi}$.

This means that each screw could not handle more tensile stress than this without permanent set. Using basic equations to the calculate tensile stress in the bolts, an acceptable bolt size could be determined. The two equations calculated the tensile stress area as well as the tensile (axial) stress per bolt. These equations are:

$$
\begin{aligned}
& A=\frac{\pi d^{2}}{4} \\
& \sigma=\frac{F}{N_{S} A}
\end{aligned}
$$

The inputs required to perform these calculations are included in Table

\subsection{2 .}

Table 2.12. Inputs for Actuator Mounting Screw Stress

\begin{tabular}{|l|c|c|}
\hline \multicolumn{1}{|c|}{ Input } & Symbol & Value \\
\hline Max force applied on each leg & $\mathrm{F}$ & $60 \mathrm{lb}$ \\
\hline Minor diameter of \#4-40 machine screw & $\mathrm{d}$ & $0.106 \mathrm{in}$. \\
\hline Number of screws & $\mathrm{N}_{\mathrm{s}}$ & 3 \\
\hline
\end{tabular}

Based on the calculations each screw would only see $2.27 \mathrm{ksi}$, which falls far below the maximum. 
10) The bending stress of the platform was determined by treating the platform as a simply supported beam with a center load (mostly due to the battery and weight of the platform itself). With these conditions, the maximum bending moment occurs at the center of the platform. The moment of inertia was determined by the section properties of the solid model. The only required equations were those for the maximum bending moment in a simply supported beam with a center load, as well as the bending stress given that maximum bending moment. These equations are:

$$
\begin{gathered}
M=M_{1}+\left(R_{1} \cdot \frac{L_{p}}{2}\right) \\
\sigma_{\max }=\frac{M_{\max } C}{I_{p}}
\end{gathered}
$$

The inputs required to perform these calculations are included in Table 2.13 .

Table 2.13. Inputs for Bending Stress in Platform

\begin{tabular}{|l|c|c|}
\hline \multicolumn{1}{|c|}{ Input } & Symbol & Value \\
\hline Maximum stroke length of horizontal actuators & $\mathrm{h}$ & $18 \mathrm{in.}$ \\
\hline Weight load seen by platform & $\mathrm{w}$ & $240 \mathrm{lb}$ \\
\hline Length of platform & $\mathrm{L}_{\mathrm{p}}$ & $48 \mathrm{in}$. \\
\hline Area moment of inertia of platform & $\mathrm{I}_{\mathrm{p}}$ & $46.125 \mathrm{in.}{ }^{4}$ \\
\hline Distance to neutral axis & $\mathrm{c}$ & $2 \mathrm{in.}$ \\
\hline
\end{tabular}

With these numbers the maximum bending stress was calculated to be 219 psi. For plywood, bending stress should not exceed 1668 psi. Therefore, with the 
plywood and 2x4 assembly, the wooden platform would suffice to take all of the loads.

\subsubsection{Component Selection}

Most of the components in the design for both the vertical legs and frame were machined. There were some, however, that had to be purchased directly. The following is a list of the mechanical components that were purchased. All of these parts are also listed in the bill of materials in Appendix C.

1) Driving motors

2) Steering motors

3) Timing belt pulley assemblies

4) Banded ball thrust bearings for wheel shaft

5) Flex couplings

6) Turntable bearings

7) Linear actuators (30" and 18" strokes)

8) Linear bearings

All of these components had at least one driving factor behind their purchase.

While meeting the specifications of the analysis was the most important factor for all the components, cost ended up being a significant factor in several decision.

1) The biggest challenge in the selection of the motors for both driving and steering was minimizing cost. Detailed research was conducted into several different manufacturers and distributors of new brushed DC motors, and all of the ones that met the requirements were prohibitively expensive. Because of this cost issue, 
research was conducted on used motors. Eventually, feasible solutions for both the driving and steering motors were found. In the case of the drive motor, a rightangle gear motor was found that ran at $12 \mathrm{~V}$, drawing no more than $8 \mathrm{~A}$ under a loading output of 26 in-lb. The right-angle configuration simplified the design by not requiring a worm gear or flexible shaft setup to account for the 90 degree angle between the motor (mounted parallel to the leg) and the wheel shaft (mounted perpendicular to the leg). Figure 2.29 shows the right angle drive motor.

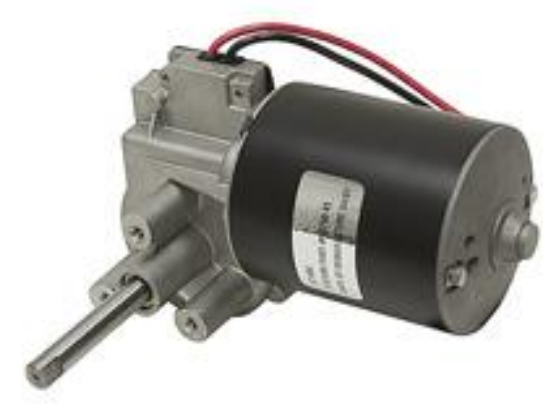

Figure 2.29 - Right Angle Geared Motor for Driving ${ }^{22}$

This specific motor also runs at 100 RPM under design loading conditions. This translates to $1.2 \mathrm{mph}$ with a 4 " diameter wheel. The cost of this motor was only $\$ 60$, as compared to costs of no less than $\$ 200$ for new motors with similar specifications.

2) The selection of the steering motor followed a very similar process as the driving

${ }^{22} 100$ RPM 12 VDC Gearmotor. Surplus Center. http://www.surpluscenter.com/item.asp?item=51649\&catname=electric. 05 Aug. 2013. 
motor. A motor with at least 12.75 in-lb of torque (which would become the required 25.5 in-lb. with the 2:1 pulley ratio) was needed to overcome the contact patch friction. The same distributor which sold the driving motors also sold inline DC gear motors for only $\$ 50$ that met the specifications. Figure 2.30 shows the inline type that was purchased.

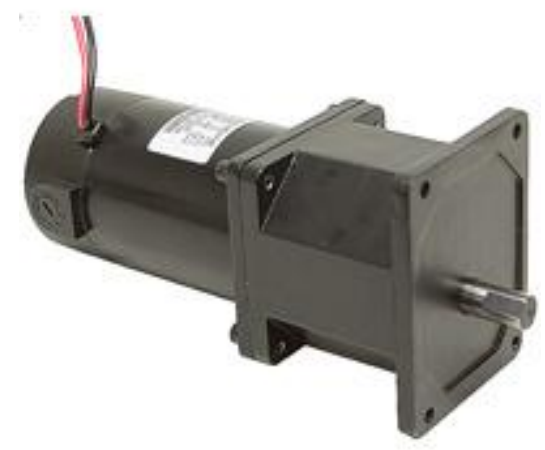

Figure 2.30 - Inline Geared Motor for Steering ${ }^{23}$

This inline geared motor runs at $20 \mathrm{rpm}$ at the design loading conditions, which translates to 0.152 revolutions per second (including the $2: 1$ pulley ratio). Although the steering motors are rated at 13A for full load, the motors won't actually be operated under this condition. The timing belt ratio reduction would allow the steering motor to draw approximately the same amperage as the driving motor. This motor is rated for $16.75 \mathrm{in}-\mathrm{lb}$ of torque, so the minimum torque requirement was met.

\footnotetext{
${ }^{23} 20$ RPM 12 VDC Inline Gearmotor. Surplus Center. http://www.surpluscenter.com/item.asp?item=5-
} 1726\&catname=electric. 05 Aug. 2013. 
3) The main factors behind the choice of a timing belt to steer the leg were the allowable tension and the spacing. The allowable tension of an L-series timing belt with $1 / 2$ " width and 3/8" pitch is $100 \mathrm{lb}$. The calculated $19.4 \mathrm{lb}$ transmitted under this applications loading condition falls far below the maximum. Originally, gears were going to be used to solve the problem of connecting the mechanical source (the motor shaft) to the leg. The distance between the motor shaft and the edge of the motor's gearbox, in addition to the short length of the shaft itself, made gears an impractical solution. Instead of trying to cram the motor as close to the leg as possible, an alternative approach was taken. By using a timing belt, any length could be chosen to allow the motor to be situated in such a way as to not interfere with the rotation of the leg.

4) As previously discussed, the choice of banded ball thrust bearings was related to the potential thrust load on the wheels. It wasn't necessary to consider other bearings mainly due to cost, as the ones that were selected for this project were only $\$ 6$.

5) The selection of flex couplings involved the bore diameters, max parallel misalignment, and transmitted torque. Since the wheel shaft size was determined by the diameter of the caster wheel hole, the flex coupling bore had to be sized according to a similar dimension. The shaft size at the wheel is 0.401 ", so the diameter that fits inside the coupling could be stepped down to the standard size of 0.375 ". The other bore, however, had to be sized based on the diameter of the driving motor shaft of 7/16". Max parallel misalignment of 0.005 " was determined to be within the max value for the chosen flex coupling based on the 
alignment geometry in the solid model. Lastly, the coupling had to be able to transmit up to 15 in-lb of torque without slipping. The chosen coupling was rated for 31 in-lb of continuous one-directional torque. Figure 2.31 shows the selected flex coupling.

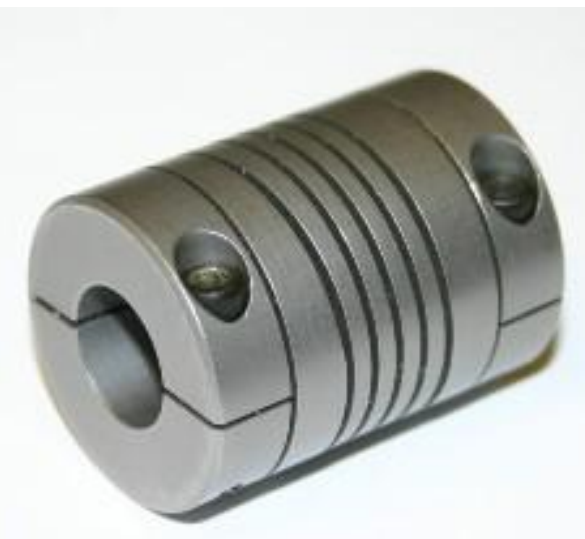

Figure 2.31 - HCR112-14-12 Flex Coupling ${ }^{24}$

6) The turntable bearing was mostly selected for ease of assembly. It comes with four bolt holes on the corners of each of the plates, allowing for easy assembly to the sandwich plate on one side, and the steering motor mounting plate on the other. Figure 2.32 shows the layout of the turntable bearing.

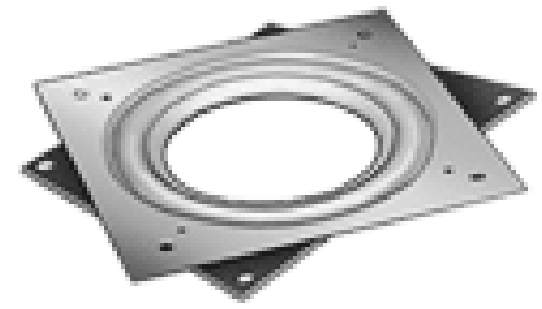

Figure 2.32 - Turntable Bearing ${ }^{25}$

24 “HCR112-16-10”, Helical Products Company, Inc. http://heli-cal.com/db/Products/. 14 Sep. 2013. 
Given that the bearing could handle the compressive load on the leg (this specific bearing is rated for $200 \mathrm{lb}$ of compressive load), the only remaining concern would be bending. Since the speed of the device is so slow, there would be no substantial inertial force that would cause the bearing to bend. This speculation is not adequate enough for a robust design, however, so testing was later conducted to verify that any possible bending load the bearing could experience would not damage the bearing.

7) While there were several different types of linear actuators that would have been adequate for this project, this specific one was chosen mainly for its slenderness, robust design, and mounting capabilities. Figure 2.33 shows the linear actuator.

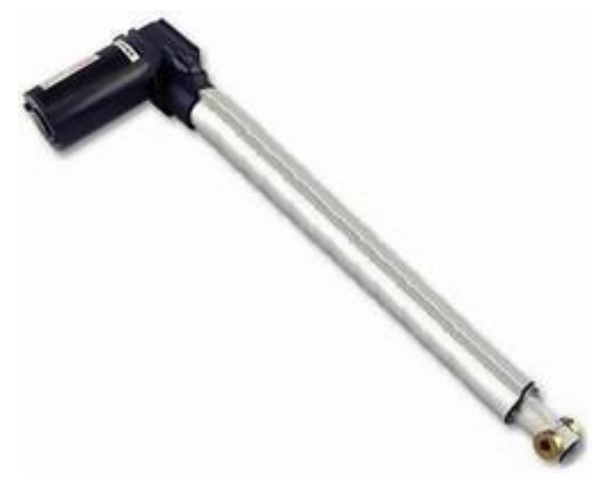

Figure 2.33 - Firgelli Automation FA-400-L-12-30 Linear Actuator ${ }^{26}$

Two different types were required: 30 " stroke for the vertical legs and 18 " stroke

\footnotetext{
25 “Square Turntable". McMaster-Carr. http://www.mcmaster.com/\#lazy-susan-bearings/=nxrsbg. 05 Aug. 2013.

${ }^{26} 400 \mathrm{lb}$ Force 30" Stroke. Firgelli Automations. http://firgelliauto.ca/400lbforce30inchstroke-p-71.html. 05 Aug. 2013.
} 
for the horizontal extensions. These designs are exactly the same, the only variation being their stroke lengths. Both exceed the load requirement of $60 \mathrm{lb}$ by being able to provide $400 \mathrm{lb}$ of force. This type of actuator moves at $0.5 \% / \mathrm{sec}$., which is a reasonable speed for the motion of the device. While current draw is rated for 10A peak, several tests were done under loading to determine that the actual current draw during application would be between 3-5A. The mounting hole at the tip of the actuator allows for easy integration with the rest of the design. A bolt can hold the tip in place inside the tip's specially designed pillow block.

8) The selection of the linear bearings required three considerations: diameter, mounting configuration, and load capacity. The diameter was based on the analysis done on the support shaft. Since a 1 " diameter with $1 / 4$ " wall thickness aluminum tubing was chosen, a linear bearing with a 1 " inner diameter had to be selected. For ease of assembly, the type of linear bearings with a mounting block was chosen. Figure 2.34 shows the linear bearing with its built-in mounting block.

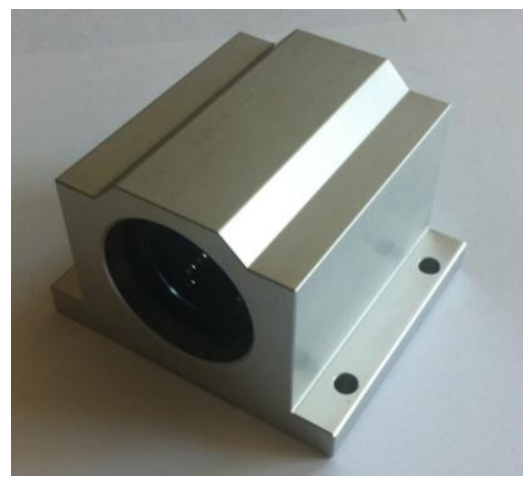

Figure 2.34 - Linear Bearing 
The specific linear bearings chosen are not meant to handle large bending loads, but for the application of this project the relatively small bending load did not produce any problems in the ability of the bearings to actuate the support shaft. ${ }^{27}$

The load capacity of the bearings is $850 \mathrm{lb}$ of dynamic load, which far exceeds the maximum $217 \mathrm{lb}$ vertical reaction load actually exerted on each bearing.

\subsection{Mechatronics Design}

The mechatronics design was guided heavily by the mechanical design. The electronic components had to be able to control all twenty joints of motion while relying on a local power supply. The design can be broken down into two subsections: hardware and software. First a description of the hardware will be given based on the mechanical components being controlled. Second, a description of the coding will be given based on the drivers for each of the components. The mechatronics system can be grouped into two areas:

- Linear actuator control

- Driving and steering motor control

\subsubsection{Linear Actuator Control}

The linear actuators chosen for the prototype each have two wire leads: power and ground. Both the 18" and 30" stroke actuators run on 12VDC, drawing up to $10 \mathrm{~A}$ at full load (rated for $400 \mathrm{lb}) .{ }^{28}$ Switching the leads alternates the actuator between extension

\footnotetext{
27 This was tested with the full assembly and under full loading conditions. The linear bearings actuated smoothly without any problems.

${ }^{28}$ Testing was done to measure the current draw at the design load. This is covered in 3 .
} 
and retraction.

Since the actuator needs to be able to switch directions, an H-bridge circuit had to be used. An H-bridge is simply a circuit that acts as a polarity switcher, capable of switching the leads of a motor from forward to reverse, as well as brake. A simple and cost-effective solution was running the actuator off of a motor driver. The motor driver circuit consists of 10 critical pin connections: 1) Motor $\mathrm{V}_{\mathrm{IN}}$, 2) Motor GND, 3) Motor Output 1, 4) Motor Output 2, 5) INA, 6) INB, 7) ENC/DIAG, 8) PWM, 9) 5V board power, and 10) board ground. ${ }^{29}$

- Motor $\mathrm{V}_{\mathrm{IN}}$ and GND are for the $12 \mathrm{~V}$, high current power input that will power the linear actuator.

- Motor Outputs 1 and 2 are where the two leads from the actuator will be connected to receive the signal from the board.

- INA and INB are the logic pins that will determine the direction of the actuator (extend or retract).

- ENC/DIAG is the pin for either an encoder or a position sensor to determine the position of the linear actuator's tip. ${ }^{30}$

- PWM is the pin that controls the amount of voltage going to the actuator. This controls the speed of actuation.

- $5 \mathrm{~V}$ power and ground are the two connections the motor driver itself needs in order to power the circuit to run the actuator.

\footnotetext{
${ }^{29}$ This configuration is based on the Pololu Robotics and Electronics Dual VNH2SP30 Motor Driver Carrier MDO3A.

${ }^{30}$ While position sensors were not used for this project, it is still important to note that the boards driving each of the components are capable of receiving signals from such sensors.
} 
Since the actuators must all run in pairs, dual motor driver chips were selected.

Figure 2.35 shows the dual motor driver chip.

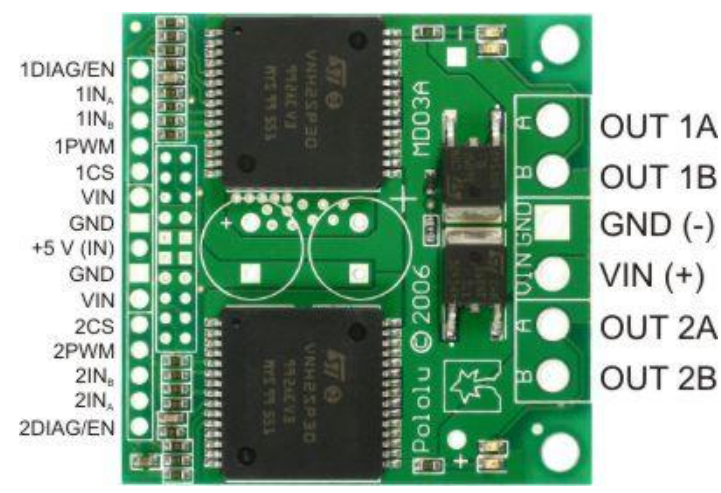

Figure 2.35 - Pololu VNH2SP30 Dual Motor Driver Board ${ }^{31}$

The dual motor driver chips are equipped with all the necessary pins in addition to a second set of Motor Outputs, INAs and INBs, ENC/DIAG, and PWM. To reduce the number of digital I/O pins required to operate the system, the INA and INB pins of the two sets of horizontal actuators were soldered together. This way whenever a signal is sent from the microcontroller to extend or retract, the actuators will move in the same direction.

In order to run all of the linear actuators, six of the dual motor drivers will be required. This means there will need to be 20 digital I/O and $12 \mathrm{PWM}$ pins for the microcontroller to control the linear actuators. ${ }^{32}$

\subsubsection{Driving and Steering Motor Control}

The driving and steering motors have conveniently similar specifications. The

\footnotetext{
31 “Pololu High-Current Dual Driver Carrier Board (VNH2SP30 or VNH3SP30) pinouts". Pololu Robotics and Electronics. http://www.pololu.com/catalog/product/708. 05 Aug. 2013.

${ }^{32}$ Once encoders are added, there would also need to be 12 analog pins.
} 
driving motor runs on $12 \mathrm{VDC}$ with $6 \mathrm{~A}$ continuous current at full load. The steering motor also runs at $12 \mathrm{VDC}$ with a specified peak current of $13 \mathrm{~A} .^{33}$

The driving and steering motors would be controlled in a similar fashion as the linear actuators. While there are enough digital I/O pins to operate each motor driver's INA and INB pins separately, the PWM signals for all of the steering and driving motors had to be consolidated from 8 down to $2 .^{34}$

The single motor driver chips used to control the steering and driving motors are made to handle loads running at between $5.5-24 \mathrm{~V}$ while drawing up to $12 \mathrm{~A}$ continuous current (30A peak). Both motors fit within this requirement, and therefore the single motor driver was chosen. The single motor driver chips use the same pin setup as the linear actuator's dual motor driver. Figure 2.36 shows this layout.

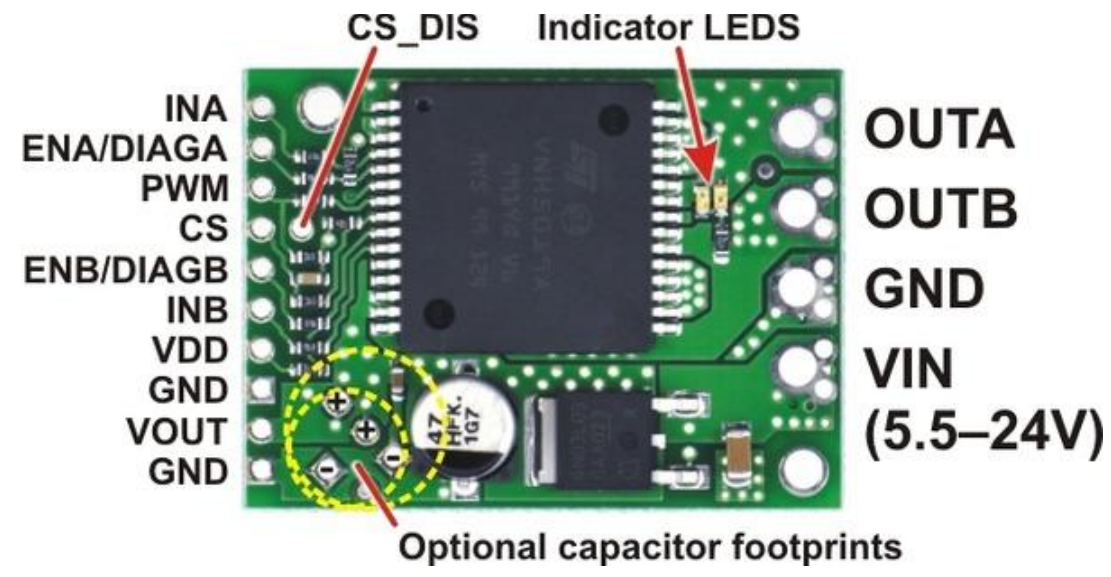

Figure 2.36 - Pololu VNH5019 Single Motor Driver Board ${ }^{35}$

\footnotetext{
${ }^{33}$ Because no additional manufacturing data was available, tests were conducted for the steering motor in no-loading and design loading conditions. The continuous current draw for the steering motor at design loading condition never exceeded $4 \mathrm{~A}$.

34 The Arduino Mega board has 15 pins which can be used as PWM.

35 "VNH5019 motor driver carrier, labeled top view". Pololu Robotics and Electronics. http://www.pololu.com/catalog/product/1451. 05 Aug. 2013.
} 
The resulting motor driver setup for the steering and driving motors will require 16 digital I/O and 2 PWM pins. ${ }^{36}$

\subsubsection{Microprocessor Selection}

The two main considerations behind the microprocessor were cost and adequate number of pins of the correct type. The Arduino Mega 2560 board, run with an ATmega1280 microprocessor, has a sufficient number of pins of each type to be able to control all the joints of motion in a somewhat limited fashion. Table 2.14 shows the available pins, as well as the number of pins required for the prototype's operation.

Figure 2.37 shows the assembled board.

Table 2.14. Arduino Mega 2560 Pin Usage Breakdown

\begin{tabular}{|c|c|c|}
\hline Pin Type & Required & Quantity \\
\hline Digital I/O & 36 & 39 \\
\hline Analog Input & 20 & 16 \\
\hline PWM & 14 & 15 \\
\hline
\end{tabular}

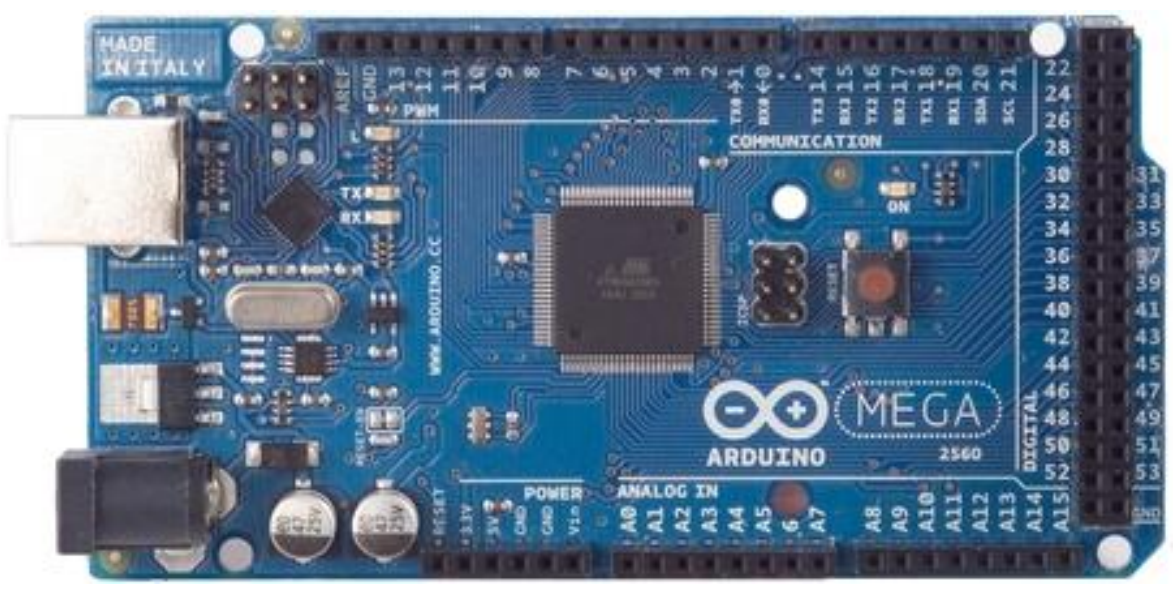

Figure 2.37 - Arduino Mega $2560^{37}$

\footnotetext{
${ }^{36}$ For position control, 8 analog pins would also be necessary.

37 “Arduino Mega 2560”. Arduino. http://arduino.cc/en/uploads/Main/ArduinoMega2560_R3_Front.jpg. 05 Aug. 2013.
} 
While there are a sufficient number of I/O and PWM pins, the Arduino Mega does not have enough analog inputs to provide for sensors for every joint. This is acceptable as the scope of the project did not include using sensors. The next version of the prototype will include sensors for the joints. ${ }^{38}$

The Arduino Mega can be operated on $12 \mathrm{~V}$, but since a laptop would be required for manual control during testing, the Arduino was simply powered by a USB cable from the computer.

\subsubsection{Power Supplies}

There would be two different power supplies on board the device. The first is a $8.4 \mathrm{~V}$, low current battery pack used to power the driver chips. The second is a $12 \mathrm{~V}$ car battery to power each of the components through the driver chips. Each of these power supplies are on board per the specification. A car battery was selected for this application for a few reasons. First, it provides $12 \mathrm{VDC}$, which is the same voltage that all the individual components need to be operated at. Second, it can provide a large current to run the device. Third, it is rechargeable.

In order to calculate the necessary amp-hours for a desired amount of operation time, some estimates had to be made regarding the usage of various components on the device. The basic estimates were made based on a combination of product data sheets and number of components.

\footnotetext{
${ }^{38}$ The addition of sensors in future iterations is discussed in 4.
} 
Table 2.15. Current Draw Requirements

\begin{tabular}{|l|c|c|c|}
\hline \multicolumn{1}{|c|}{ Type } & $\begin{array}{c}\text { Estimated Continuous } \\
\text { Current at Design Load (A) }\end{array}$ & $\begin{array}{c}\text { Component } \\
\text { Quantity }\end{array}$ & $\begin{array}{c}\text { Total Current } \\
\text { Draw (A) }\end{array}$ \\
\hline Actuator & 5 & 12 & 60 \\
\hline Steering Motor & 6 & 4 & 24 \\
\hline Driving Motor & 6 & 4 & 24 \\
\hline
\end{tabular}

If all of the components were to draw their continuous current at design load simultaneously, then the system would be drawing 108A. The car battery selected has 35 amp-hours, which means the entire system could be operating at full power for 19.4 minutes. This is, of course, an entirely unrealistic estimate since the components will never all be running at one time. In fact, with the two different types of motion (climbing stairs and regular driving), there will never be more than 8 components moving at once. Table 2.16 demonstrates the different operating conditions and their power requirements.

Table 2.16. Current Draw for Various Conditions

\begin{tabular}{|l|c|c|c|c|}
\hline $\begin{array}{c}\text { Operating } \\
\text { Condition }\end{array}$ & $\begin{array}{c}\text { Motors } \\
\text { On }\end{array}$ & $\begin{array}{c}\text { Actuators } \\
\text { On }\end{array}$ & $\begin{array}{c}\text { Total Current } \\
\text { Draw (A) }\end{array}$ & $\begin{array}{c}\text { Available Time at } \\
\text { Full Current (min) }\end{array}$ \\
\hline Climbing Stairs & 2 & 8 & 52 & 40 \\
\hline Regular Driving & 4 & 0 & 24 & 87 \\
\hline
\end{tabular}

Both of these estimates are worst-case, since only certain stages use eight actuators. Also, only two motors will be used if the device is driving straight. Only four are needed during turning and driving. Worst case conditions show the device can run off of a $35 \mathrm{amp}-\mathrm{hr}$ car battery for at least an hour, assuming mostly driving and not a lot of obstacle or stair climbing. This is enough to show functionality. 


\subsubsection{Overall System Configuration}

The Arduino board, batteries, motor drivers, terminal blocks, and surge protection circuit will all be placed on top of the platform. Figure 2.38 shows a diagram of the configuration of the electronic components.

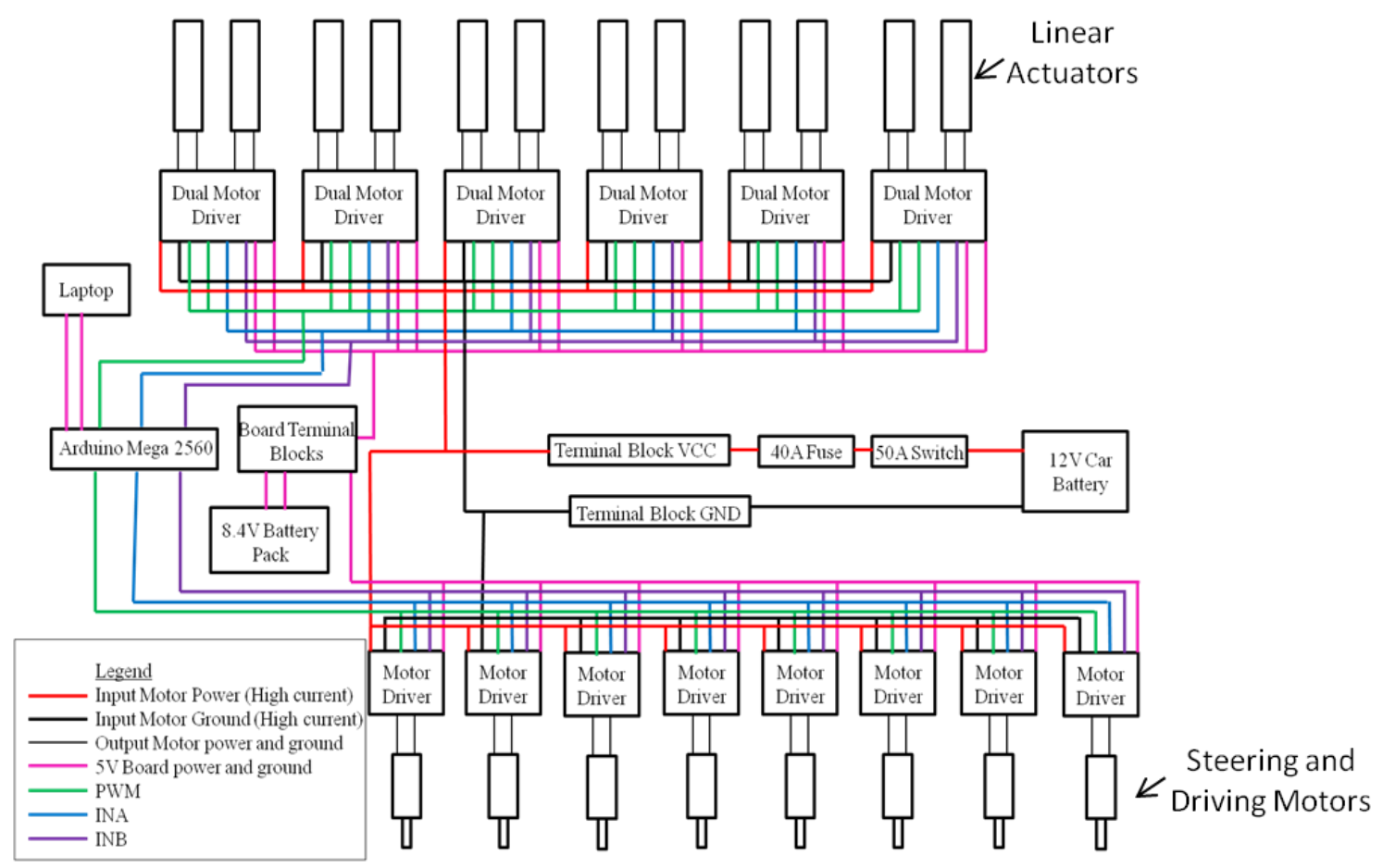

Figure 2.38 - Electronic Components Assembly Diagram

Figure 2.38 demonstrates all of the critical connections between the major components of the circuit. There were three modifications made from the actual setup for the sake of diagram simplicity. First, the data pins were all lumped together as one connection going to the microcontroller. ${ }^{39}$ Second, the high current power and ground connections from the terminal blocks will each have their own wires, and will not be

\footnotetext{
${ }^{39}$ This is, of course, not the actual configuration. Each PWM, INA, and INB pin will have its own separate connection to an I/O pin on the microcontroller. Simply because of the number of connections required for this circuit, placing them all in the diagram would only produce confusion rather than clarity.
} 
lumped together as shown in the diagram. Lastly, the power connections coming from the board terminal blocks will in fact come from two terminal blocks (power and ground) rather than one.

\subsubsection{Software}

The purpose of the software is solely to control the motion of the device. Since the coding is only focused on hardware control, using the Arduino language greatly simplified the effort required to get functionality. The code accomplishes hardware control by sending output signals from the MCU's digital I/O and PWM pins. These signals are sent via the hardwired connections between the Arduino Mega and the motor driver chips. The outputs from the I/O pins handle the motor's INA and INB logic.

The initialization of the software mainly involves declaring several variables to correspond to the numbered I/O and PWM pins connected to each of the motor driver chips. The naming scheme identifies the motor driver being referred to. An example is “int Pair_2_SMotor_L_INA = 22;”. This stands for Pair 2, steering motor, left side ${ }^{40}$, INA pin. The initialization of the function variables, I/O pins, and PWM pins occurs outside of the main function for global access. When later adaptations of the prototype are made that include position control, it will no longer be feasible to keep the variable declarations as global.

There are five variables which are important for the program's functions. Table 2.17 lays out each variable's name, assigned initialization value, and purpose.

\footnotetext{
${ }^{40}$ The left or right side is determined from the view of someone sitting on the platform looking forward.
} 
Table 2.17. Global Variable Declarations

\begin{tabular}{|c|c|c|}
\hline $\begin{array}{c}\text { Variable/Constant } \\
\text { Name }\end{array}$ & \begin{tabular}{|c|}
$\begin{array}{c}\text { Initialization } \\
\text { Value }\end{array}$ \\
\end{tabular} & Purpose \\
\hline Input_A & 0 & $\begin{array}{l}\text { This variable is the dummy variable used in } \\
\text { the motor driver functions in order to assign a } \\
\text { specific value of true "1" or false "0" to that } \\
\text { motor driver's INA pin. This, along with } \\
\text { Input_B, determines the direction the motor } \\
\text { will spin. }\end{array}$ \\
\hline Input_B & 0 & $\begin{array}{l}\text { This variable is the dummy variable used in } \\
\text { the motor driver functions in order to assign a } \\
\text { specific value of true "1" or false "0" to that } \\
\text { motor driver's INA pin. This, along with } \\
\text { Input_A, determines the direction the motor } \\
\text { will spin. }\end{array}$ \\
\hline motor_on & 70 & $\begin{array}{l}\text { This is a constant that represents the PWM } \\
\text { value that will be assigned to a specific motor } \\
\text { driver's PWM pin. Potential values range } \\
\text { from } 0-255 \text {. }\end{array}$ \\
\hline motor_off & 0 & $\begin{array}{l}\text { This is a constant that represents the PWM } \\
\text { value that will be assigned to a specific motor } \\
\text { driver's PWM pin. Potential values range } \\
\text { from } 0-255 \text {. }\end{array}$ \\
\hline P_W_M_value & 0 & $\begin{array}{l}\text { This variable is the dummy variable used in } \\
\text { the motor driver functions in order to assign a } \\
\text { PWM value to motor driver's PWM pin". }\end{array}$ \\
\hline state & 0 & $\begin{array}{l}\text { This variable is used to represent the state } \\
\text { that the program is in. }\end{array}$ \\
\hline
\end{tabular}

The structure of the software relies heavily on calling functions to complete different jobs. The program consists of essentially one "task" which transitions from state 0 to state 1 at the beginning of the program. State 0 is the initialization state, while state 1 is the state in which a lengthy switch-case structure is used for specific commands. The 
switch-case implements the usage of keyboard commands that are issued by the person controlling the device. Each case involves one type of motion. For example, case 'a' causes vertical actuator Pair 1 to extend. Each case accomplishes its motion by calling one or more of the program's basic functions. Since the program is all manually controlled, there was no need for a cooperative multitasking structure. There are a total of three functions used: motorForward, motorBackward, and motorBrake. A description of each function's properties is included in Table 2.18.

Table 2.18. Function Properties and Descriptions

\begin{tabular}{|c|l|c|l|}
\hline Function Name & Input Variables & $\begin{array}{c}\text { Return } \\
\text { Value }\end{array}$ & \multicolumn{1}{|c|}{ Description } \\
\hline motorForward( ) & $\begin{array}{c}\text { int Input_A, int } \\
\text { Input_B,int } \\
\text { P_W_M_value }\end{array}$ & void & $\begin{array}{l}\text { This function sets Input_A high } \\
\text { and Input_B low. It also assigns } \\
\text { P_W_M_value the value of } \\
\text { motor_on. }\end{array}$ \\
\hline motorBackward( ) & $\begin{array}{c}\text { int Input_A, int } \\
\text { Input_B,int } \\
\text { P_W_M_value }\end{array}$ & void & $\begin{array}{l}\text { This function sets Input_A low } \\
\text { and Input_B high. It also } \\
\text { assigns P_W_M_value the } \\
\text { value of motor_on. }\end{array}$ \\
\hline motorBrake( ) & $\begin{array}{c}\text { int Input_A, int } \\
\text { Input_B, int } \\
\text { P_W_M_value }\end{array}$ & void & $\begin{array}{l}\text { This function sets Input_A low } \\
\text { and Input_B low. It also assigns } \\
\text { P_W_M_value the value of } \\
\text { motor_off. }\end{array}$ \\
\hline
\end{tabular}

The remaining portion of the code lays out the details of the switch case. The details of this switch-case can be found in the actual code, located in Appendix F.

\subsection{Manufacturing}

Every component machined for the leg was made out of metal, whereas the frame was constructed almost exclusively out of wood. While Appendix A contains all of the 
part drawings required to machine these parts, there were several considerations that were involved in the process.

The only special consideration for the frame base involved reversing the direction of the actuator holes. Each hole has a slit in order to fit the linear actuator inside of it, and one half of the base had the slots facing one direction, while the other half had them facing the reverse direction. Figure 2.39 shows this hole layout.

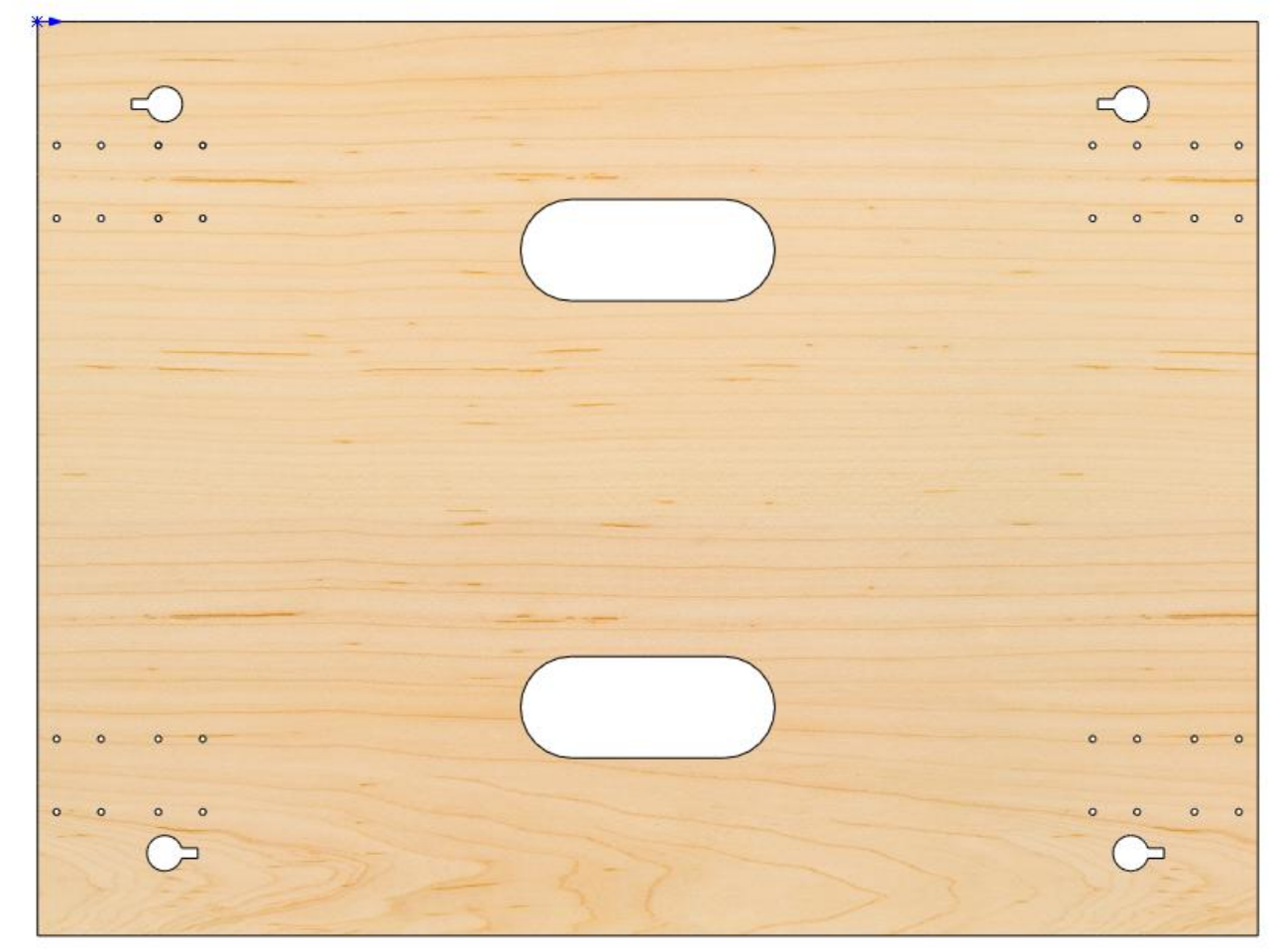

Figure 2.39 - Frame Base with Opposite-Facing Actuator Slots

The reason for this configuration is that the legs needed to be aligned with each other, so the center of the circles needed to match up. Also, in order to make the linear actuator motors overhang on the outside of the platform, the directions of the slots had to be reversed. The reason that the motors were chosen to face away from the platform was 
so that planks could be used to support the actuator from moving up and down. Some kind of fixture had to be created in order to keep the actuator body fixed, and simply adding a vertical board to the frame with a hole to support the motor was the simplest and most workable solution. Figure 2.40 shows this feature.

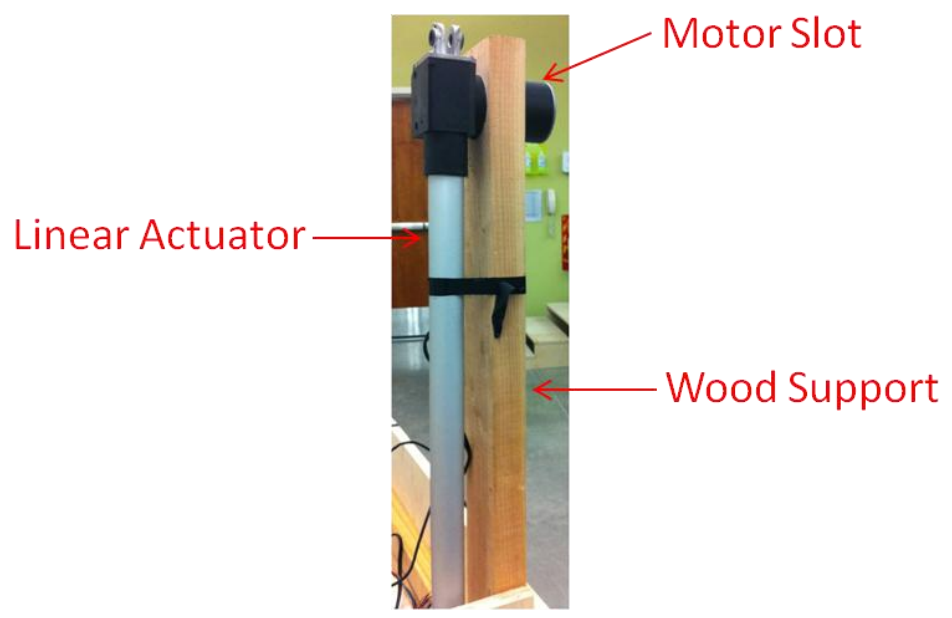

Figure 2.40 - Actuator Support

All of the wood pieces were fastened using wood screws. Since each screw was used to fasten two pieces of wood together, a slightly larger hole was drilled in the first piece before the screw was drilled in. This is so that the threads on the screw would create a compressive force between the two pieces of wood. This would not occur nearly as well if the larger hole wasn't drilled first, since the screw head is no longer acting as a clamp for its lower threads. The spacing between screws wasn't exact, as each screw is rated for well over the required loading condition. The screws were placed as a best estimate to ensure a rigid structure.

Most of the parts for the leg required manual milling work, while some required the lathe. All of the operations were done using standard machining methods, and no special tooling was required. 


\section{TESTING}

\subsection{Plan and Objectives}

Proving that each of the sequences of motion could be achieved required two

different sets of tests. First, the device had to be able to climb up a set of stairs. Second, the device had to be able to climb over an arbitrarily shaped but reasonably sized obstacle. Each of these sets of tests was done by using a laptop keyboard as the controller, and initiating the correct commands to move the different joints of motion in stages. This section provides some images of the stages accomplished in the two tests, as well as any relevant discoveries made about the device by each of these motions.

\subsection{Stair Climbing Sequence Tests}

The first set of tests was done on the stair climbing sequence. Each of the stages of this sequence were pre-determined by the sequence laid out in 2.1.4. A specially fabricated wooden staircase with steps made of 11 " x 36 " $\mathrm{x} 3 / 4$ " thick plywood sheet was made to allow the device to perform the sequence. As previously discussed, the treads were kept at their standard length of 11", while the risers were half-scaled to 4". The staircase was placed at the base of Pair 1's legs, at which point the climbing sequence could commence. Because many of the stages could be replicated without any structural issues whatsoever, the entirety of the images of each of the stages of the stair-climbing sequence are presented in Appendix D. 
The configuration of legs for this test placed the motorized pairs at Pairs 2 and 4.

Pairs 1 and 3 therefore had caster wheels. Figure 3.1 shows the transition from Stage 1 to Stage 2 .

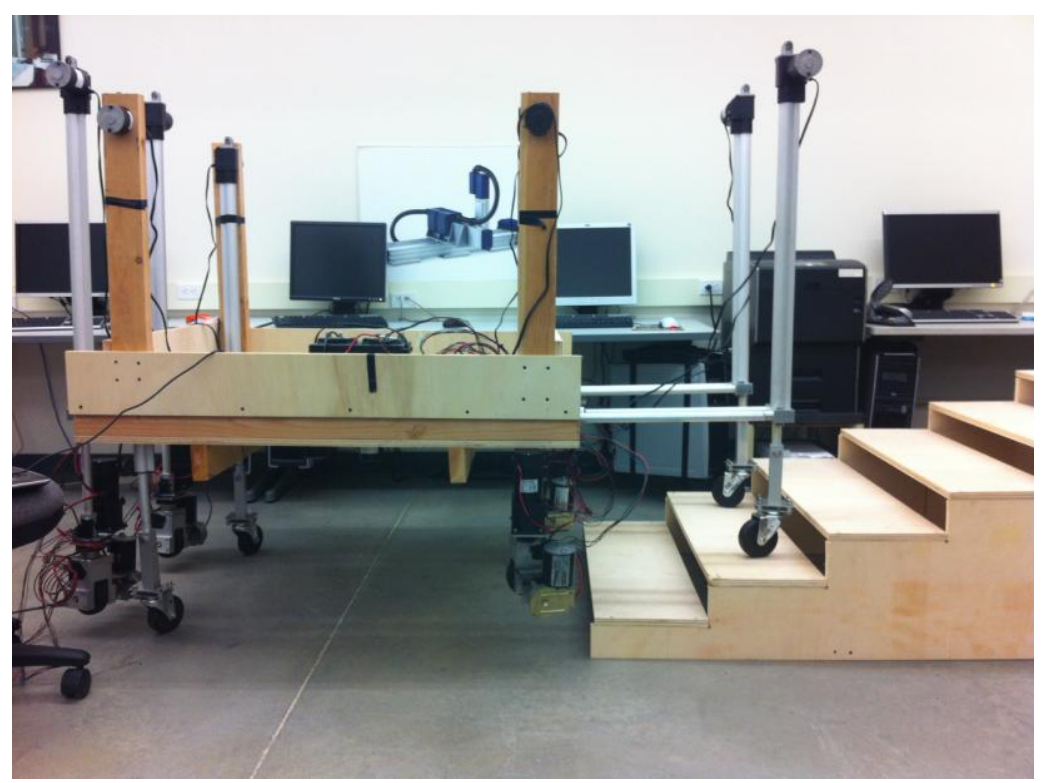

Figure 3.1 - Stage 1 to Stage 2 Transition

This transition shows how Pair 2 must raise its legs before the platform can be moved to the right to place Pair 2 on the first step. Initially, it was thought that simply by retracting the horizontal actuators of Pair 1 that the platform would simply slide forward on Pair 3's casters. However, this assumption encounters two problems. First, Pair 1's legs also have casters, which means there is no locking mechanism in place to ensure that the platform would not slide off the stairs while the horizontals are retracting. This early discovery made it immediately clear that motorized legs on Pairs 1 and 3 would be far superior to having them on Pairs 2 and $4 .^{41}$ A motorized pair could lock the wheels in

\footnotetext{
${ }^{41}$ This addresses the configuration concern raised in 2.1.3.
} 
place, not allowing the platform to slide. The second problem encountered while trying to accomplish Stage 2 was that the casters weren't rotating freely enough to ensure that the platform would move straight forward. The initial angle of the casters would determine which direction they would slide. Fortunately, these two issues could be overcome by simultaneously driving the wheels of Pair 4 forward while Pair 1's horizontal actuators were retracting. This worked very well to bring the platform forward and allow Pair 2's legs to be placed on the first step. The success of this motion is shown in Figure 3.2.

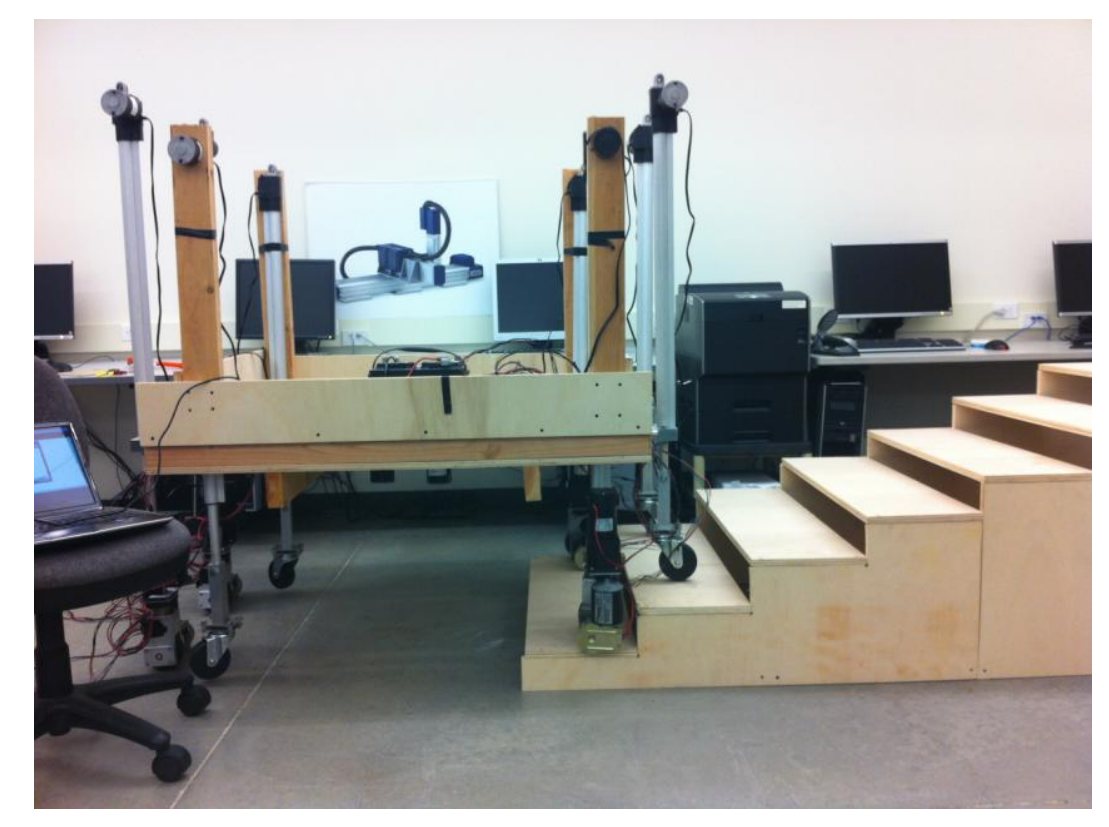

Figure 3.2 - Completion of Stage 2

Each of the remaining even stages (Stage 4, Stage 6, etc.) faced the same issue. Each time the method of simultaneously retracting Pair 1's horizontal actuators and driving Pair 4's wheels forward worked to bring the platform forward. Thus, up to and including Stage 9 of the sequence, each stage was successful. 
The largest difficulties were encountered after Stage 9. The completion of Stage 9 is shown in Figure 3.3.

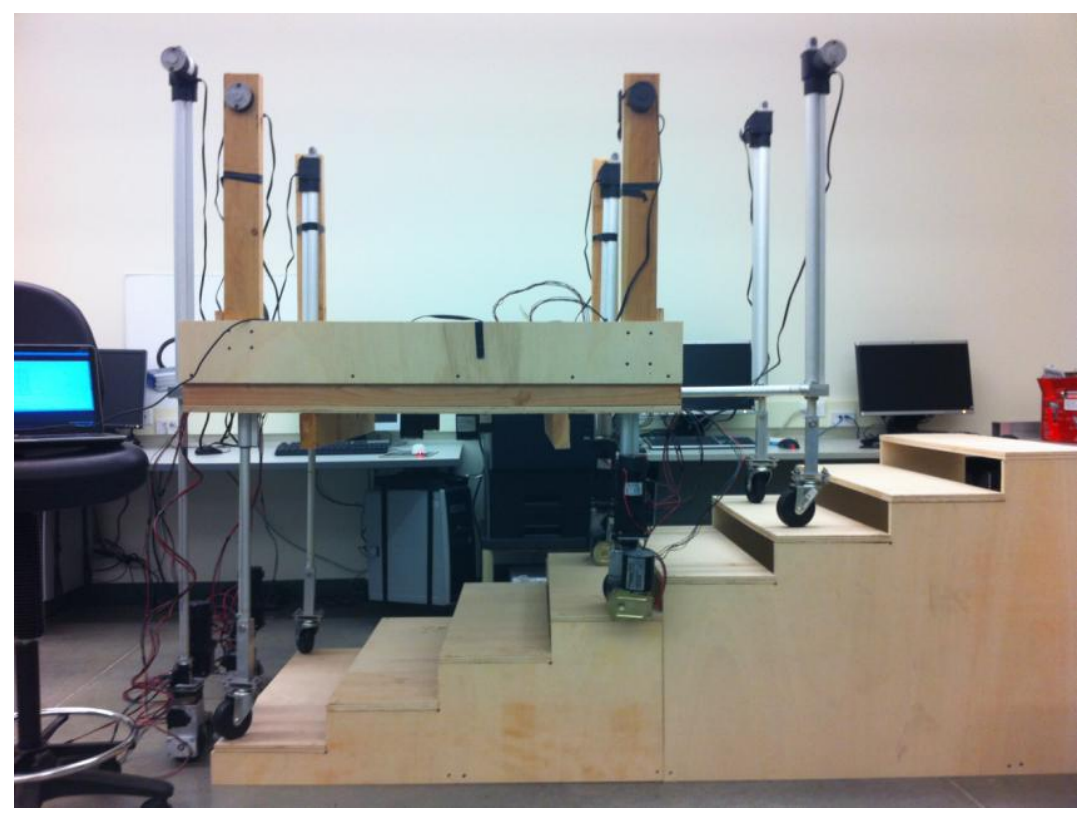

Figure 3.3 - Completion of Stage 9

In order to transition from Stage 9 to Stage 10, Pairs 2 and 3 must be lifted the distance of one step to allow the platform to move to the right and place Pairs 2 and 3 back down on the next step. This requires the entire load of the platform to be carried by Pairs 1 and 4. Up to this point, there had been little issue with placing the full load on these pairs. However, because of a mechanical issue in the horizontal actuators, the vertical actuators in Pairs 1 and 4 had a tendency to tilt left-right (into and out of the page). This created an instability in the system as it was climbing, such that Stage 11 could not be attempted. Risk of crashing was simply too great. In order to even 
accomplish Stage 10, the aid of a person was required to hold the back legs straight up.

Figure 3.4 shows the completed Stage $10 .^{42}$

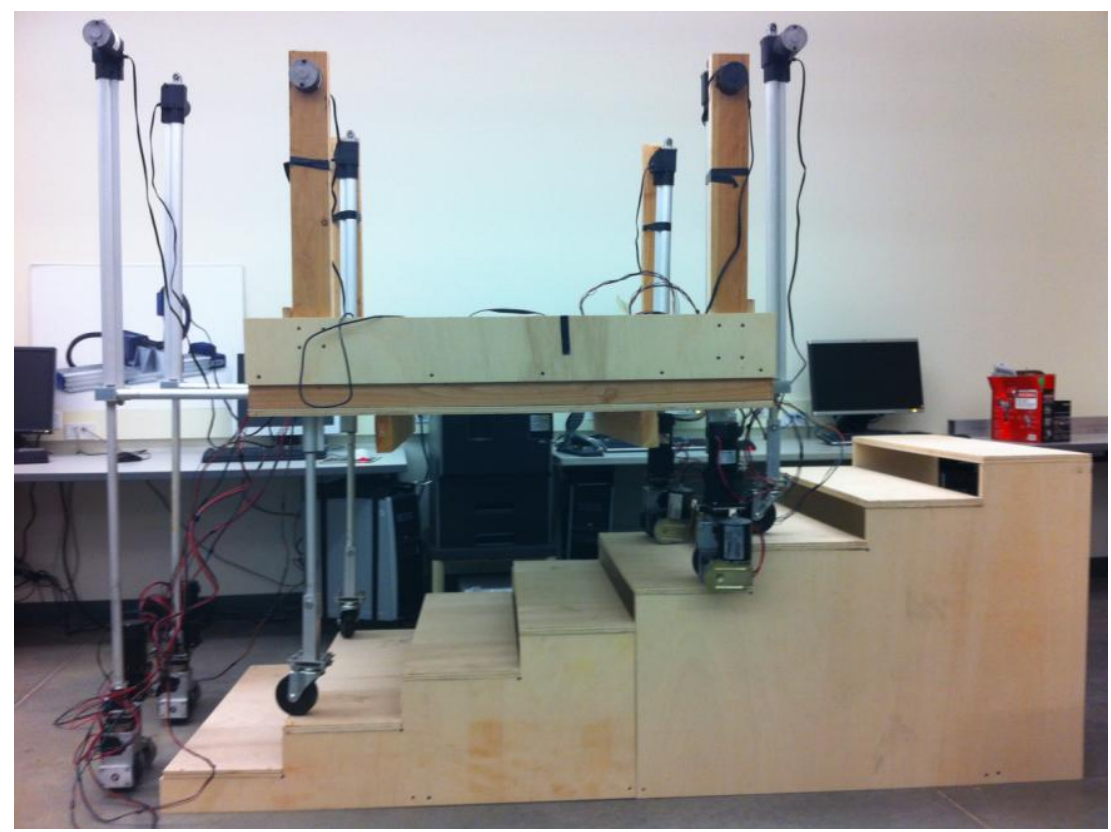

Figure 3.4 - Completion of Stage 10

The problem with the horizontal actuators was caused by the fact that the tubes inside the horizontal actuators were rotating. This was a completely unforeseen feature of the tube actuators that had been purchased to accomplish the motion. This rotation, while a minor concern for the actuators themselves, causes the four brackets that hold up Pairs 1 and 4 to tilt left-right. This instability is amplified the more the vertical as well as the horizontal legs are extended. A solution to the tilting was found, however. A rigid steel rod was inserted between the actuators of Pairs 1 and 4. This rod forced Pairs 1 and 4 to

\footnotetext{
${ }^{42}$ The platforms weight was rested on Pairs 2 and 3 so that the device could be shown in the image without the aid of someone to hold it in place.
} 
remain mostly straight, thereby dodging the effects of tilting. Figure 3.5 shows the rod inserted between the actuators.

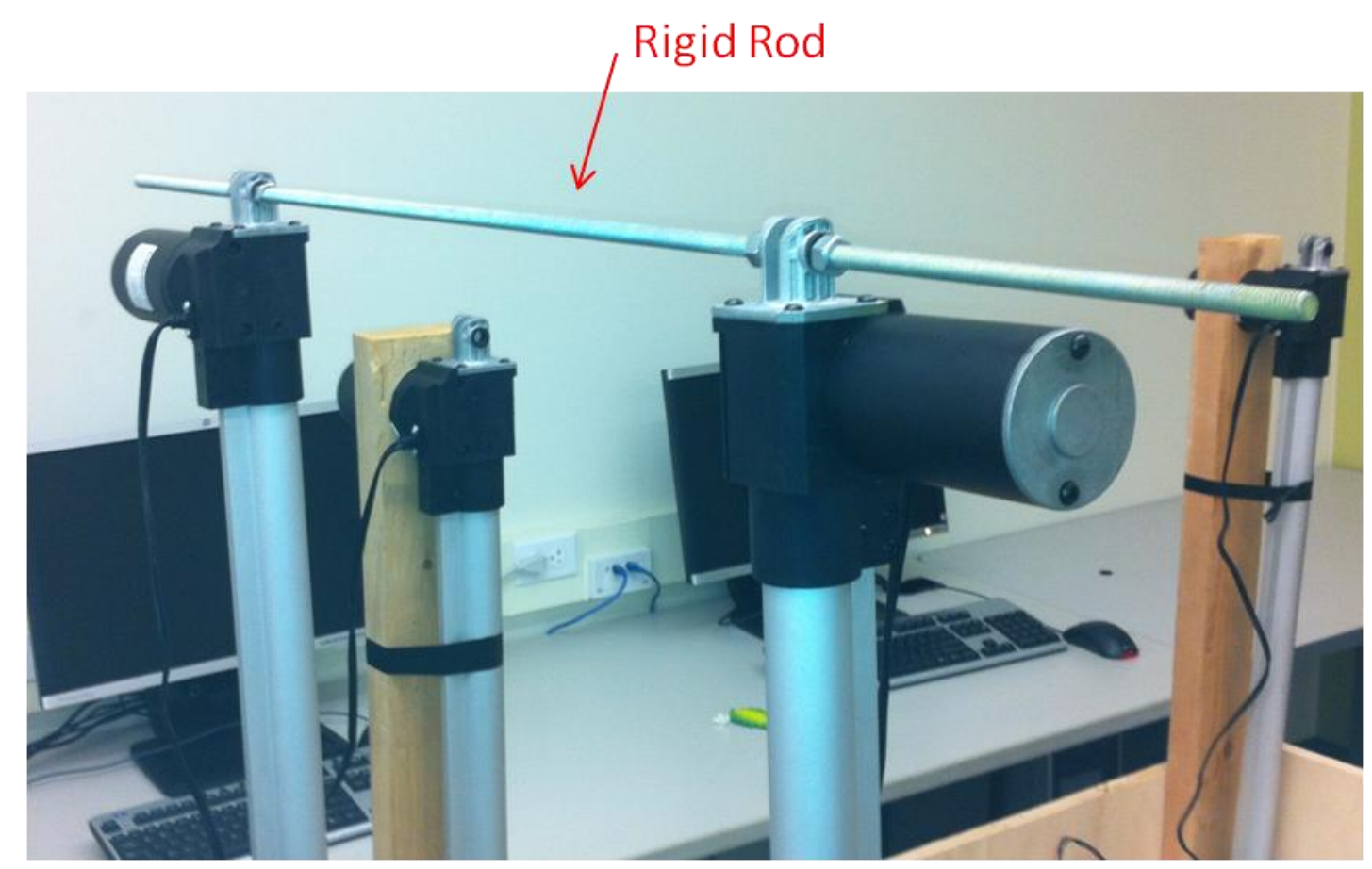

Figure 3.5 - Rigid Rod Added to Reduce Tilting

In addition to the rigid rod, a different type of actuator, would have aided in reducing tilting. A final evaluation of the stair climbing sequence tests demonstrates that the device as designed can complete all stages.

\subsection{Obstacle Climbing Sequence Tests}

The second set of tests was performed by controlling the device as it traversed an obstacle. One of the key aspects of the motion during this sequence is for the platform of the device to stay stable and flat as it is carried over an obstacle. The beginning of the sequence involved the vehicle rolling up to the obstacle with Pair 1's vertical legs 
retracted. The obstacle used for this test was 10" wide (left-right on the page) and 14" tall. Figure 3.6 shows the initial position before beginning Stage 1 .

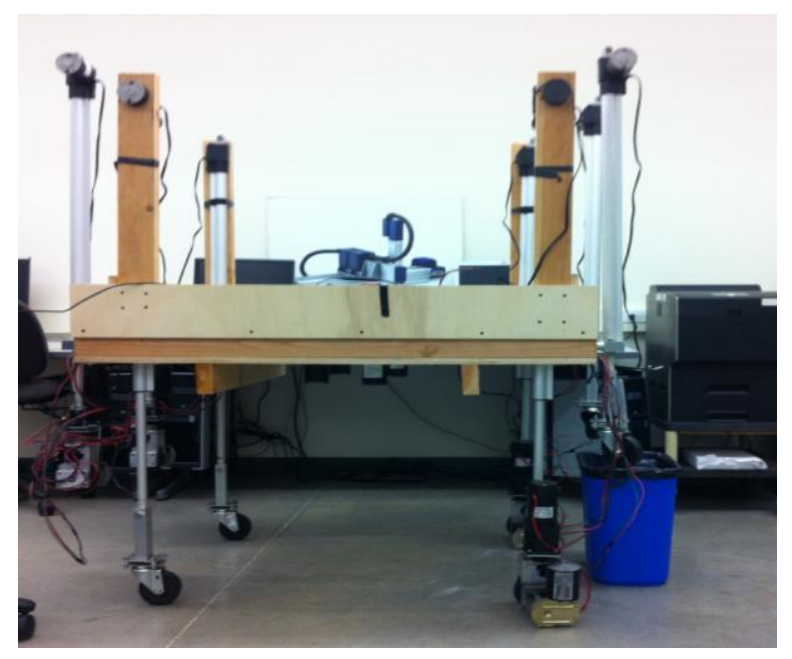

Figure 3.6 - Vehicle in Position to Begin Stage 1

In order for the vehicle to begin the sequence, the horizontal actuators of Pair 1 must extend. This way Pair 1's vertical legs can extend and take the front load of the vehicle. Figure 3.7 shows the completion of Stage 1.

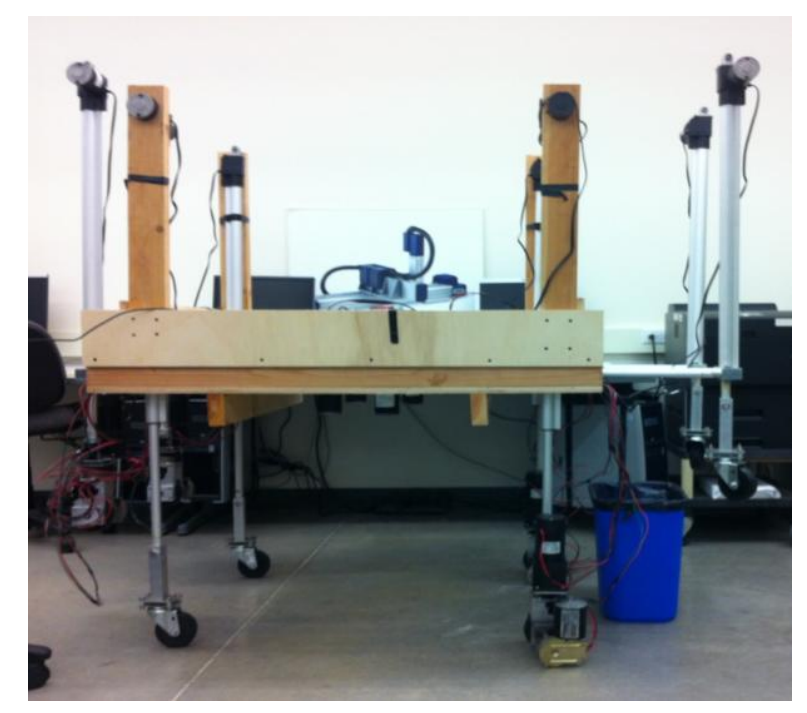

Figure 3.7 - Completion of Stage 1 
According to the original diagrams, Stage 2 involves lowering Pair 1 while raising both Pairs 2 and 3. Because of the instability of Pair 1 and Pair 4's legs while extended, only Pair 2 was raised. This is acceptable until Pair 3's legs must travel over the obstacle. The test failed, however, while attempting to complete Stage 3a. Figure 3.8 shows an image of the device at Stage 2, prior to failure.

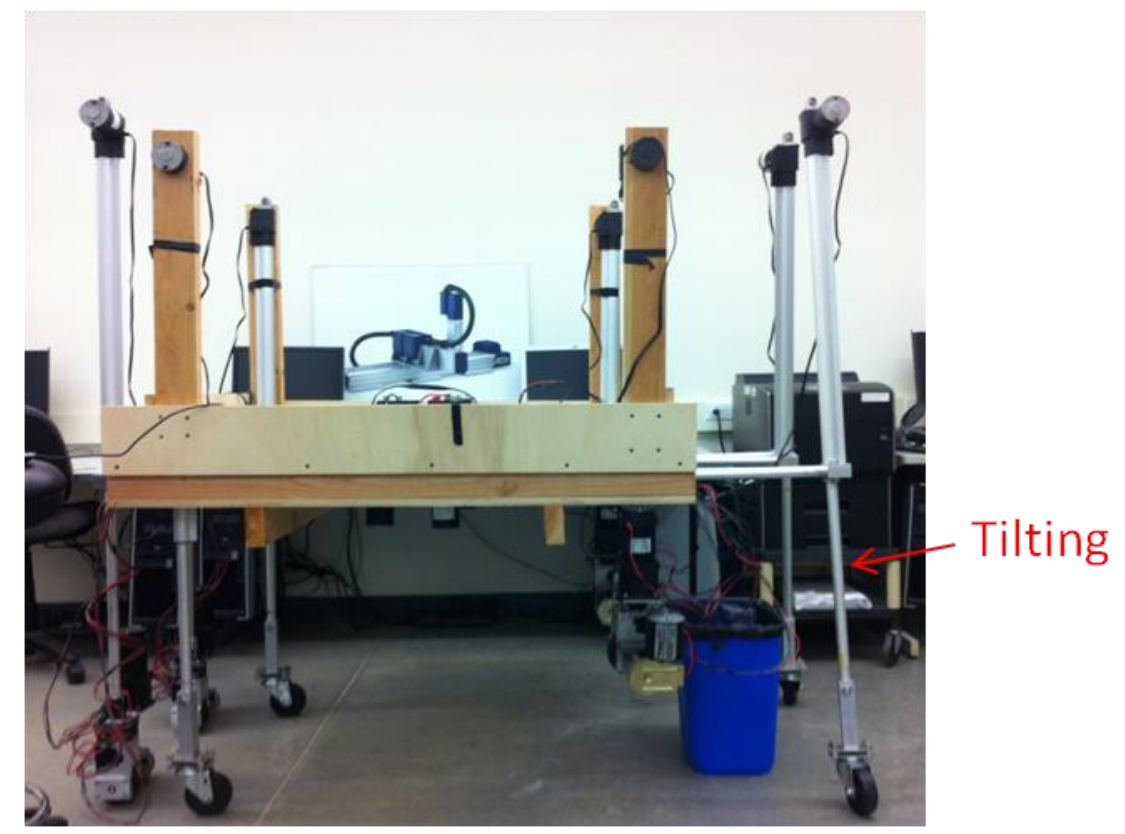

Figure 3.8 - Completion of Stage 2

When looking at Pair 1 in this image, it is clear that the same tilting issue experienced in the first set of tests is also being experienced here. Even with the addition of the rigid rod to reduce tilting, the twisting in the horizontal actuators themselves caused enough of an issue to discontinue the testing at this point. An attempt was made to commence Stage 3a, which involved using the drive motors of Pair 4 to drive the device forward. Only about one second after the drive motors turned on, Pair 1's legs completely gave way and the vehicle crashed on its front-left corner. Nothing was damaged or 
displaced during the crash, but it became clear that accomplishing the obstacle climbing sequence would have to be done with a smaller obstacle.

It is important to note that many of the design features were verified during the testing stages. The steering and driving both functioned adequately on all four legs. The wooden supports for vertical actuators of Pairs 2 and 3 functioned properly to keep the actuators straight up and down. The platform itself demonstrated more than enough rigidity, even when it crashed. Lastly, all of the electronics worked as-designed, giving full functionality for the steering, driving, and motion of the linear actuators.

Because the device lacked position control, the climbing sequences had to be accomplished using manual control. Because exact positions could not be achieved, an efficient way of surmounting this problem was by fine-tuning the PWM values of each of the motor drivers to force each of the actuators to move at the same speed. Due to stiction on the inside of the linear actuators, each of them were prone to move at different speeds. By changing the PWM values so that each actuator in a pair matched the speed of the other, the sequences required less manual tuning in between stages. This not only saved time during the testing process, it also laid the grounds for additional features to be added for the next version of the prototype.

In order to accomplish each stage of any given sequence, it is obvious that position control be ultimately involved. This ensures that the device can stop at a specific location, while also paving the way for the device to be pre-programmed with certain sequences so that the driver would not have to control a device with so many joints of motion. Tweaking the PWM values, however, also revealed the need for velocity control 
in addition to position control. If all of the actuators can be ensured to move at the same speed, the platform can be ensured to stay level. Adjusting PWM values is not a final solution, but it did show that the platform could stay flat during the motion in each sequence. 


\section{CONCLUSIONS AND RECOMMENDATIONS}

This thesis began with several stated objectives, all of which were met with varying degrees of success. As was already stated in this document, there are various additions to this version of the prototype that will be made in the future, and these will be discussed here as well. Figure 4.1 and Figure 4.2 show final images of the solid model and actual prototype, which can be used for reference in the discussion of the objectives.

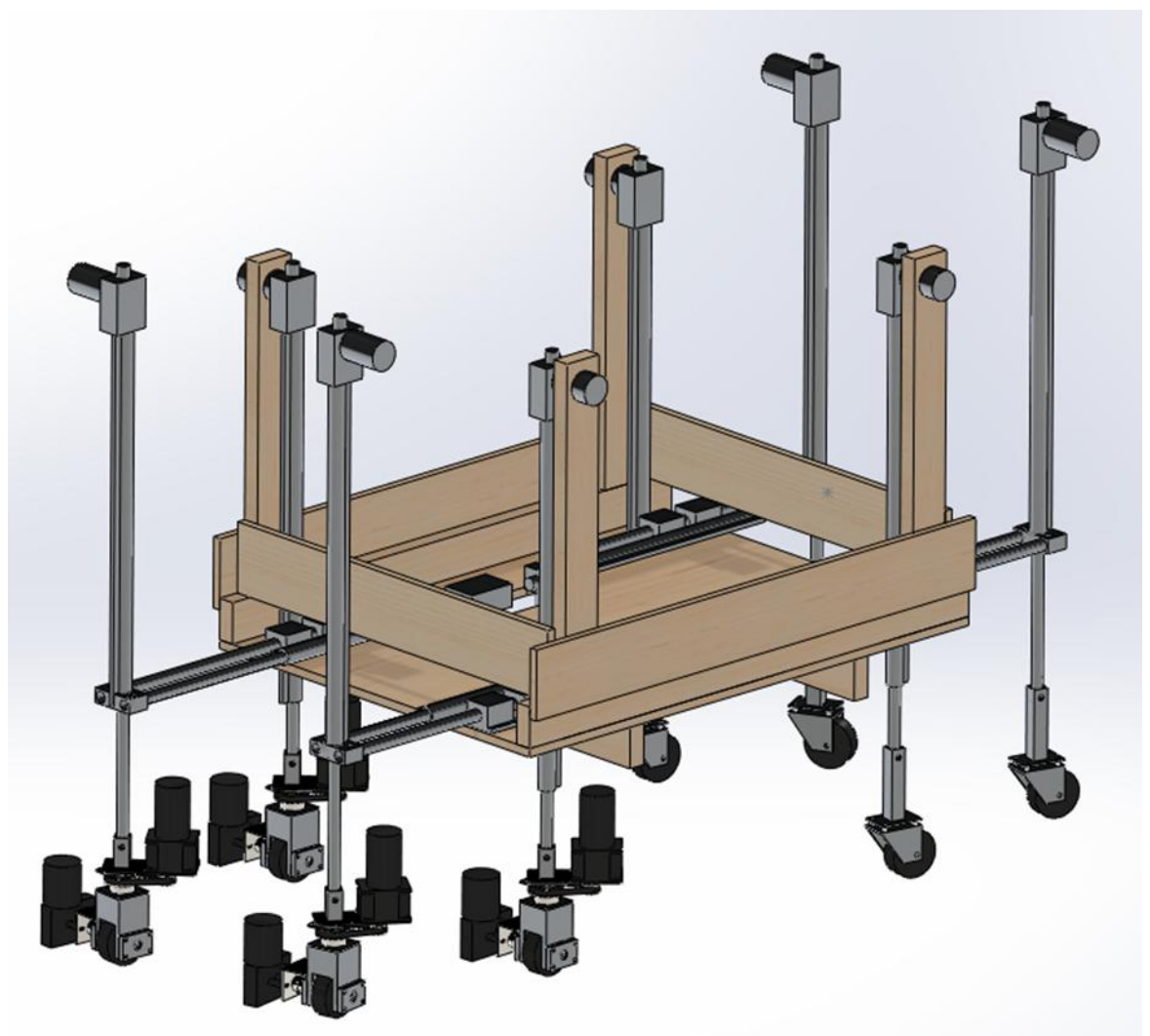

Figure 4.1 - Complete Solid Model of 8-Legged Robotic Transporter 


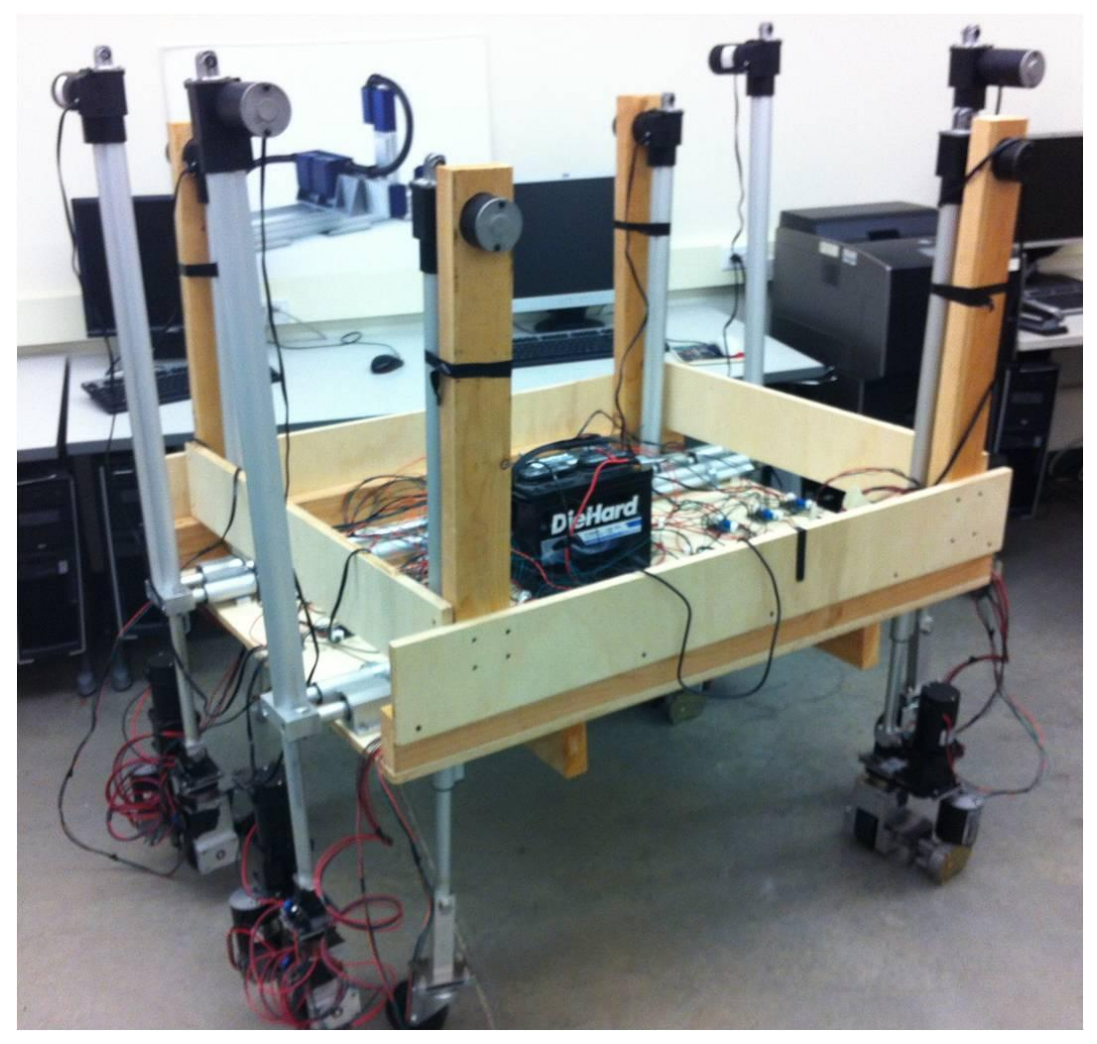

Figure 4.2 - Complete 8-Legged Robotic Transporter

The first objective was for the device to be able to travel up and down a flight of stairs. As the testing verified, the device was able to accomplish this through all stages while being manually controlled. A sequence of commands issued from a computer keyboard controlled the motion of the device. This allowed it to ascend the staircase in a series of stages, which were identical to those laid out previously in this document. This objective was not perfectly met, however, since the staircase that was used was scaled down for cost purposes. A future design will need to be able to handle a full sized staircase.

The second objective requires the device to be composed of 8 vertical legs, 4 of which are fixed to the platform and can only move vertically, with another 4 that can 
move horizontally as well as vertically. This goal was achieved by using 12 different linear actuators -8 vertical and 4 horizontal. The 4 horizontal actuators were shielded from bending by placing a hollow aluminum shaft parallel to it, which took all of the gravity load of the device. While all the actuators would typically move in pairs during all modes of motion, both the mechanical hardware and the software allow each of the actuators to move independently of each other. As discovered during the testing, the horizontal actuators had a problem with rotation. This would eventually have to be fixed by choosing a different type of actuators for the design.

The third objective was to place a weight on top of the platform to simulate the transportation of cargo or persons. While the mechanical components for this prototype were not designed to be able to carry a person, a $30 \mathrm{lb}$ car battery was placed on the platform to simulate the weight as well as perform the critical task of supplying power.

The fourth objective required that the device be powered with an on-board supply. This came in three forms. First, a car battery was used to supply high-current power to the components through the motor driver chips. Second, a separate $8.4 \mathrm{~V}$, low amperage battery pack was used to power the chips. Third, the USB cable connected to the laptop computer powered the Arduino Mega 2560. While this was not necessary, the cable was required in order to send keyboard commands, making it redundant to supply power from the $8.4 \mathrm{~V}$ battery pack. If needed, however, the battery pack could serve this function.

The fifth objective states that the platform on the device stay level at all times. Without position control, this was challenging. Ultimately, manual control was able to bring the actuators close to, but not perfect, alignment. The main reason for this discrepancy is that the linear actuators did not have linear encoders, making it impossible 
to give feedback that could have ensured that all actuators were extended to the same length. Since the actuators extend and retract at different speeds because of internal stiction, the legs had to be independently adjusted to achieve a reasonable state of levelness. Despite the setbacks of having no position control, the lack of encoders did not stop the device from being able to sufficiently demonstrate all stages of motion in the testing phase. It is important to note that the lack of levelness that resulted was not a problem with the mechanical design, simply a problem with the system not containing components necessary for position control. For scope and cost reasons, these components were saved for a future iteration of the prototype.

Given the relative success of each of these five objectives, it is important that a general conclusion be made. The results of the research done in this thesis indicate that pursuing a further iteration of this device is warranted. None of the issues encountered are insurmountable. That being said, there are still several problems that were encountered that need to be addressed for future iterations of the design. While most of these changes constitute additional features which are outside the scope of the objectives of this thesis, there are a few that represent improvements of design decisions made for this prototype.

There are several changes that could be implemented to enhance the current design. First, there were several parts of the prototype that were simply too large. The 4 ft. $x 3 \mathrm{ft}$. platform is bulky and could be downsized. Now that there is a prototype that spells out what electronic components are required to make the device run, a future iteration could use this information to fill the available space more efficiently. The $3 \mathrm{ft}$. width could be reduced comfortably by 6-8 inches without causing any concern for either 
tipping or having enough space for electronics. The objective here would be to reduce the width such that the device could comfortably fit between the rails of most staircases. The $4 \mathrm{ft}$. length dimension could be reduced at the cost of offsetting the horizontal actuators. The original reason $4 \mathrm{ft}$. was chosen was to allow for opposing horizontal actuators to be collinear. If one were to reduce the 48 inches required in order to fit two 18 -inch stroke actuators, they would have to be placed side by side. ${ }^{43}$ Another option would be to place the horizontal actuators on top of each other, so that overlap would not result in offsetting the vertical actuators. Placing the actuators on top of each other would likely require that a different type of linear actuator be chosen entirely, however. This is because the right angle of the motor to the stroke makes it difficult to stack it on top of another of the same type. An important note on this option is that if the actuator type were to change for the vertical legs, several of the mechanical components would have to be completely redesigned. However, if only the horizontal actuators were changed, very few mechanical components would require redesign. As discussed previously, the usage of track actuators would be far preferable to tube actuators. Track actuators would provide substantial additional rigidity to avoid the issue of twisting that caused some of the later stages of the testing to fail.

Another group of components that are simply too cumbersome are the drive and steering motors. Many components were designed to accommodate such motors, which were selected for cost reasons. A future iteration would want to include smaller motors, if possible. This would allow the drive and steering portion of the prototype to shrink in

\footnotetext{
${ }^{43}$ If the $18 "$ stroke length was to increase, it would also be difficult to reduce the $4 \mathrm{ft}$. dimension.
} 
size, as it would not be necessary to support such large and heavy components.

In order to advance to a second iteration of the design, there are a few key additions that will need to be made. First, the device will eventually need to have at least some (if not mostly) autonomous elements. The only way to achieve this is to incorporate position control into the design. This will require not only selecting different driving and steering motors, but also purchasing linear encoders that can track the stroke of the linear actuators. The second critical element to autonomy is the selection of actuators that have adequate stroke lengths to achieve stair climbing, overcoming obstacles, etc. While the concepts tested in this prototype can serve as a guide for this, some dimensions will have to be reexamined. It is possible that both the 30 " and 18 " stroke actuators will have to be increased. ${ }^{44}$ Once position control and correct actuator stroke dimensions are implemented, the software can be rewritten to include a position controller for each of the joints of motion. It is very likely that with the onslaught of many additional signals, namely ENC/DIAG and possibly analog current sensing, a different microcontroller board will need to be chosen (or a second Arduino Mega 2560 that can communicate with the first one). The Arduino Mega 2560 succeeds for this prototype because it has enough digital I/O and PWM pins to control all of the motor drivers. It does not, however, have enough analog inputs or ENC/DIAG pins to handle position control for all the motors. In this case that a second board is not added and the Arduino Mega 2560 is completely replaced, it is also possible that the coding platform will need to be changed as well. Starting with the format of Arduino code written for this prototype, one could

\footnotetext{
${ }^{44}$ It is certain that the 30 " stroke will have to increase, but the 18 " stroke depends on the final length of the platform.
} 
expand and create adequate code for a semi-autonomous device.

Another feature that could be added to simplify the hardware and increase the aesthetic appeal is to control the motor drivers remotely. This would remove the need for the excessive number of data wires that were required in order to make this prototype function. While power would still have to be supplied by a hard line, all of the data transmission could be accomplished with remote signals. 


\section{BIBLIOGRAPHY}

[1] Goren Michael; Goren, Jeremy E. Stair-Climbing Human Transporter. U.S. Patent 7,246,671, July 24, 2007.

[2] "Drive Wheel Motor Torque Calculations", EML2322L - MAE Design and Manufacturing Laboratory. University of Florida. 03 Aug. 2013.

http://www2.mae.ufl.edu/designlab/motors/EML2322L\%20Drive\%20Wheel\%20 Motor\%20Torque\%20Calculations.pdf

[3] McGraw Hill. Shigley's Mechanical Engineering Design $9^{\text {th }}$ Edition. New York: The McGraw-Hill Companies, Inc. 2011. Print.

[4] “Timing Belt Theory”, Gates Mectrol Inc., 2006. http://www.thomasnet.com/white-papers/abstract/101106/timing-belt-theory.html

[5] Young and Freedman. University Physics $12^{\text {th }}$ Edition. San Francisco: Pearson Education, Inc. 2008. Print. 
Appendix A: $\quad$ PART DRAWINGS 


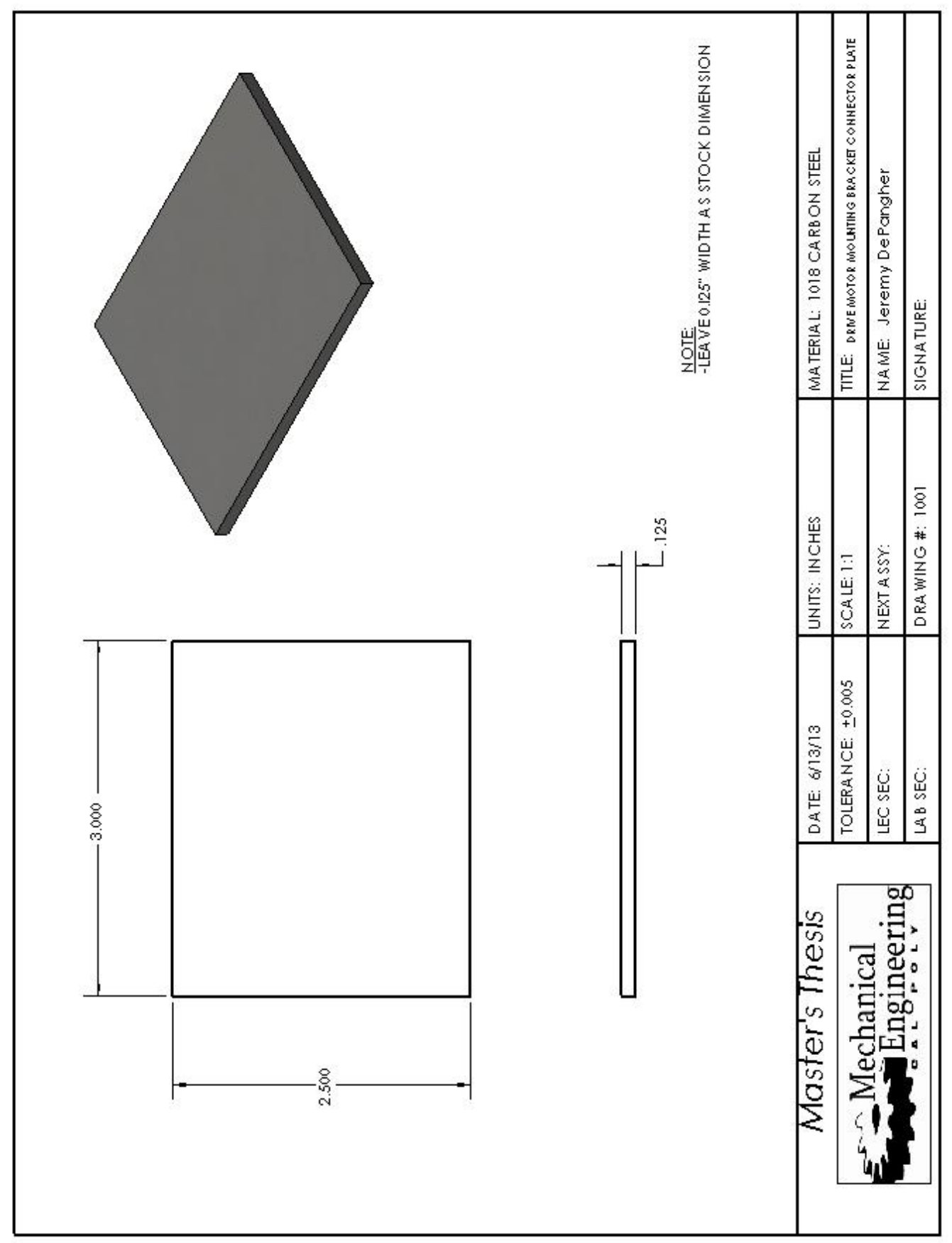





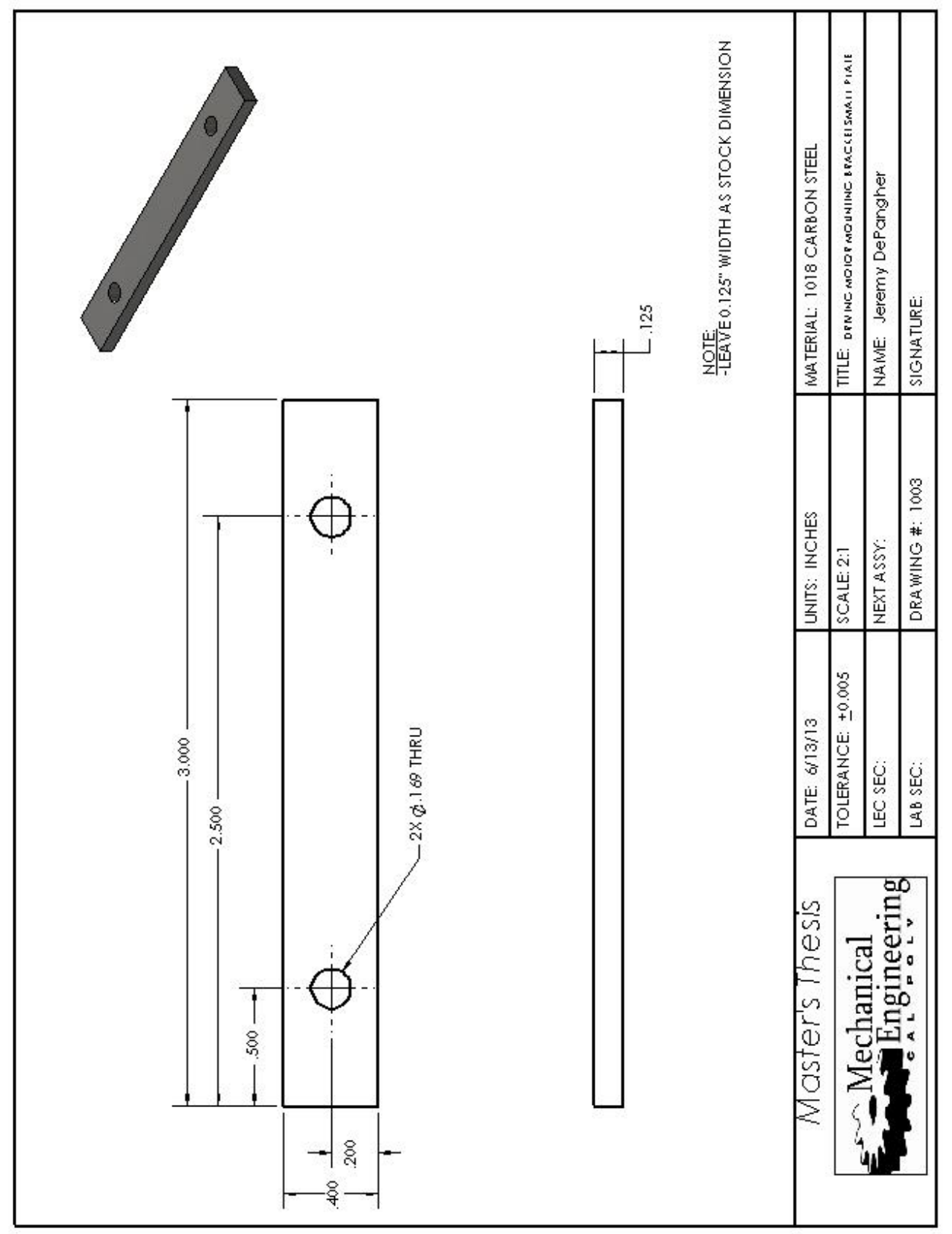




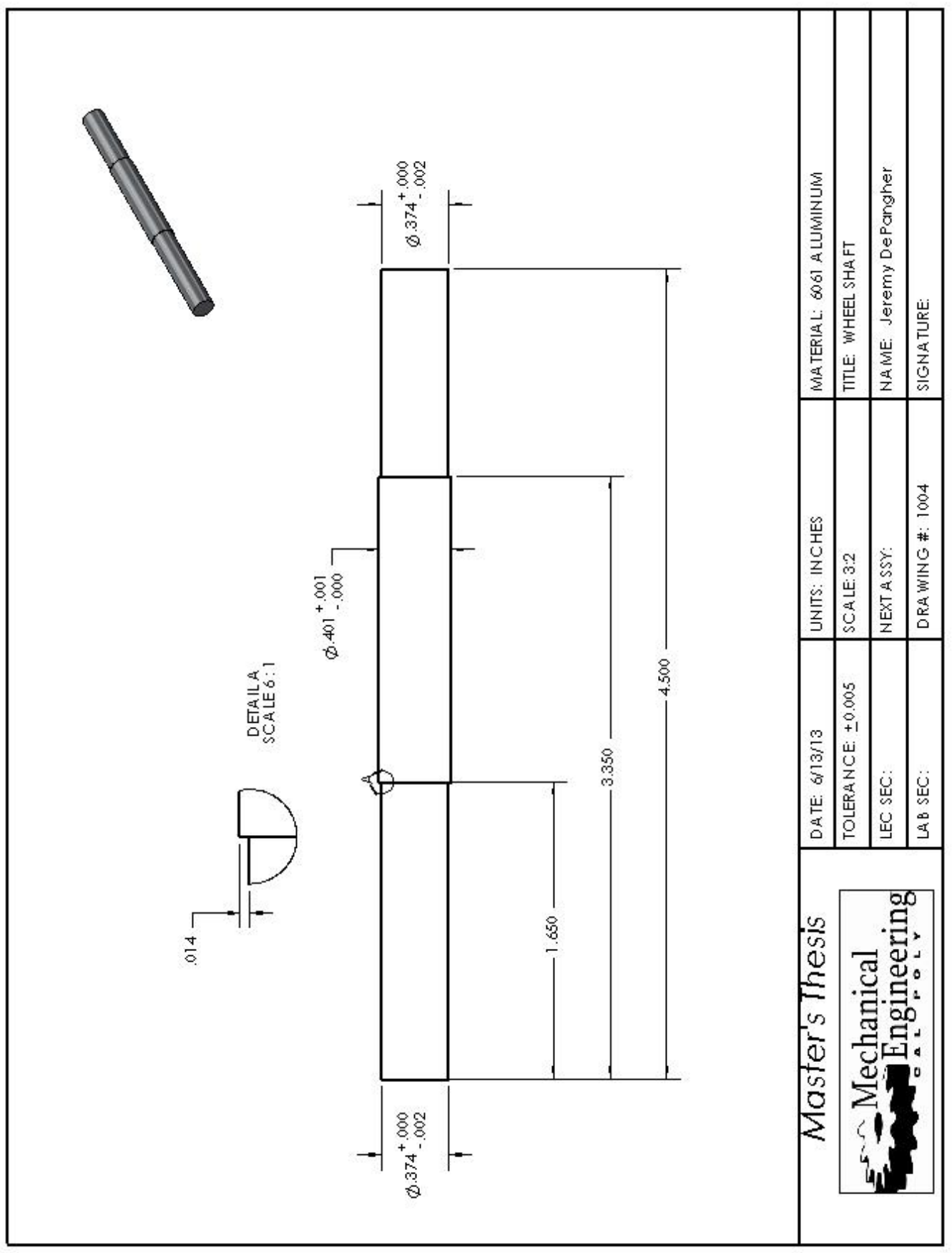




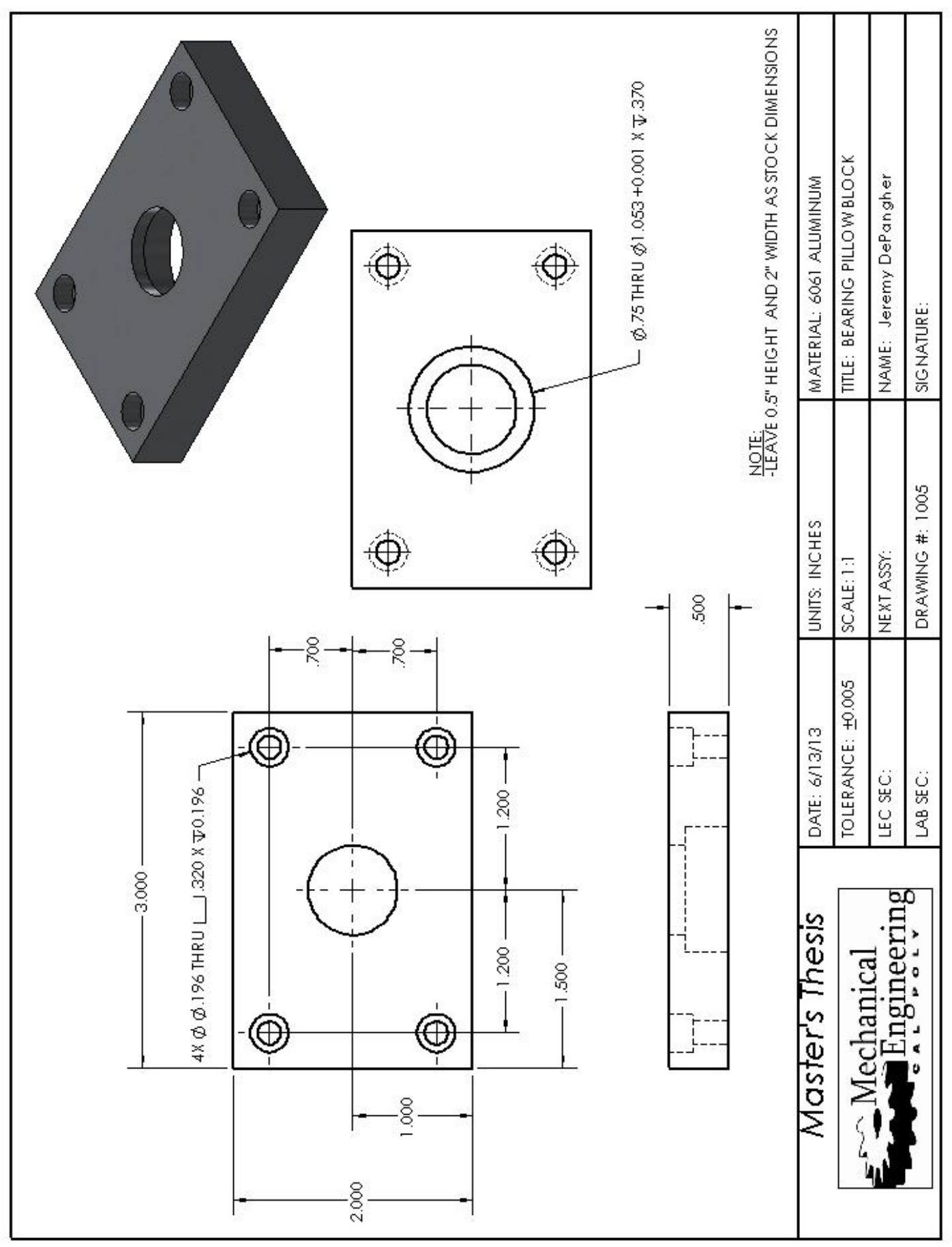




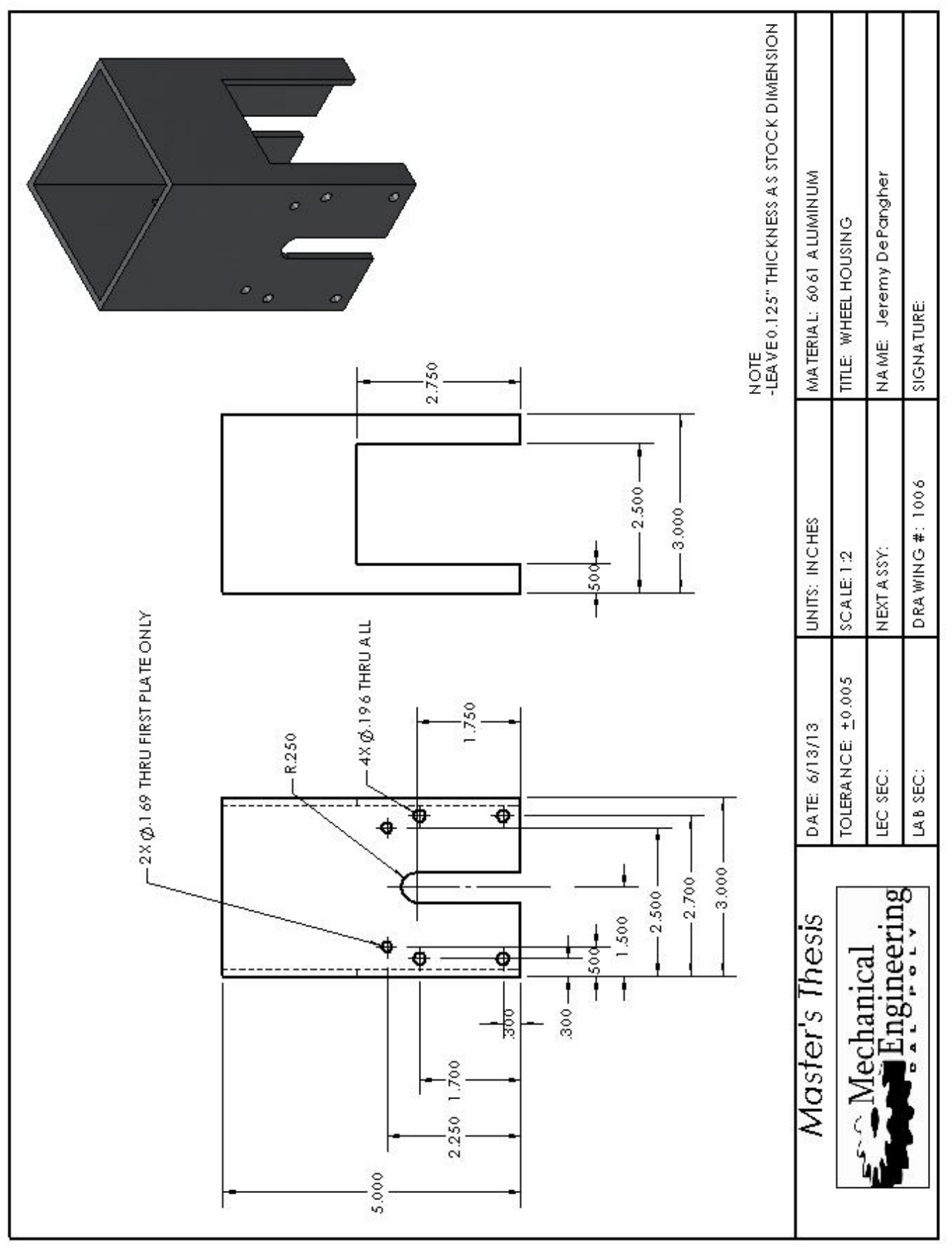




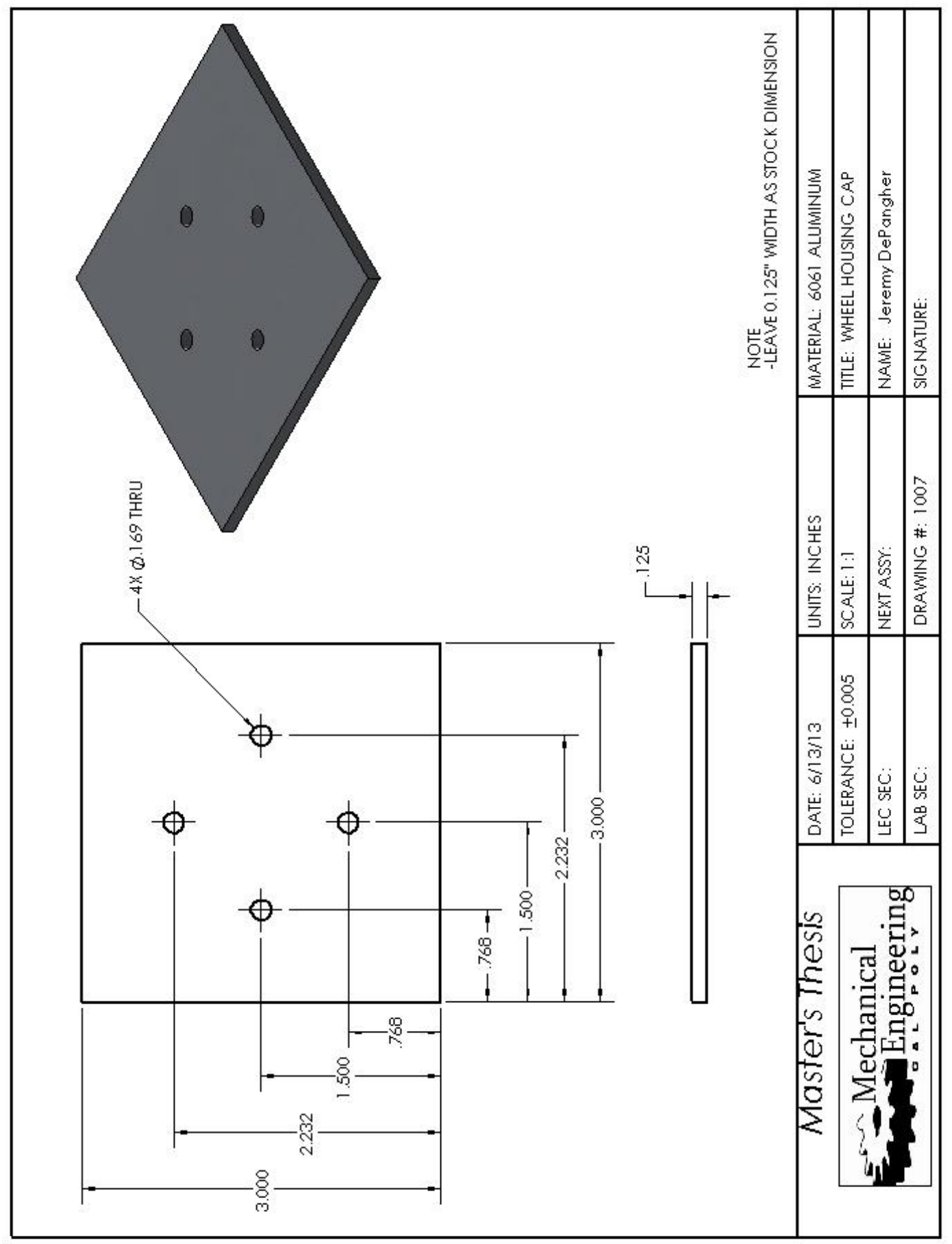




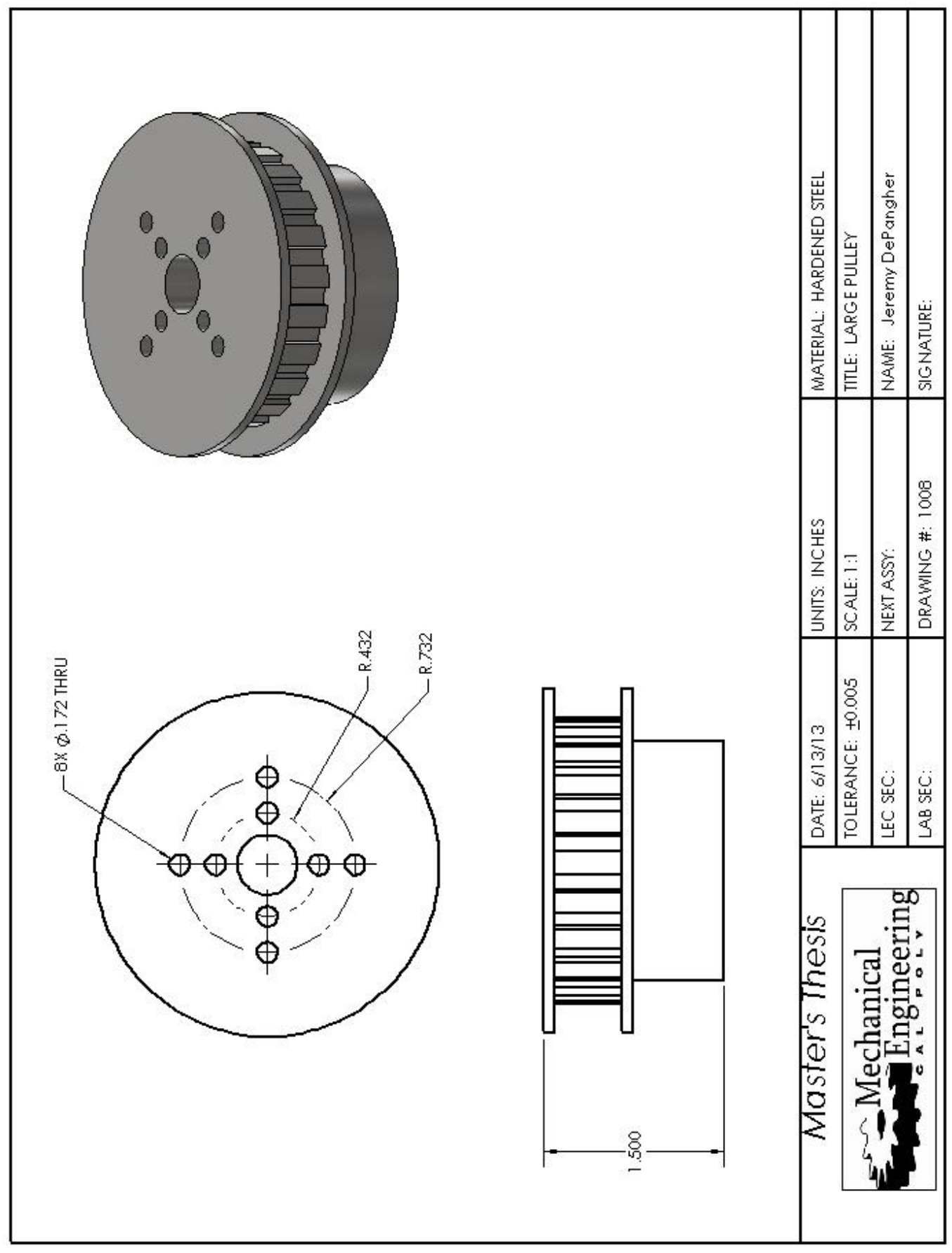




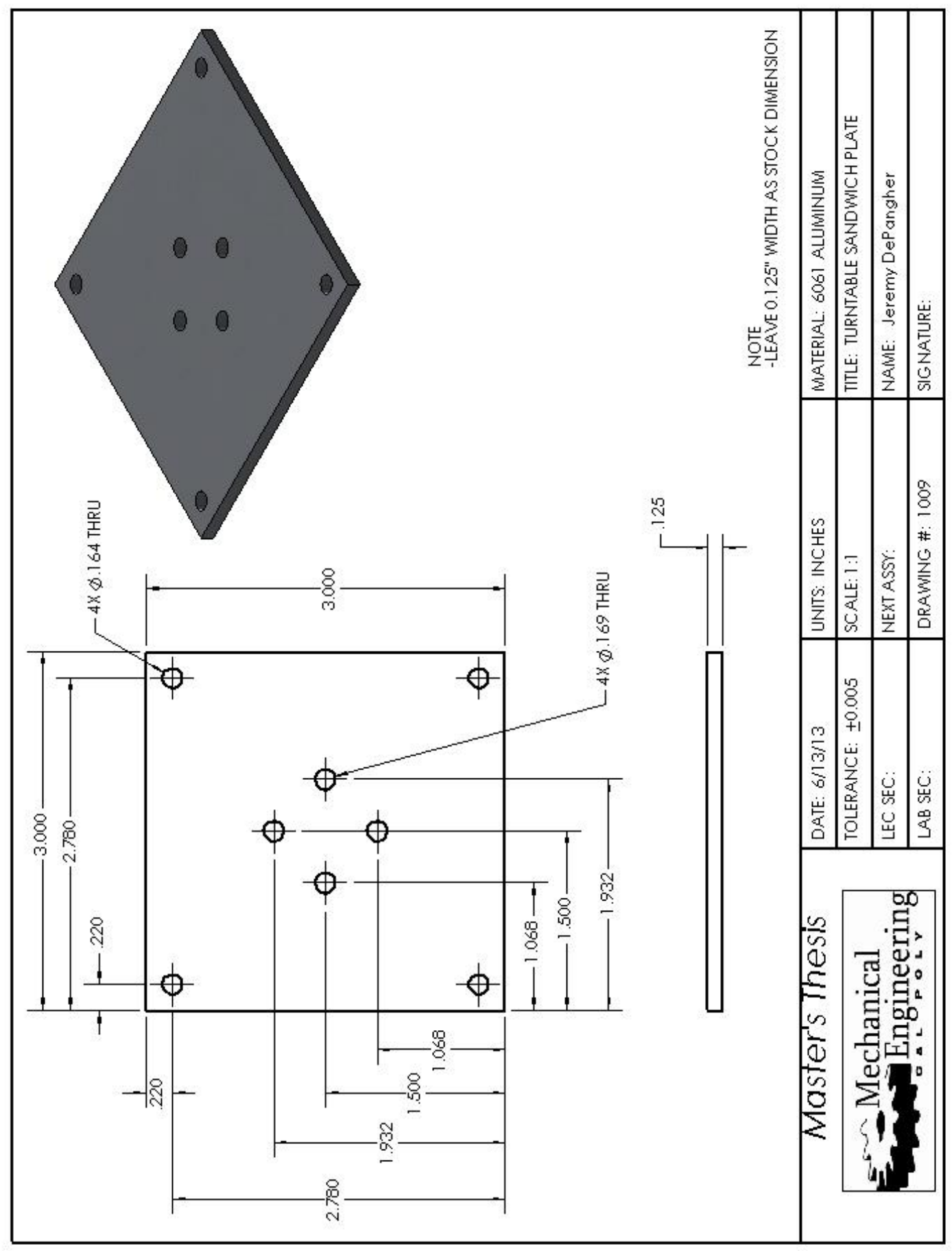




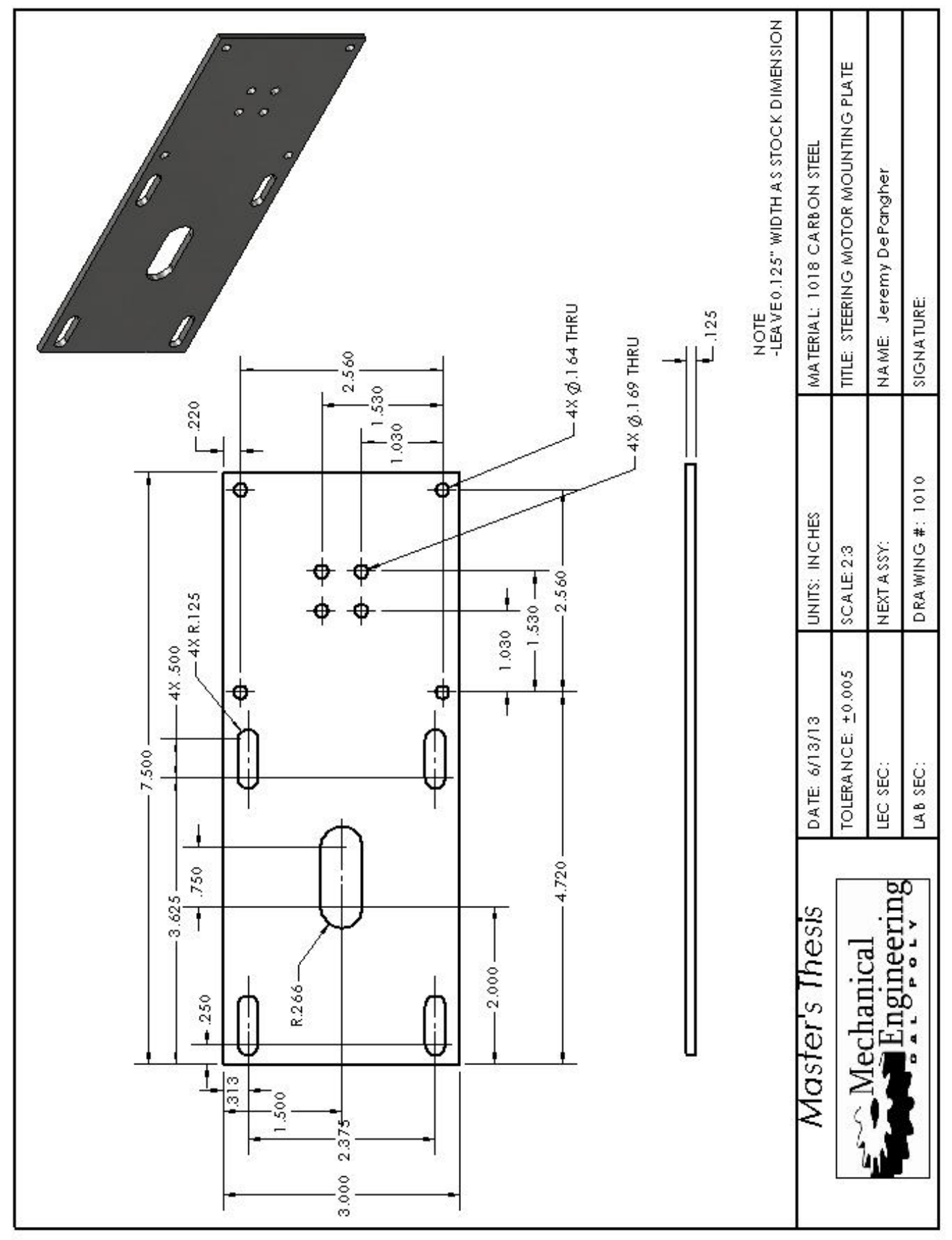




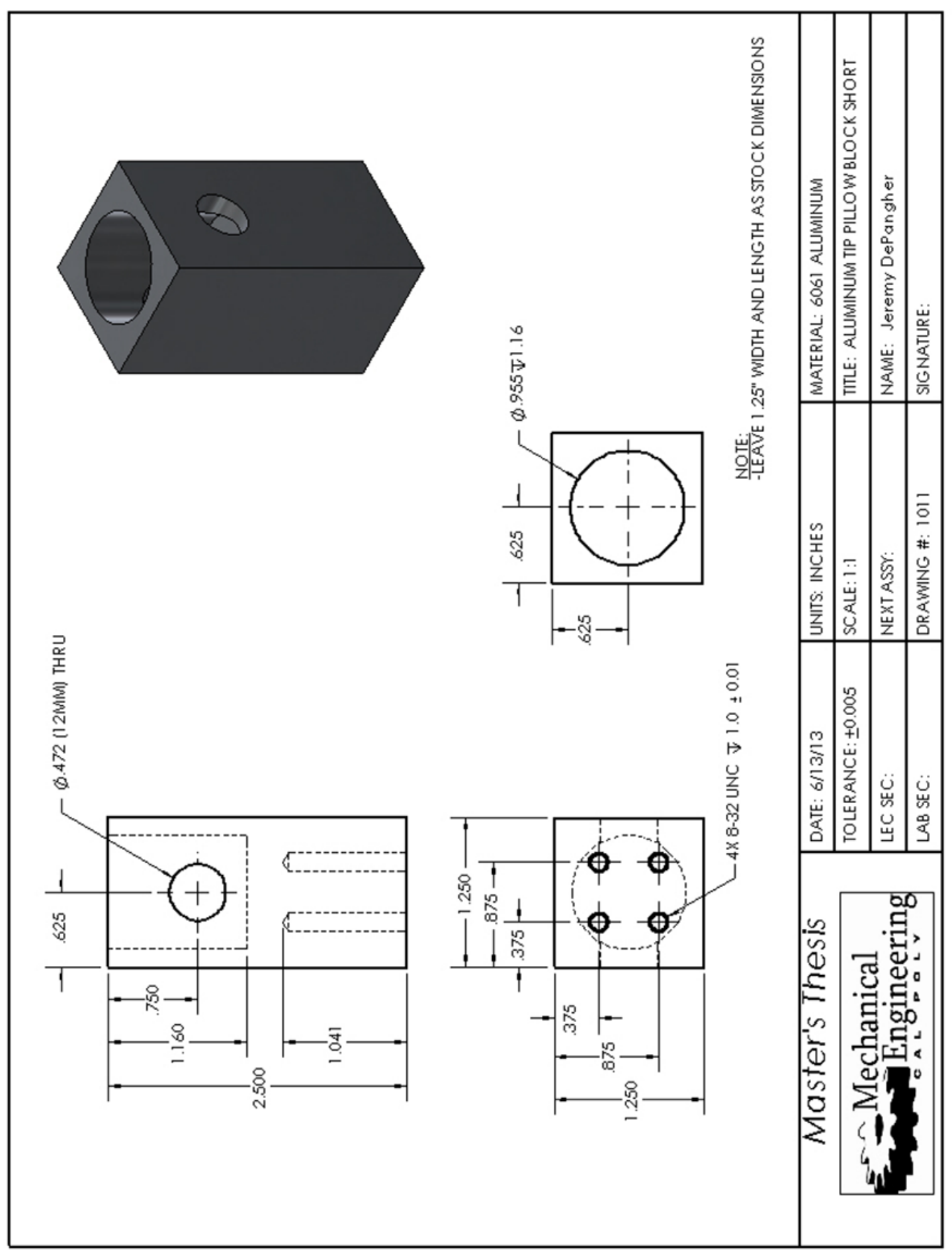




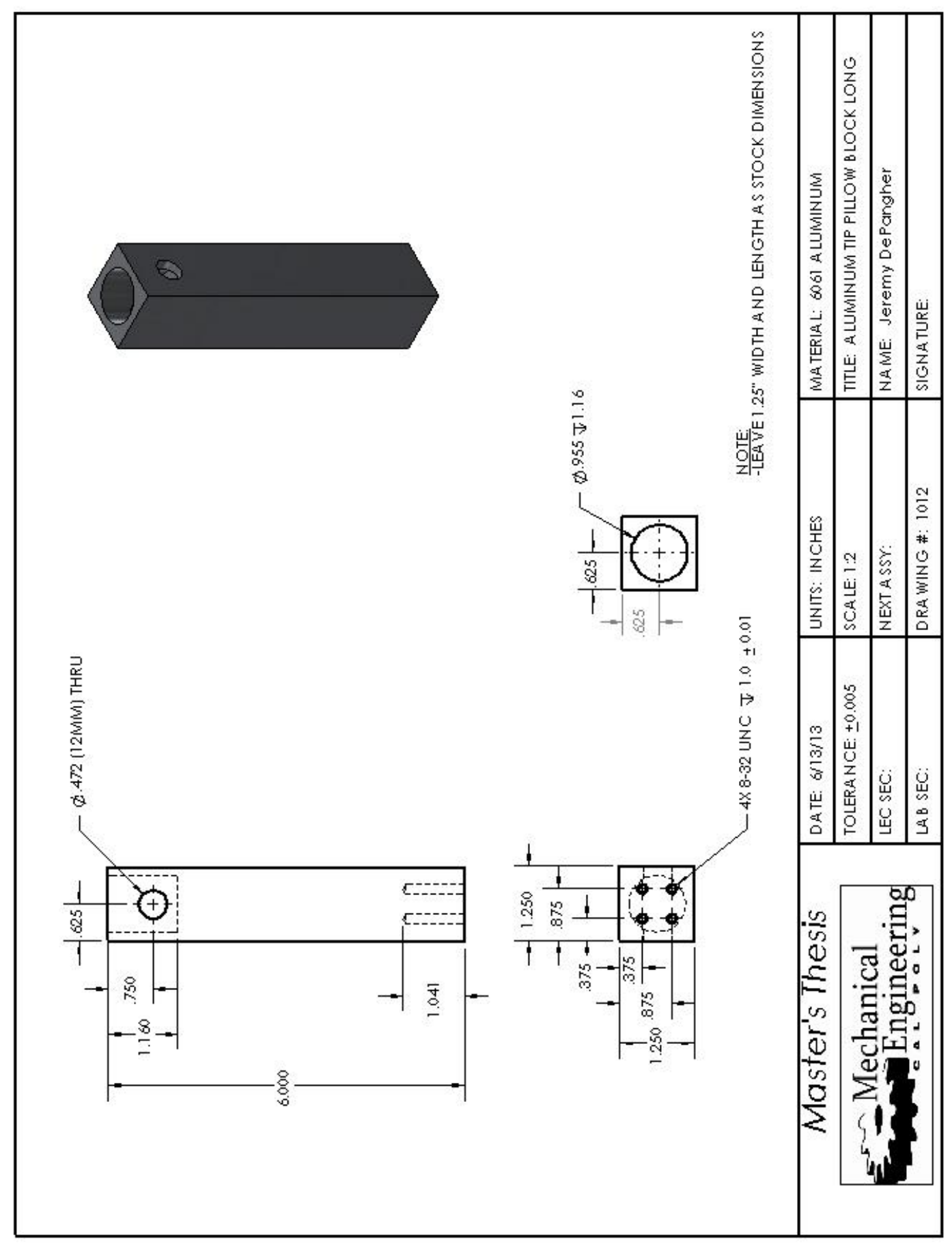




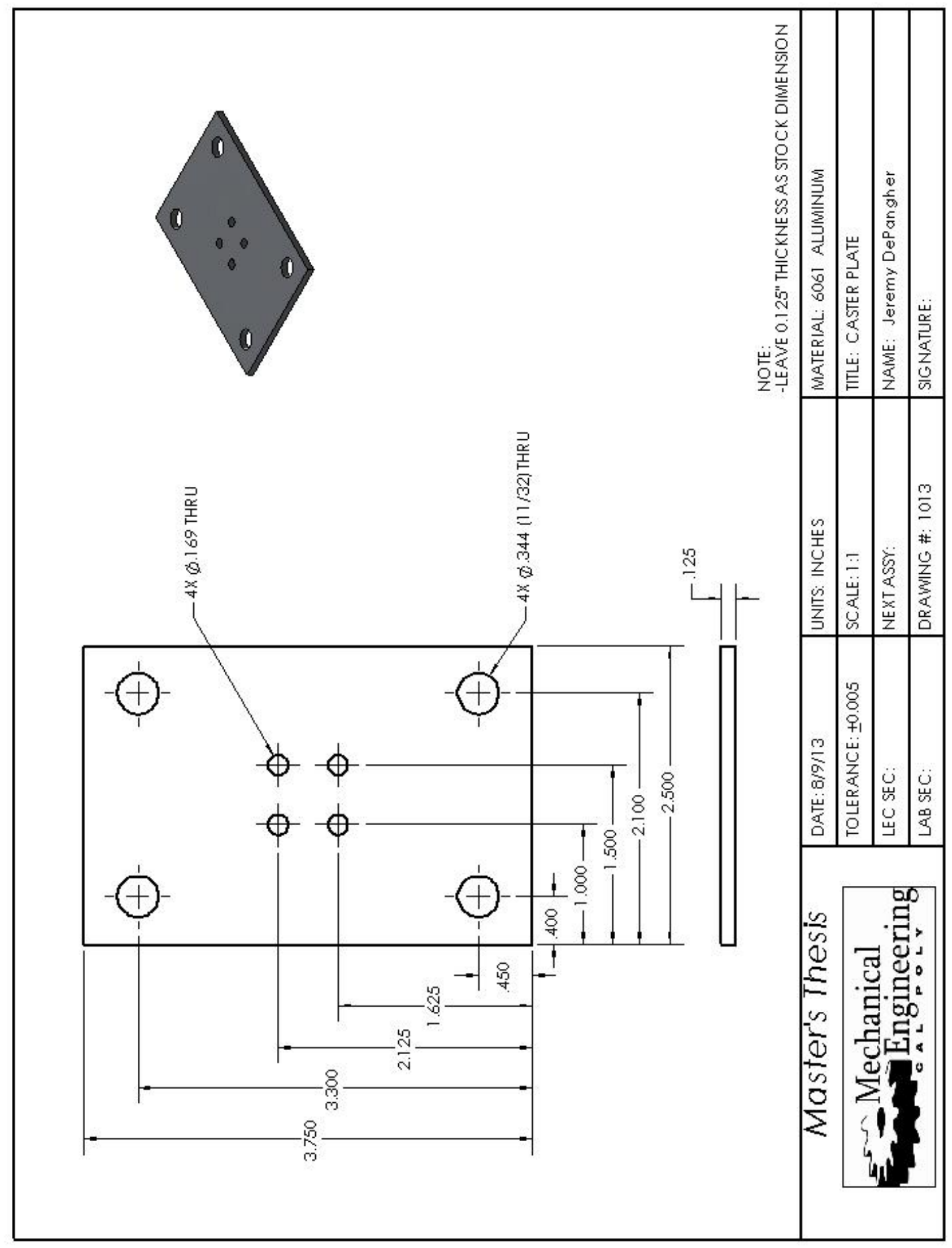




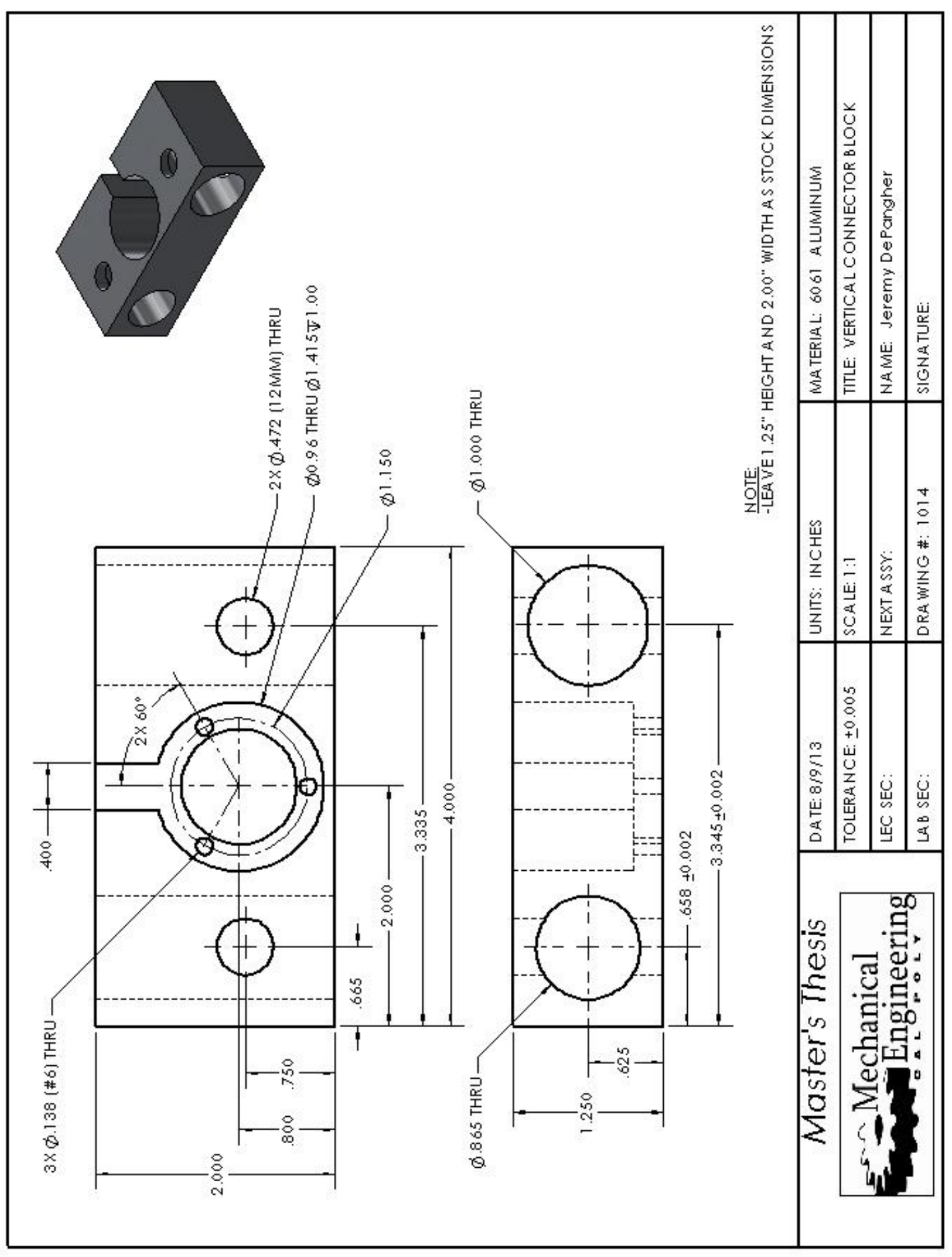




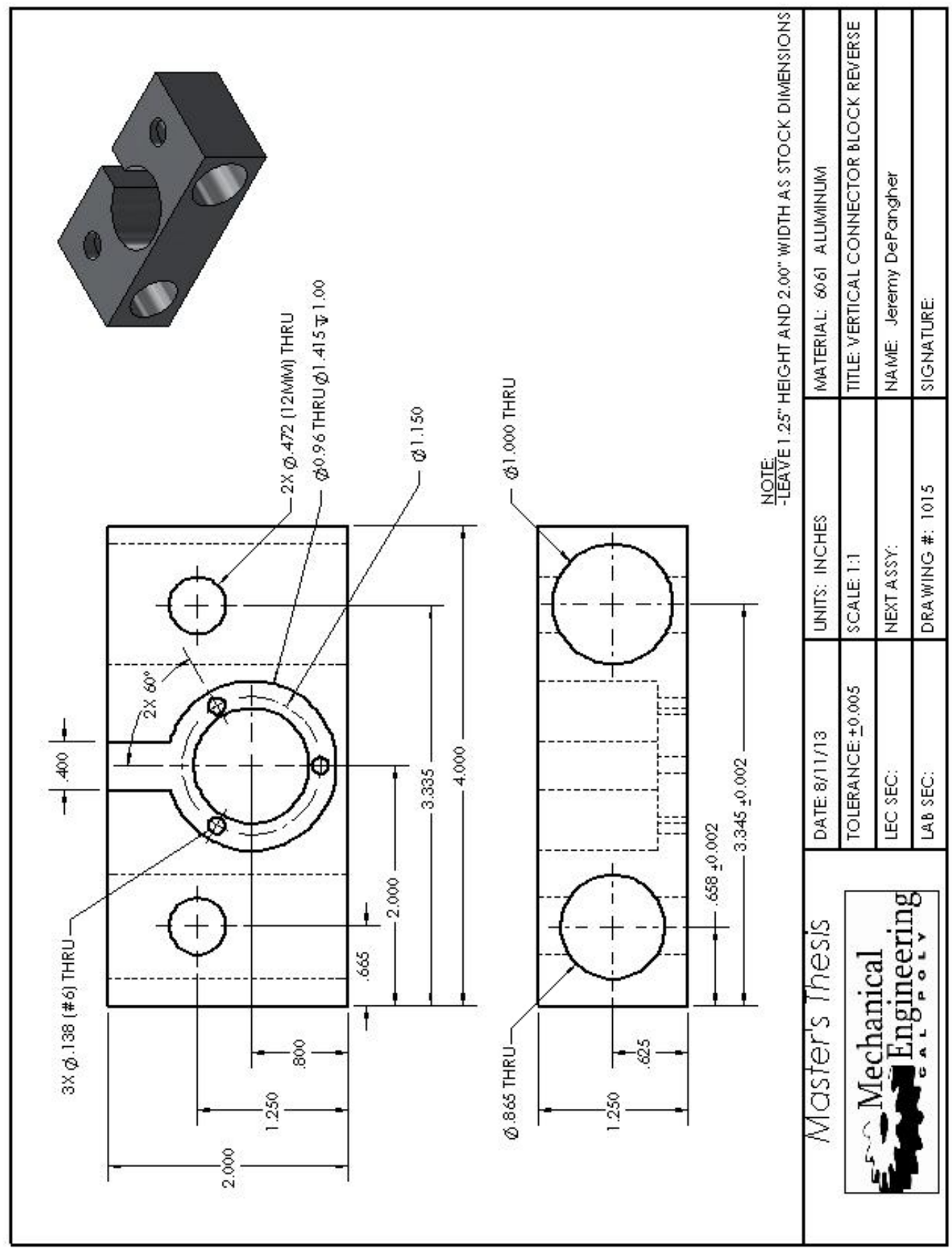




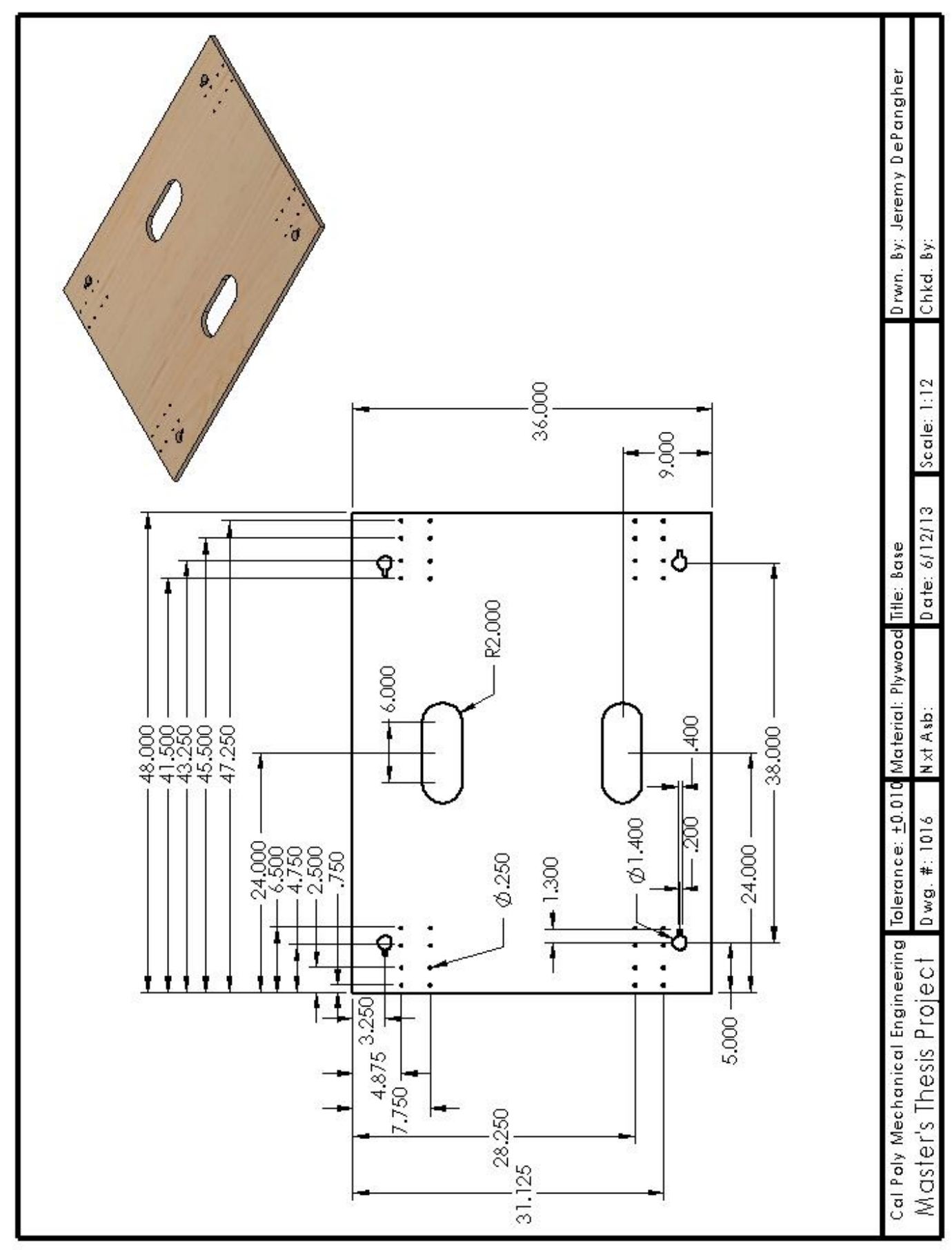




\section{Appendix B: ENGINEERING CALCULATIONS}

\section{Drive Motor Torque}

\section{Equations}

Knowns

$G V W=240[\mathrm{lb}] \quad$ Gross vehicle weight

$W_{d}=\frac{G V W}{4[\mathrm{lb}]} \quad$ Weight on each drive wheel

$R=2$ [in] Radius of wheel

$V_{\max }=1.2 \cdot \frac{5280}{3600[\mathrm{ft} / \mathrm{s}]} \quad$ Max vehicle speed

$a_{\text {time }}=2[\mathrm{~s}] \quad$ Time to accelerate to max speed

$\alpha=0[\mathrm{deg}] \quad$ Max incline angle

$f=0.02$. Surface friction factor for fair concrete

$R F=1.15 \quad$ Resistance factor, accounts for frictional lossesbetween the wheels and their axles

$\mu=0.4 \quad$ Coefficient of friction between plastic and concrete

Step 1: Determine Rolling Resistance

$R R=G V W \cdot f$

Step 2: Determine Grade Resistance

$G R=G V W \cdot \sin (\alpha)$

Step 3: Determine Acceleration Force

$F A=G V W \cdot \frac{V_{\max }}{32.2 \cdot a_{\text {time }}}$

Step 4: Determine Total Tractive Effort

$T E=R R+G R+F A$

Step 5: Determine Wheel Motor Torque

$T_{w}=T E \cdot R \cdot R F$

Step 6: Determine Maximum Tractive Torque

$M T T=W_{d} \cdot \mu \cdot R \quad$ This is the maximum torque the vehicle can transmit to theground.

If $\mathrm{MTT}>\mathrm{T}_{w}$, then the design will succeed

\section{Solution}




$$
\begin{array}{ll}
\alpha=0[\mathrm{deg}] & a_{\text {time }}=2[\mathrm{~s}] \\
f=0.02[-] & F A=6.559 \\
G R=0 & G V W=240[\mathrm{lb}] \\
M T T=48 & \mu=0.4 \\
R=2[\mathrm{in}] & R F=1.15 \\
R R=4.8 & T E=11.36 \\
T_{w}=26.13 & V_{\max }=1.76 \\
W_{d}=60 &
\end{array}
$$


Deflection of Drive Bracket

\section{Equations}

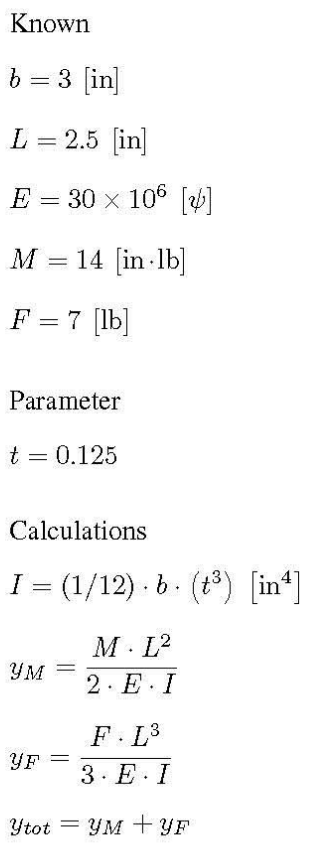

\section{Calculations}

\section{Solution}

$$
\begin{array}{ll}
b=3[\mathrm{in}] & E=3.000 \times 10^{7}[\mathrm{psi}] \\
F=7[\mathrm{lb}] & I=0.0004883 \\
L=2.5[\mathrm{in}] & M=14 \\
t=0.125 & y_{F}=0.002489 \\
y_{M}=0.002987 & y_{\text {tot }}=0.005476
\end{array}
$$




\section{Deflection of Wheel Shaft}

\section{Equations}

\section{Knowns}

$d=0.375[$ in $] \quad$ Diameter of wheel shaft

$L=4$ [in] Total length between bearings of wheel shaft

$F=60[\mathrm{lb}] \quad$ Weight on each wheel

$I=\pi \cdot \frac{d^{4}}{64} \quad$ Area moment of inertia of aluminum shaft

$E=10.4 \times 10^{6} \quad$ Young ‘s Modulus for aluminum

Maximum Deflection

$y=F \cdot \frac{L^{3}}{48 \cdot E \cdot I}$

\section{Solution}

$$
\begin{array}{ll}
d=0.375[\mathrm{in}] & E=1.040 \times 10^{7} \\
F=60[\mathrm{lb}] & I=0.0009707 \\
L=4[\mathrm{in}] & y=0.007924
\end{array}
$$




\section{Tension and Reduction of Timing Belt}

\section{Equations}

Calculate Belt Length

$C=3.5 \quad$ Center distance between pulleys

$d_{1}=p \cdot z_{p 1} / p i \quad$ Pitch diameter of driving pulley

$d_{2}=p \cdot z_{p 2} / p i \quad$ Pitch diameter of driven pulley

$L=(2 \cdot C)+\left(\pi \cdot d_{1} / 2\right)+\left(\pi \cdot d_{2} / 2\right) \quad$ Length of belt

Calculate Effective Tension

$p=0.375$ [in] L-Series timing belt pitch

$z_{p 1}=10 \quad$ Number of teeth of driving pulley

$z_{p 2}=22 \quad$ Number of teeth of driven pulley

$b=0.5[\mathrm{in}] \quad$ Belt width

$T_{\max }=25.5[\mathrm{in} \cdot \mathrm{lb}] \quad$ Max required torque to steer

$n=2.2 \quad$ Pulley ratio

$T_{1 a l l}=100[\mathrm{lb}] \quad$ Max allowable tension for 0.5 inch wide belt

$T_{1}=\frac{T_{\max }}{n[\mathrm{in} \cdot \mathrm{lb}]} \quad$ Driving torque

$T_{e}=2 \cdot \frac{T_{1}}{d_{1}[\mathrm{lb}]} \quad$ Effective tension on belt

If $\mathrm{T}_{1 a l l}>\mathrm{T}_{e}$, then belt is strong enough for design

\section{Solution}

$$
\begin{array}{ll}
b=0.5[\mathrm{in}] & C=3.5 \\
d_{1}=1.194 & d_{2}=2.626 \\
L=13 & n=2.2 \\
p=0.375[\mathrm{in}] & T_{1}=11.59 \\
T_{1 a l l}=100[\mathrm{lb}] & T_{e}=19.42 \\
T_{\max }=25.5 & z_{p 1}=10[-] \\
z_{p 2}=22[-] &
\end{array}
$$




\section{Steer Motor Torque}

\section{Equations}

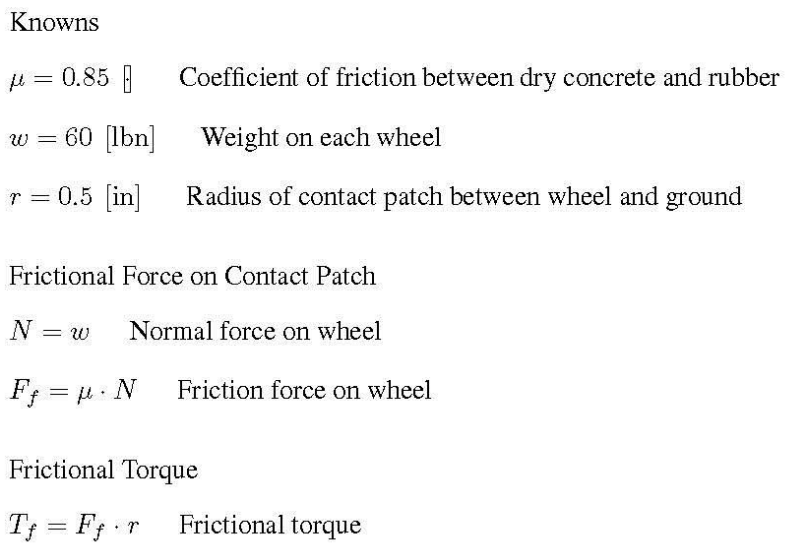

\section{Solution}

$$
\begin{array}{ll}
F_{f}=51 & \mu=0.85[-] \\
N=60 & r=0.5[\mathrm{in}] \\
T_{f}=25.5 & w=60[\mathrm{lbn}]
\end{array}
$$




\section{Deflection of Steering Plate}

\section{Equations}

$$
\begin{aligned}
& \text { Knowns } \\
& F=8 \text { [lb] } \\
& L=4 \text { [in] } \\
& E=30 \times 10^{6}[\psi] \\
& b=3 \text { [in] } \\
& h=0.125 \text { [in] } \\
& I=(1 / 12) \cdot b \cdot\left(h^{3}\right)
\end{aligned}
$$

Max Deflection

$$
y_{\max }=F \cdot \frac{L^{3}}{3 \cdot E \cdot I}
$$

\section{Solution}

$$
\begin{array}{ll}
b=3[\mathrm{in}] & E=3.000 \times 10^{7}[\mathrm{psi}] \\
F=8[\mathrm{lb}] & h=0.125[\mathrm{in}] \\
I=0.0004883 & L=4[\mathrm{in}] \\
y_{\max }=0.01165 &
\end{array}
$$




\section{Horizontal Support Shaft Deflection}

\section{Equations}

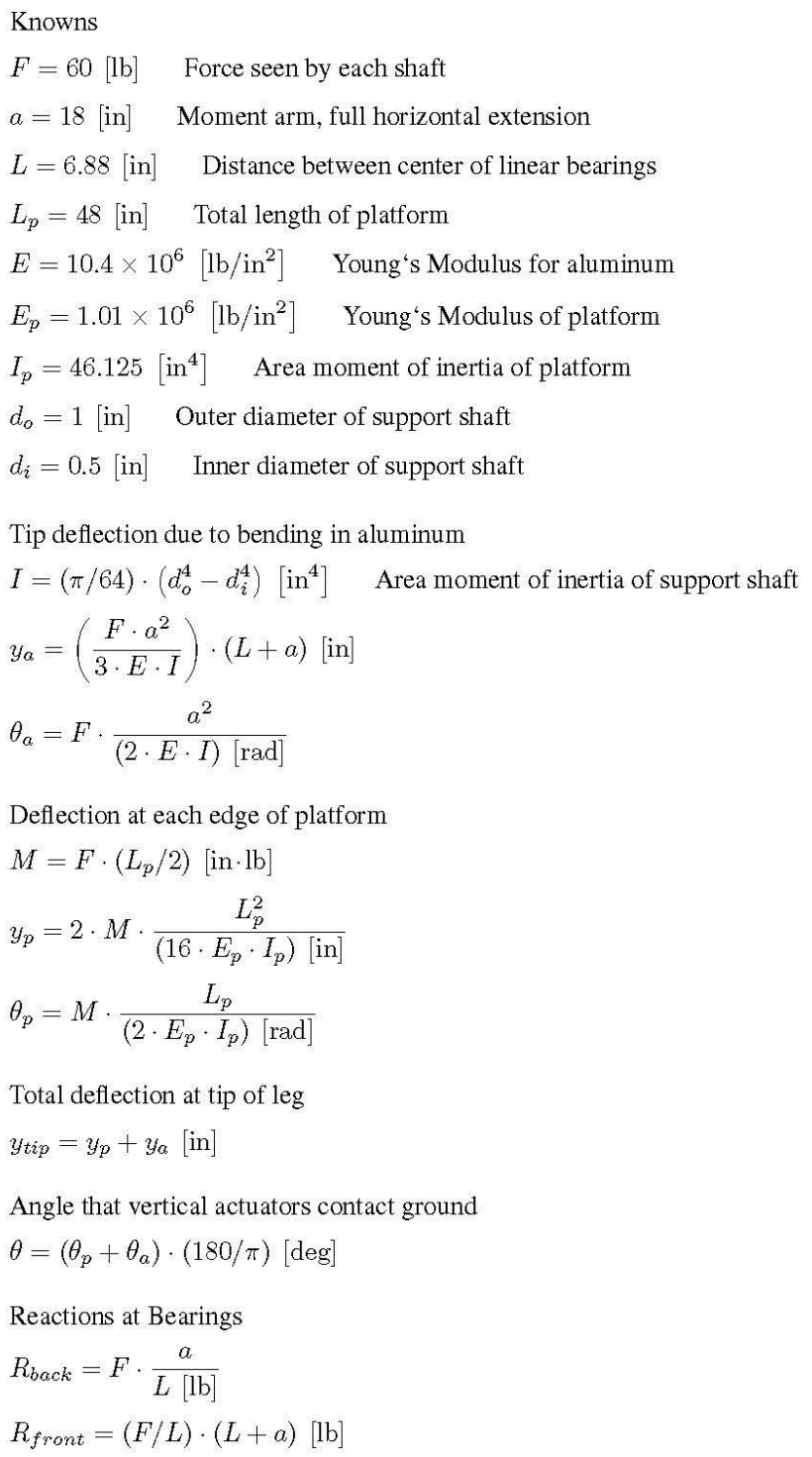

\section{Solution}




$$
\begin{array}{ll}
a=18[\mathrm{in}] & d_{i}=0.5[\mathrm{in}] \\
d_{o}=1[\mathrm{in}] & E=1.040 \times 10^{7}[\mathrm{psi}] \\
E_{p}=1.010 \times 10^{6} & F=60[\mathrm{lb}] \\
I=0.04602 & I_{p}=46.13 \\
L=6.88[\mathrm{in}] & L_{p}=48[\mathrm{in}] \\
M=1440 & R_{\text {back }}=157 \\
R_{\text {front }}=217 & \theta=1.206 \\
\theta_{a}=0.02031 & \theta_{p}=0.0007418 \\
y_{a}=0.3369 & y_{p}=0.008902 \\
y_{\text {tip }}=0.3458 &
\end{array}
$$




\title{
Allowable Torque of Wheel Shaft Press Fit
}

\section{Equations}

\author{
Knowns \\ $d=0.401$ [in] Nominal diameter of shaft \\ $d_{o}=4[\mathrm{in}] \quad$ Outside diameter of wheel \\ $d_{i}=0[\mathrm{in}] \quad$ Inside diameter of shaft \\ $\nu_{i}=0.333 \quad$ Poisson's ratio for aluminum \\ $\nu_{o}=0.5 \quad$ Poisson's ratio for hard rubber \\ $E_{o}=14.5 \times 10^{3}\left[\mathrm{lb} / \mathrm{in}^{2}\right] \quad$ Young's Modulus of hard rubber \\ $E_{i}=10 \times 10^{6}\left[\mathrm{lb} / \mathrm{in}^{2}\right] \quad$ Young's Modulus of aluminum \\ $f=1$. Worst case friction factor, aluminum on hard rubber \\ $L=1.6$ [in] Length of interference fit \\ $T_{\text {all }}=25.5[\mathrm{in} \cdot \mathrm{lb}] \quad$ Minimum allowable torque
}

Interference Pressure

$p=\frac{\delta}{\left(d / E_{o}\right) \cdot\left(\frac{d_{o}^{2}+d^{2}}{\left(d_{o}^{2}-d^{2}\right)}+\nu_{o}\right)+\left(d / E_{i}\right) \cdot\left(\frac{d^{2}+d_{i}^{2}}{\left(d^{2}-d_{i}^{2}\right)}-\nu_{i}\right)}$

Allowable Torque Before Slipping

$T_{\text {all }}=(\pi / 2) \cdot f \cdot p \cdot L \cdot d^{2}[\mathrm{in} \cdot \mathrm{lb}]$

Diameteral interference must be at least $0.00265 \mathrm{in}$.

\section{Solution}

$\begin{array}{ll}d=0.401[\mathrm{in}] & \delta=0.002655[\mathrm{in}] \\ d_{i}=0[\mathrm{in}] & d_{o}=4[\mathrm{in}] \\ E_{i}=1.000 \times 10^{7}[\mathrm{psi}] & E_{o}=14500[\mathrm{psi}] \\ f=1[-] & L=1.6[\mathrm{in}] \\ \nu_{i}=0.333 & \nu_{o}=0.5 \\ p=63.1 & T_{\text {all }}=25.5\end{array}$


Tension in Linear Actuator Mounting Screws

\section{Equations}

Knowns

$F=60[\mathrm{lb}] \quad$ Max force applied on each leg

$d=0.106$ [in] Minor diameter of \#4-40 machine screw

$N_{s}=3 \quad$ Number of screws

Calculate Tensile Stress Areas

$A=(\pi / 4) \cdot\left(d^{2}\right)\left[\mathrm{in}^{2}\right] \quad$ Axial stress area

Calculate Tensile Stress

$\sigma=\frac{F}{\left(N_{s} \cdot A\right)\left[\mathrm{lb} / \mathrm{in}^{2}\right]} \quad$ Axial stress per screw

If yield strength of steel $\left(53.7 \mathrm{e} 3 \mathrm{lb} / \mathrm{in}^{2}\right)$ is higher than the calculated tensile stress, screws will not yield

\section{Solution}

$$
\begin{array}{ll}
A=0.008825 & d=0.106[\mathrm{in}] \\
F=60[\mathrm{lb}] & N_{s}=3 \\
\sigma=2266 &
\end{array}
$$




\section{Bending Stress in Wood Platform}

\section{Equations}

\section{Knowns}

$h=18$ [in] Maximum stroke length of horizontal actuators

$w=240[\mathrm{lb}] \quad$ Weight seen by platform

$L_{p}=48[$ in] Lenght of platform

$I_{p}=46.125\left[\mathrm{in}^{4}\right] \quad$ Area moment of inertia of platform

$c=2[$ in] Distance to neutral axis

Forces and Moments

$M_{1}=h \cdot(w / 2)[\mathrm{in} \cdot \mathrm{lb}] \quad$ Moments created by vertical legs extended 18 in from platform $R_{1}=(w / 2)[\mathrm{lb}] \quad$ Reaction forces on vertical legs

Calculate Max Bending Moment at Center of Platform

$M_{\max }=M_{1}+\left(R_{1} \cdot L_{p} / 2\right)[\mathrm{in} \cdot \mathrm{lb}]$

Calculate Max Bending Stress in Platform

$\sigma_{\max }=M_{\max } \cdot \frac{c}{I_{p}\left[\mathrm{lb} / \mathrm{in}^{2}\right]}$

If maximum bending stress seen by wood is less than $1668\left[\mathrm{lb} / \mathrm{in}^{2}\right]$, wood will not fail

\section{Solution}

$$
\begin{array}{ll}
c=2[\mathrm{in}] & h=18[\mathrm{in}] \\
I_{p}=46.13 & L_{p}=48[\mathrm{in}] \\
M_{1}=2160 & M_{\max }=5040 \\
R_{1}=120 & \sigma_{\max }=218.5 \\
w=240[\mathrm{lb}] &
\end{array}
$$




\section{Appendix C: BILL OF MATERIALS}

Table C.1. Bill of Materials

\begin{tabular}{|c|c|c|}
\hline Component & Description & Quantity \\
\hline Right angle gearmotor & $100 \mathrm{RPM}, 12 \mathrm{VDC}$ & 4 \\
\hline Inline gearmotor & $20 \mathrm{RPM}, 12 \mathrm{VDC}$ & 4 \\
\hline Driving motor bracket & Connector plate & 4 \\
\hline Flex coupling & HCR112-14-12, 7/16" and 3/8" bores & 4 \\
\hline Bearing pillow block & Pillow block for thrust bearings & 8 \\
\hline Banded ball thrust bearings & $0.375 "$ bore & 8 \\
\hline Wheel shaft & Shaft for drive wheel & 4 \\
\hline Rubber wheel & - & 4 \\
\hline Caster rubber wheel assembly & - & 4 \\
\hline Caster plate & - & 4 \\
\hline Wheel housing & Housing for drive wheel & 4 \\
\hline Large pulley & 22 teeth, $2.875^{\prime \prime} \mathrm{OD}$ & 4 \\
\hline Small pulley & 10 teeth, 1.438 " OD, with setscrew & 4 \\
\hline Timing belt & L-series, 130L050 & 4 \\
\hline Turntable sandwich plate & - & 4 \\
\hline Turntable bearing & - & 4 \\
\hline Steering motor mounting plate & - & 4 \\
\hline $\begin{array}{l}\text { Aluminum tip pillow block } \\
\text { short }\end{array}$ & $\begin{array}{l}\text { Block connecting actuator tip to } \\
\text { motorized leg assembly }\end{array}$ & 4 \\
\hline $\begin{array}{l}\text { Aluminum tip pillow block } \\
\text { long }\end{array}$ & $\begin{array}{l}\text { Block connecting actuator tip to caster } \\
\text { leg assembly }\end{array}$ & 4 \\
\hline 30" stroke linear actuator & - & 8 \\
\hline $18 "$ stroke linear actuator & - & 4 \\
\hline Vertical connector block & $\begin{array}{l}\text { Connects } 30 " \text { linear actuators to } 18 " \\
\text { linear actuators and parallel support shaft }\end{array}$ & 2 \\
\hline $\begin{array}{l}\text { Vertical connector block } \\
\text { reverse }\end{array}$ & $\begin{array}{l}\text { Connects 30" linear actuators to } 18 " \\
\text { linear actuators and parallel support shaft }\end{array}$ & 2 \\
\hline Linear pillow block bearing & - & 8 \\
\hline Parallel support shaft & $\begin{array}{c}\text { Supports horizontal actuators from } \\
\text { bending }\end{array}$ & 4 \\
\hline Plywood base & $36 "$ x 48" x 3/4" & 1 \\
\hline Plywood side supports & $6 "$ x 48" x 3/4" & 2 \\
\hline
\end{tabular}




\begin{tabular}{|c|c|c|}
\hline Plywood back supports & $5.5^{\prime \prime}$ x 48" x 3/4" & 2 \\
\hline $2 \times 4$ vertical actuator supports & 28" height & 4 \\
\hline $2 \times 4$ base length supports & 48" length & 2 \\
\hline $2 \times 4$ base width supports & 36" length & 2 \\
\hline Arduino Mega 2560 & Microprocessor board & 1 \\
\hline Double Motor Drivers & Controls linear actuators & 6 \\
\hline Single Motor Drivers & Controls steer and drive motors & 8 \\
\hline Battery pack & Supplies board power & 1 \\
\hline Car battery & Supplies component power & 1 \\
\hline 23 slot ground terminal block & Splits high amperage connections & 2 \\
\hline 15 slot ground terminal block & Splits low amperage connections & 2 \\
\hline $50 \mathrm{amp}$ switch & - & 1 \\
\hline 40 amp fuse & - & 1 \\
\hline Fuse box & - & 1 \\
\hline 22 gauge copper wire & 300', red, black, and green & 1 \\
\hline 14 gauge copper wire, stranded & $\begin{array}{l}120 \text {, red and black, for high current } \\
\text { connections }\end{array}$ & 1 \\
\hline 8 gauge copper wire, stranded & $\begin{array}{l}6, \text { red and black for battery terminal } \\
\text { connections }\end{array}$ & 1 \\
\hline Wire staples & Single nail with hook & 33 \\
\hline Steel piping strap & 6" segments & 8 \\
\hline 6-32 bolt, 1/4" length & $\begin{array}{c}\text { Connects steering mounting plate to } \\
\text { turntable bearing }\end{array}$ & 16 \\
\hline $6-32$ hex nut & $\begin{array}{l}\text { Connects steering mounting plate to } \\
\text { turntable bearing }\end{array}$ & 16 \\
\hline 8-32 Threaded rod, 2.5" length & $\begin{array}{l}\text { Connects wheel housing, large pulley, } \\
\text { and turntable sandwich plate together }\end{array}$ & 16 \\
\hline $8-32$ hex nut & Fastens onto threaded rod & 32 \\
\hline 10-32 bolt, 3/4" length & $\begin{array}{c}\text { Connects bearing pillow blocks to wheel } \\
\text { housing, and steer motor to mounting } \\
\text { plate }\end{array}$ & 48 \\
\hline 10-32 hex nut & $\begin{array}{c}\text { Connects bearing pillow blocks to wheel } \\
\text { housing, and steer motor to mounting } \\
\text { plate }\end{array}$ & 48 \\
\hline $12 \mathrm{~mm}$ bolt, $11 / 2 "$ length & $\begin{array}{c}\text { Connects actuators to tip pillow blocks, } \\
\text { and actuators to vertical connector } \\
\text { blocks }\end{array}$ & 16 \\
\hline $12 \mathrm{~mm}$ hex nut & $\begin{array}{c}\text { Connects actuators to tip pillow blocks, } \\
\text { and actuators to vertical connector } \\
\text { blocks }\end{array}$ & 16 \\
\hline
\end{tabular}




\begin{tabular}{|c|c|c|} 
6mm bolt, 1" length & Connects drive motor to bracket & 12 \\
\hline $5 / 16 "$ bolt, 1 1/4" length & Connects caster wheels to caster plate & 4 \\
\hline $5 / 16 "$ bolt, 1" length & Connects caster wheels to caster plate & 12 \\
\hline $5 / 16 "$ hex nut & Connects caster wheels to caster plate & 16 \\
\hline $\begin{array}{c}\text { 5/8 ID nylon spacer, 7/16" } \\
\text { length }\end{array}$ & $\begin{array}{c}\text { Separates caster plate from caster } \\
\text { assembly }\end{array}$ & 16 \\
\hline $1 / 4 "$ bolt, 1 1/2" length & Connects linear bearings to wood base & 32 \\
\hline $1 / 4 "$ hex nut & Connects linear bearings to wood base & 32 \\
\hline $\begin{array}{c}\text { W GA wood screws, 1 1/2" } \\
\text { length }\end{array}$ & Wooden platform assembly & 74 \\
\hline $\begin{array}{c}\text { C-40 machine screws, 0.62" } \\
\text { length }\end{array}$ & Connects actuators to connector blocks & 12 \\
\hline
\end{tabular}




\section{Appendix D: $\quad$ DATA SHEETS}

\section{RPM 12 VDC GEARMOTOR}

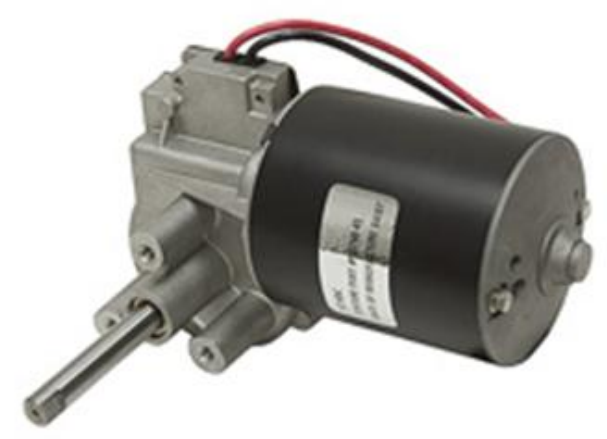

Enlarge

Item $\#$ 5-1649

\section{Item Specs More Specs More Photos Drawing}

100 RPM 12 VDC STATURE ELECTRIC GEARMOTOR

Brand new, STATURE ELECTRIC model RA-AFSL-30AN-35 right-angle gear-motor. Ball bearings and bronze bushings, steel worm gear, brass output gear and die cast aluminum gearbox. Two pole, permanent magnet motor with internal brushes. Three mounting holes tapped for M6 machine screvs. Rated to withstand 300 in-lbs. max back-drive torque.

\section{SPECIFICATIONS}

- Speed 100 RPM

- Voltage 12 DC

- Amperage 3.0 Amps no load 6.0 Amps cont. 62 Amps peak

- Power 1/30 Hp cont.

- Torque 20 in-lbs. cont.

- Gear Ratio 35:1

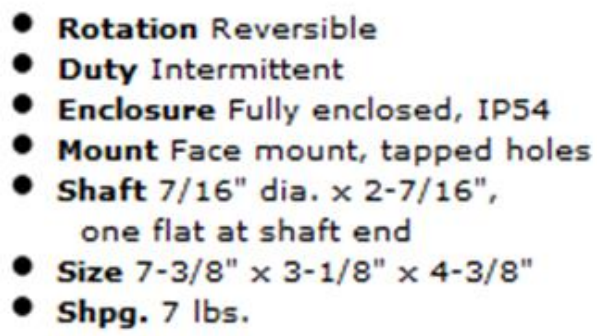




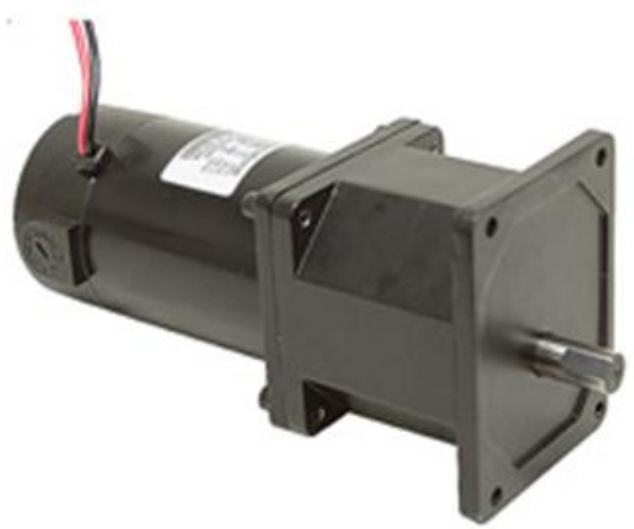

\section{RPM 12 VDC INLINE GEARMOTOR}

\section{Enlarge}

\section{Item Specs}

\section{RPM 12 VDC INLINE GEARMOTOR}

New, T \& L INTERNATIONAL permanent magnet inline gearmotor.

\section{SPECIFICATIONS}

- Speed 20 RPM

- Voltage 12 DC

- Enclosure TENV

- Amperage 13 Amps

- Torque 16.75 in - lbs.

- Rotation Reversible

- Mount 4 bolt on 2-3/8" $\times 3-3 / 8^{\prime \prime}$

- Duty Intermittent centers

- Shaft $1 / 2 "$ diam. $\times 7 / 8 " \mathrm{w} /$ dual flats

- Size 7-5/8" × 3-3/8" x 3-7/8"

- Shpg. 8 lbs. 


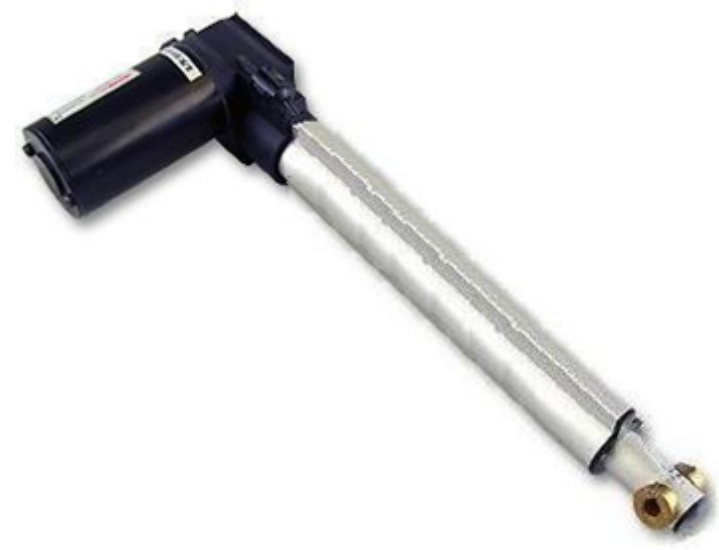

400 Ib Force 18" Stroke [FA-400-L-12-18]

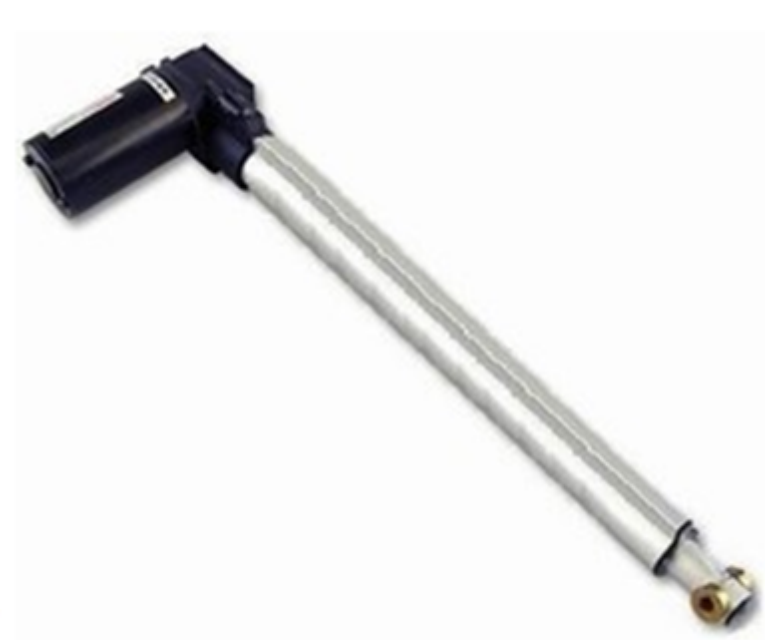

FA-400-L-12-30"

These units are $400 \mathrm{lbs}$ force with Aluminum shaft, and a tough plastic Case. 2 wire configuration for ease of use, 12vdc operation, fixed limit switches, very quiet,

Use MB3 mounting brackets for these actuators

\begin{tabular}{||l||l||}
\hline Input & 12VDC \\
\hline \hline Load Capacity & 400 lbs (Push and pull) 400lbs static \\
\hline \hline Speed & $\begin{array}{l}\text { Approx 1/2" per sec (no load) 2/5" per sec } \\
\text { loaded }\end{array}$ \\
\hline \hline Stroke Length & Standard stroke sizes 3" 6" 9" 12" 18" 24" 30" \\
\hline \hline Mounting & Clevis on fixed end, uses MB3 brackets on both ends \\
\hline \hline Limit Switch & Build-in not movable \\
\hline \hline Duty Cycle & $20 \%$ \\
\hline \hline Current Draw & Up to 10 amps at full load \\
\hline Inner Tube & Aluminium Alloy \\
\hline \hline IP Grade & IP43 \\
\hline \hline Operation Temperature & - 26degs C 65degs C \\
\hline Safety Certificate & CE Certificate \\
\hline
\end{tabular}


Appendix E: SEQUENCE TESTING IMAGES

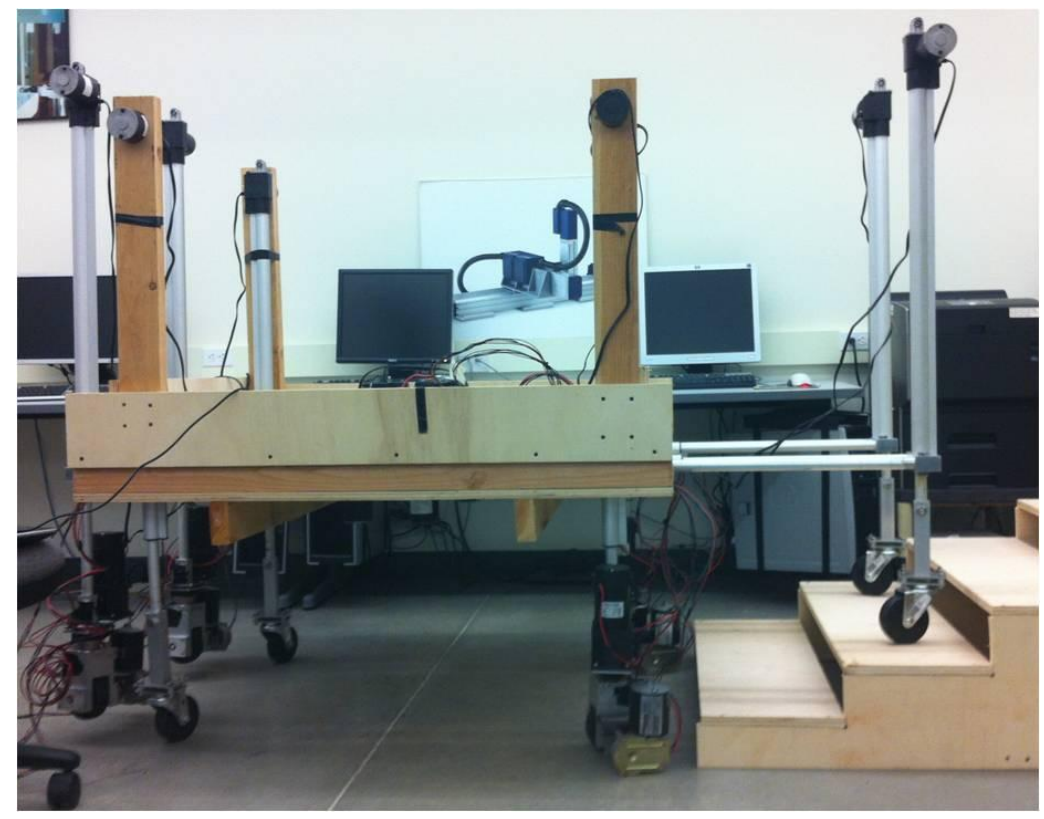

Figure E.1 - Stair Climbing Stage 1

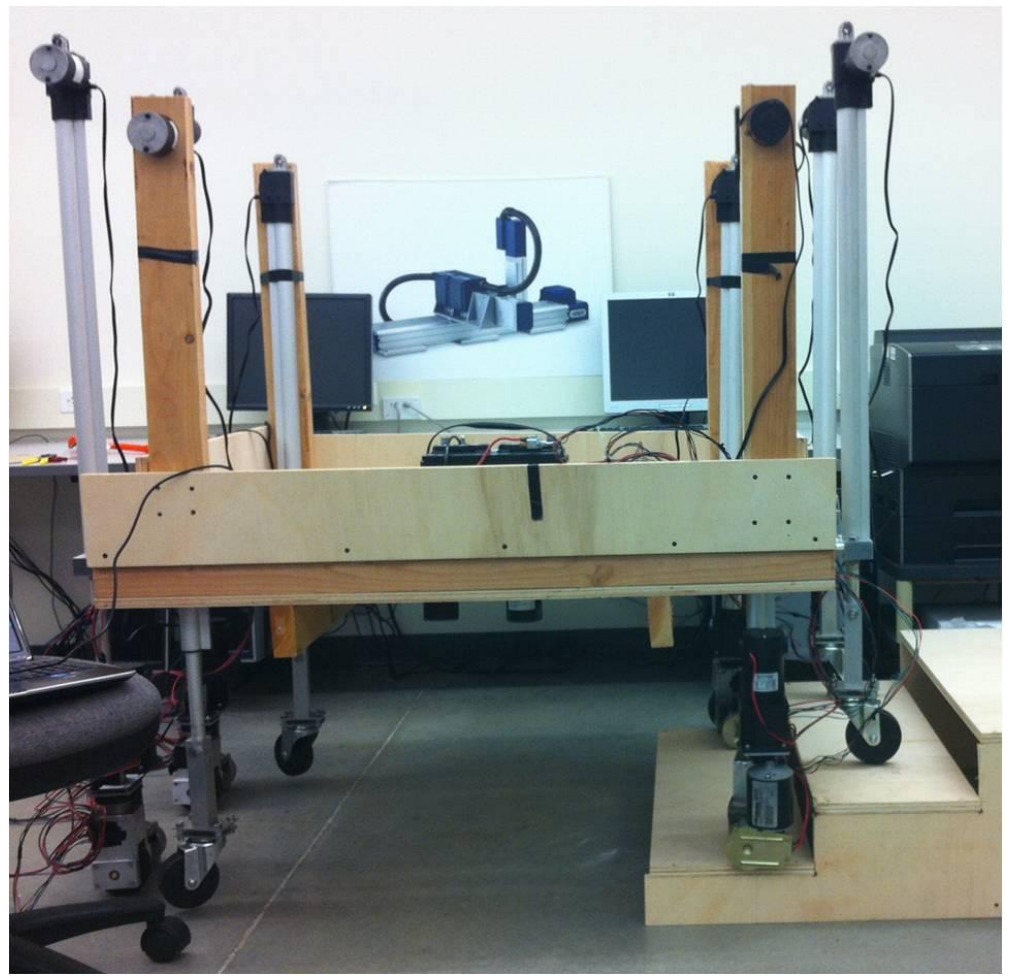

Figure E.2 - Stair Climbing Stage 2 


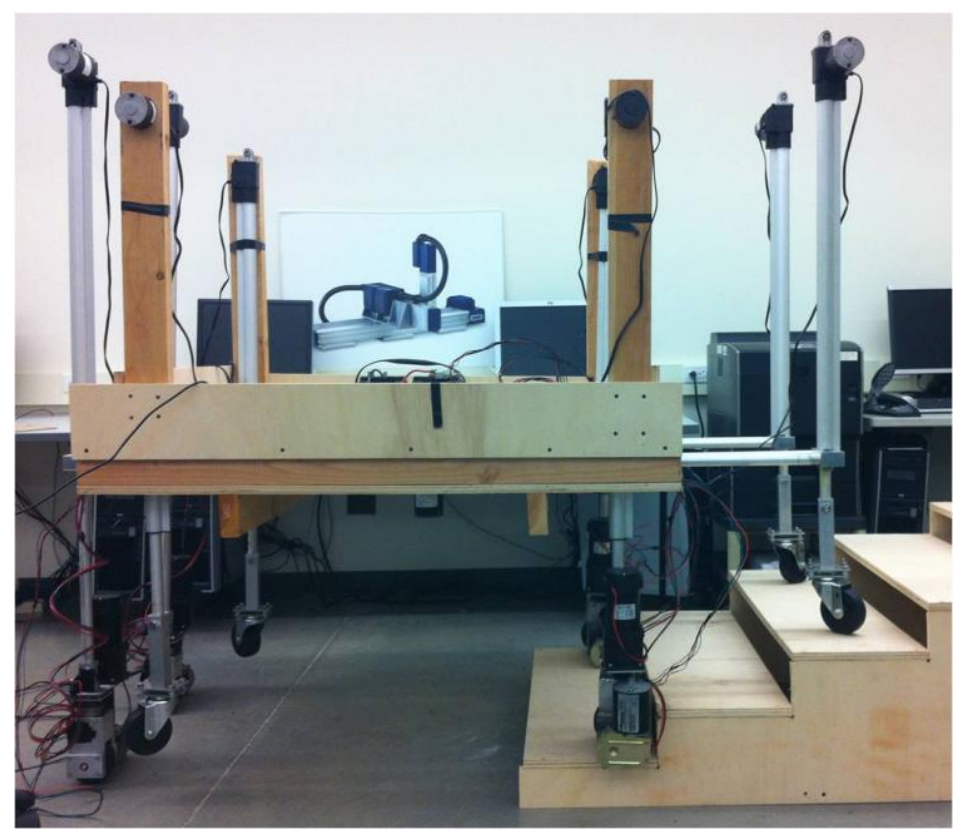

Figure E.3 - Stair Climbing Stage 3

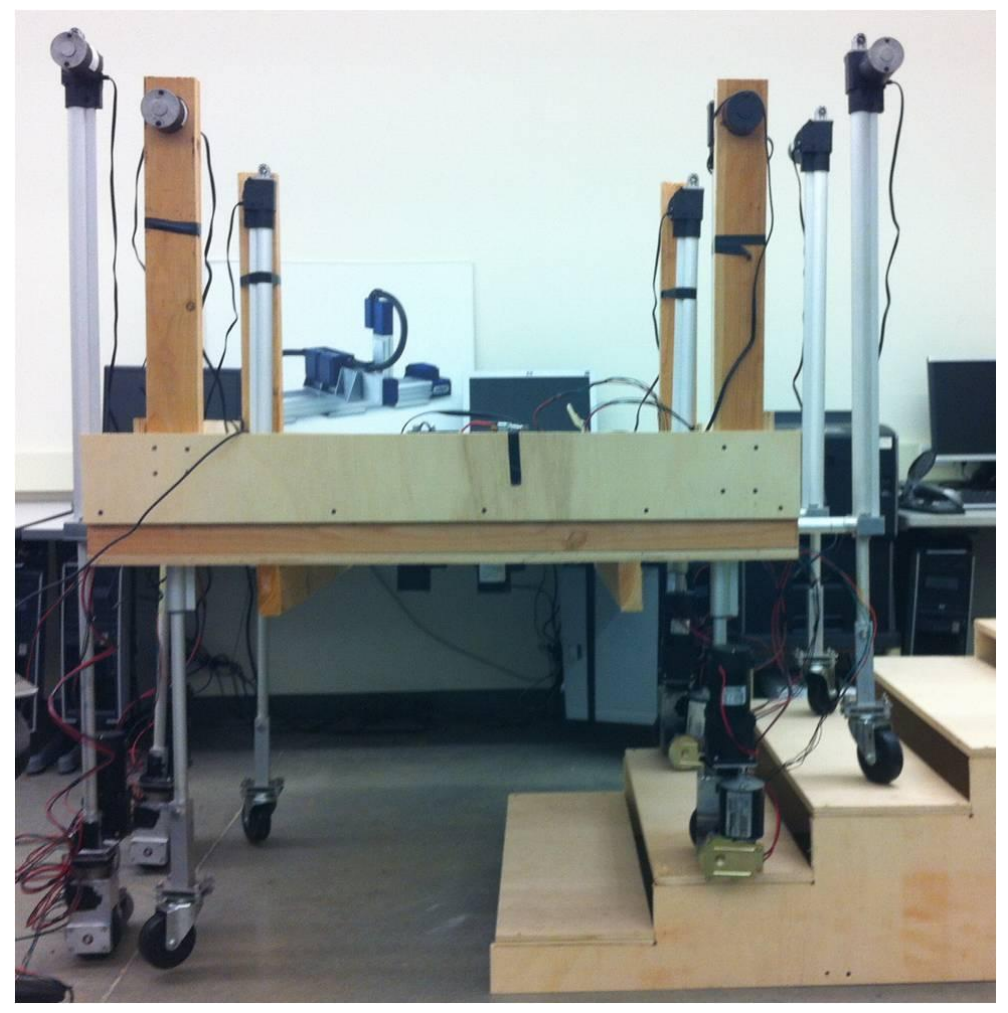

Figure E.4 - Stair Climbing Stage 4 


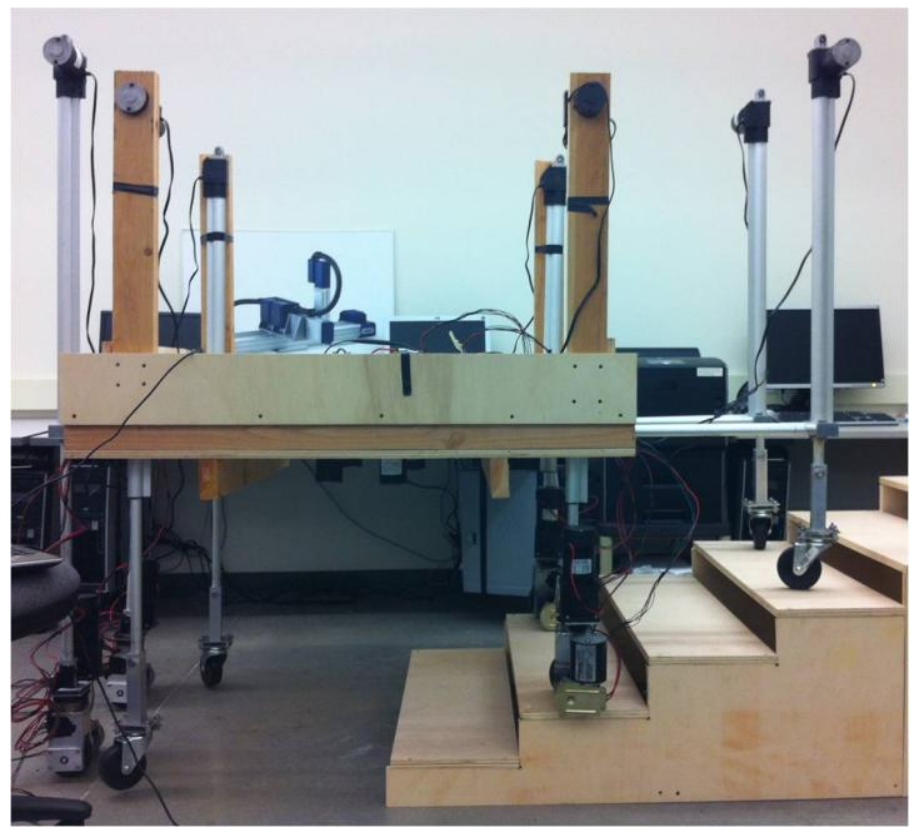

Figure E.5 - Stair Climbing Stage 5

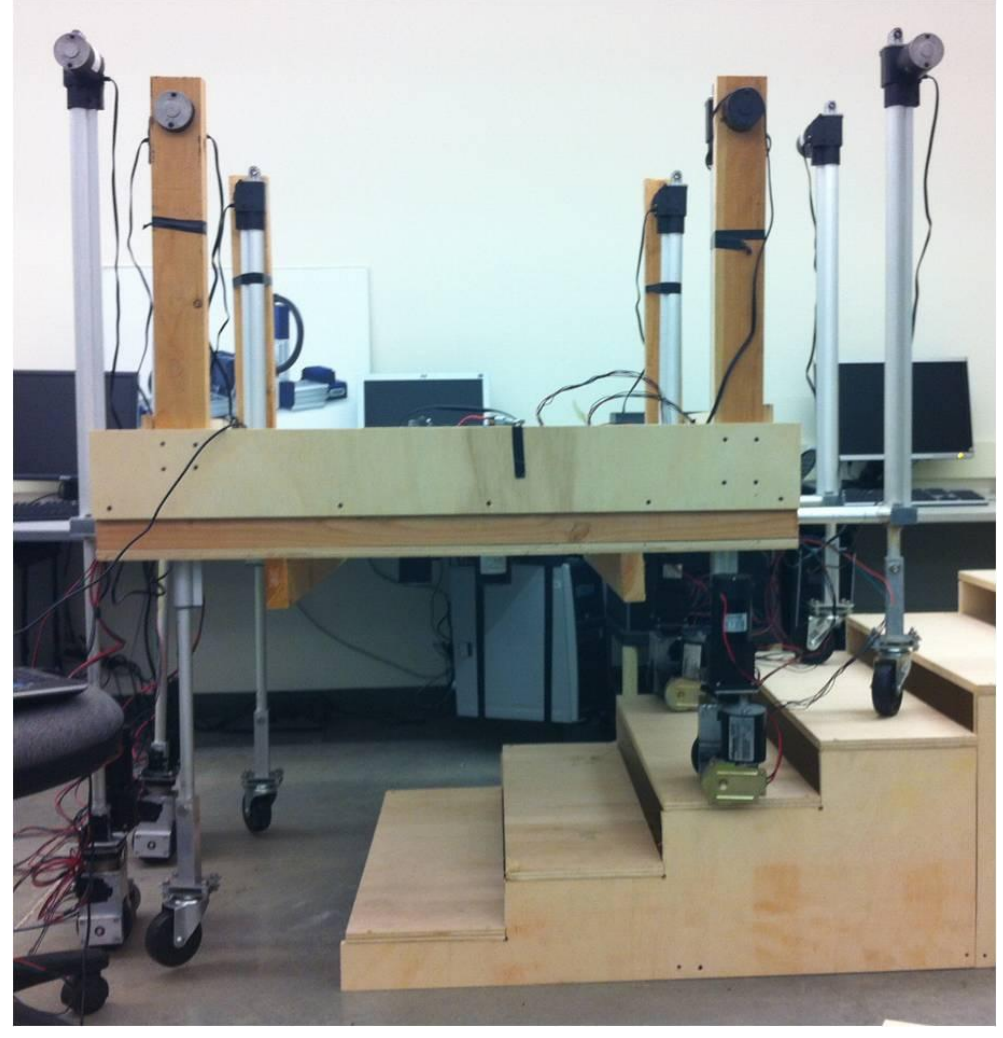

Figure E.6 - Stair Climbing Stage 6 


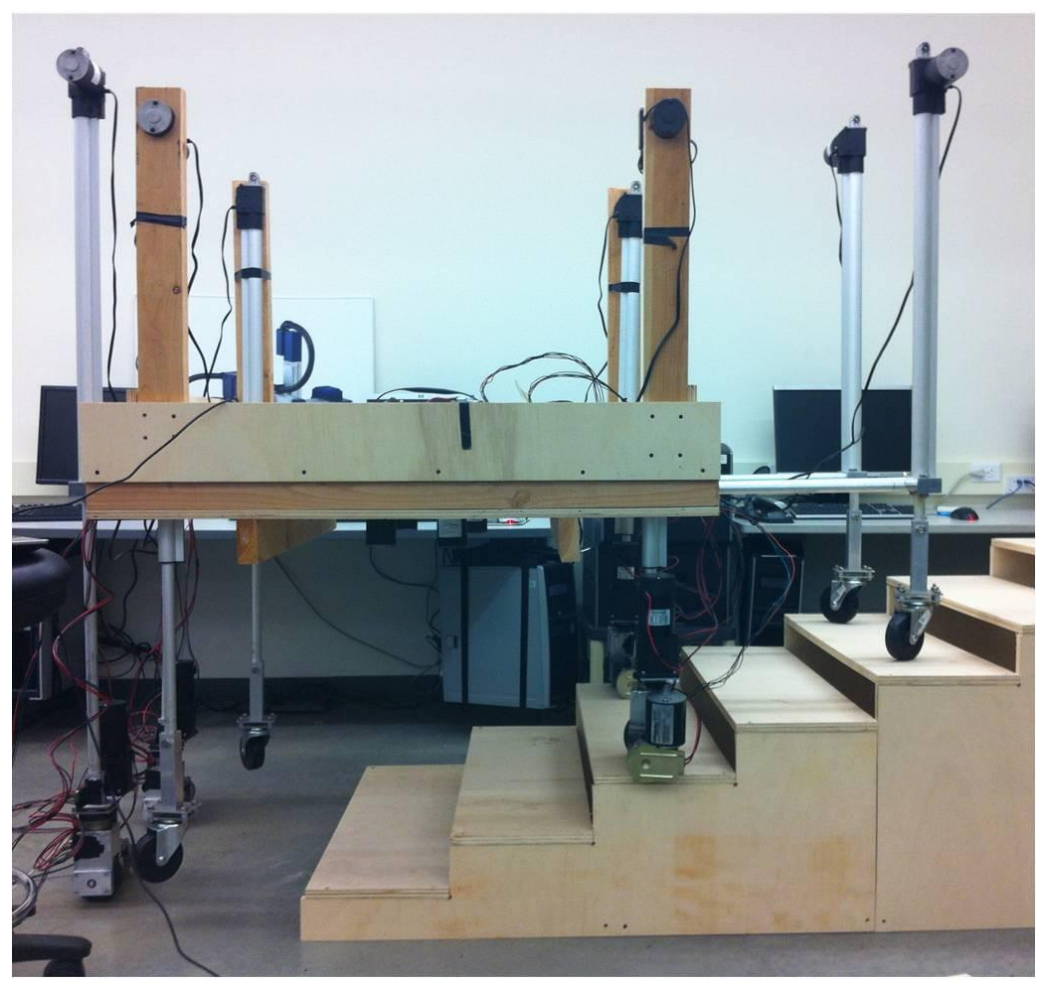

Figure E.7 - Stair Climbing Stage 7

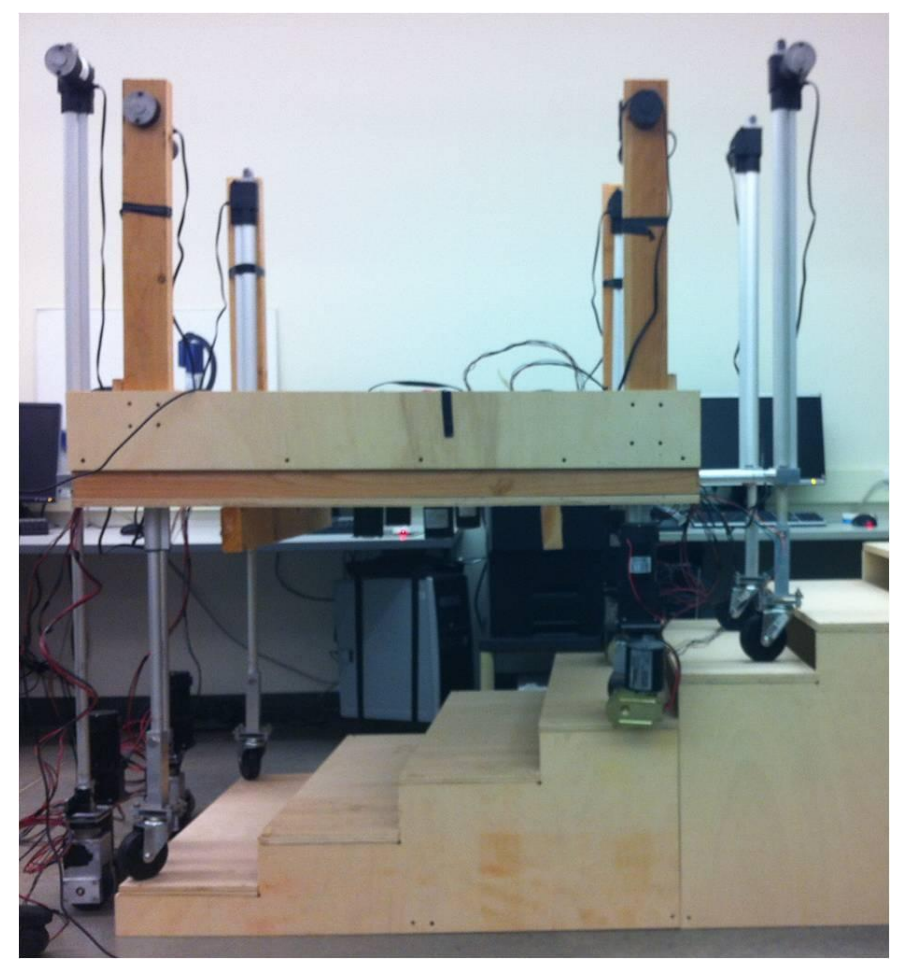

Figure E.8 - Stair Climbing Stage 8 


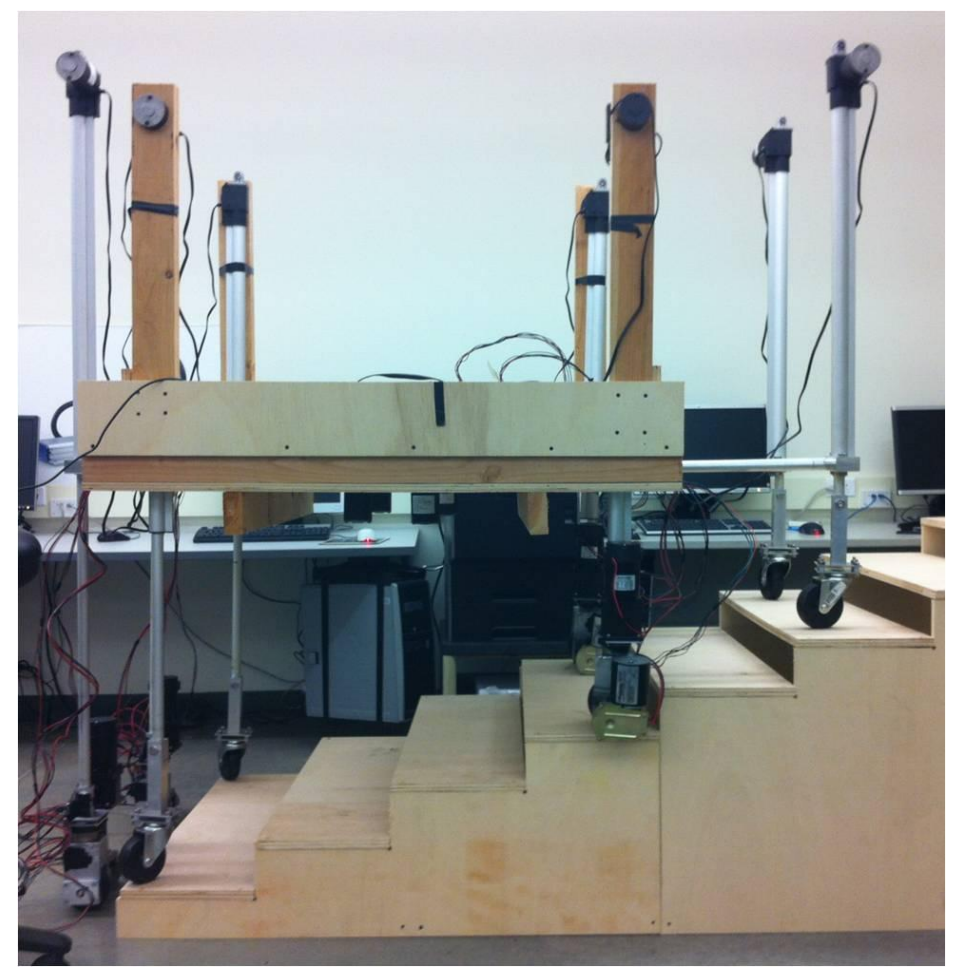

Figure E.9 - Stair Climbing Stage 9

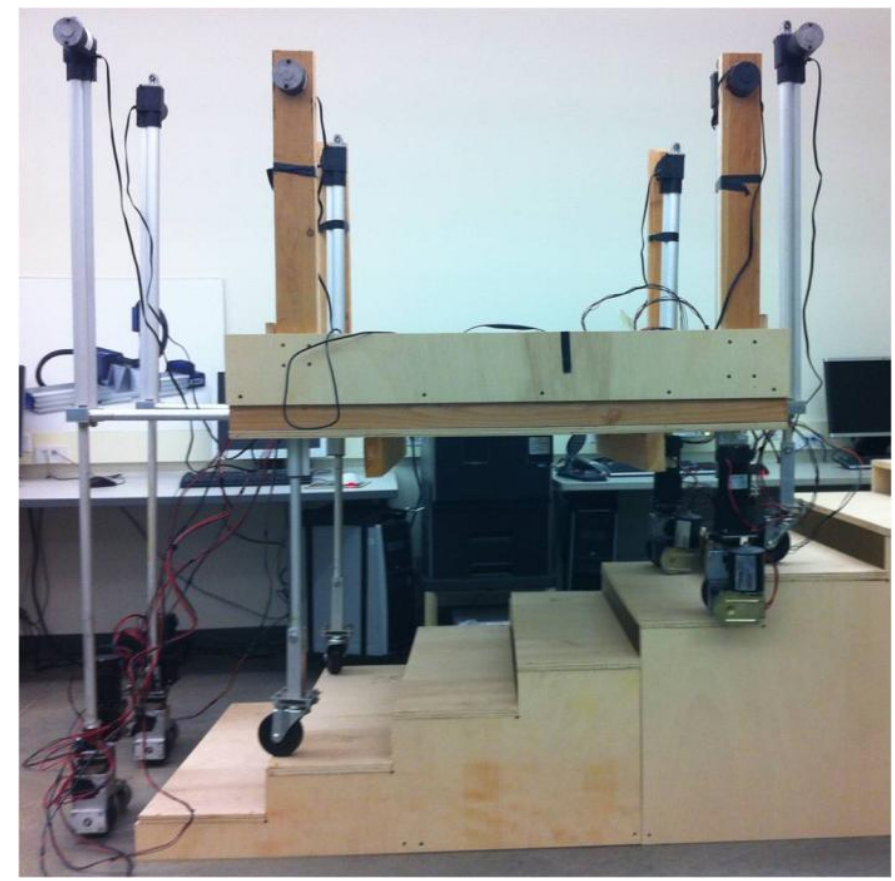

Figure E.10 - Stair Climbing Stage 10 


\section{Appendix F: SOFTWARE CODE}

/*

Manual controller for an 8-legged robotic transporter

This code allows 20 different joints of motion to be controlled manually by inputting keyboard commands.

$$
\star /
$$

int Input_A $=0$;

int Input $\mathrm{B}=0$;

int $\mathrm{P} \mathrm{W}^{-} \mathrm{M}$ value $=0$;

int motor_speed $=0$;

int $\operatorname{motor} 1 \mathrm{~L}=160$;

int $\operatorname{motor} 1 \mathrm{R}=160$;

int motor_2L $=150$;

int motor $2 \mathrm{R}=90$;

int motor $3 \mathrm{~L}=150$;

int motor_3R $=190$;

int motor_4L $=220$;

int motor $4 \mathrm{R}=150$;

int motor $5 \mathrm{~L}=255$;

int motor_5 $\mathrm{R}=90$;

int motor_6L $=120$;

int motor_6R $=120$;

int motor_on $=70$;

int motor_off $=0$;

int state $=0$;

//Pair 2, Left Side

int Pair 2 SMotor L INA $=52$;

int Pair_2 SMotor_L_INB $=53$;

int Pair_2_DMotor_L_INA $=14$;

int Pair_2 ${ }^{-}$DMotor_L_INB $=15$;

//Pair 2, Right Side

int Pair_2_SMotor_R_INA $=16$;

int Pair 2 SMotor $\mathrm{R}$ INB $=17$;

int Pair_2_DMotor_R_INA $=18$;

int Pair_2_DMotor_R_INB $=20$;

//Pair 4, Left Side

int Pair_4_SMotor_L_INA $=22$;

int Pair_4_SMotor_L_INB $=23$;

int $\mathrm{Pair}^{-}$DMotor L INA $=24$;

int Pair_4_DMotor_L_INB $=25$;

//Pair 4, Right Side

int $\mathrm{Pair} 4$ SMotor $\mathrm{R}$ INA $=26$;

int $\mathrm{Pair} 4$ SMotor $\mathrm{R}$ INB $=27$;

int Pair_4_DMotor_R_INA $=28$;

int Pair_4_DMotor_R_INB $=29$;

//Digital I/O and PWM pin declarations

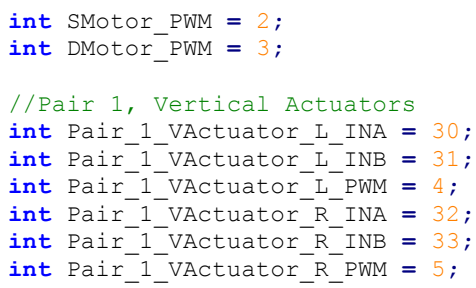

//Pair 1, Vertical Actuators

int Pair 1 VActuator L INA $=30$;

int Pair 1 VActuator L INB $=31$;

int Pair_1_VActuator_L_PWM $=4 ;$

int Pair $^{-}{ }^{-}$VActuator ${ }^{-}$INA $=32$;

int Pair 1 VActuator $\mathrm{R}$ INB $=33$;

int Pair_1_VActuator_R_PWM $=5$;

//Pair 2, Vertical Actuators

int Pair 2 VActuator L INA $=34$;

int Pair_2_VActuator_L_INB $=35$;

int Pair_2_VActuator_L_PWM $=6$;

int Pair 2 VActuator $\mathrm{R}$ INA $=36$;
// Function variable for INA pins

// Function variable for INB pins

// Function variable for PWM pins

// Function variable for varying motor speed

// PWM value for Pair 1 actuator left side

// PWM value for Pair 1 actuator right side

// PWM value for Pair 2 actuator left side

// PWM value for Pair 2 actuator right side

// PWM value for Pair 3 actuator left side

// PWM value for Pair 3 actuator right side

// PWM value for Pair 4 actuator left side

// PWM value for Pair 4 actuator right side

// PWM value for front horizontal pair left side

// PWM value for front horizontal pair right side

// PWM value for back horizontal pair left side

// PWM value for back horizontal pair right side

// Constant for PWM value assigned to drive and steer motors

// Constant to turn off motors

// State variable for switch-case

// INA of the left steering motor for Pair 2

// INB of the left steering motor for Pair 2

// INA of the left drive motor for Pair 2

// INB of the left drive motor for Pair 2

// INA of the right steering motor for Pair 2

// INB of the right steering motor for Pair 2

// INA of the right drive motor for Pair 2

// INB of the right drive motor for Pair 2

// INA of the left steering motor for Pair 4

// INB of the left steering motor for Pair 4

// INA of the left drive motor for Pair 4

// INB of the left drive motor for Pair 4

// INA of the right steering motor for Pair 4

// INB of the right steering motor for Pair 4

// INA of the right drive motor for Pair 4

// INB of the right drive motor for Pair 4

// PWM of steering motors

// PWM of driving motors

// INA of the vertical acutators, Pair 1, left side // INB of the vertical acutators, Pair 1, left side

// PWM of the vertical actuators, Pair 1, left side

// INA of the vertical acutators, Pair 1, right side

// INB of the vertical acutators, Pair 1, right side

// PWM of the vertical actuators, Pair 1, right side

// INA of the vertical acutators, Pair 2, left side // INB of the vertical acutators, Pair 2, left side

// PWM of the vertical actuators, Pair 2, left side

// INA of the vertical acutators, Pair 2, right side

\section{2}




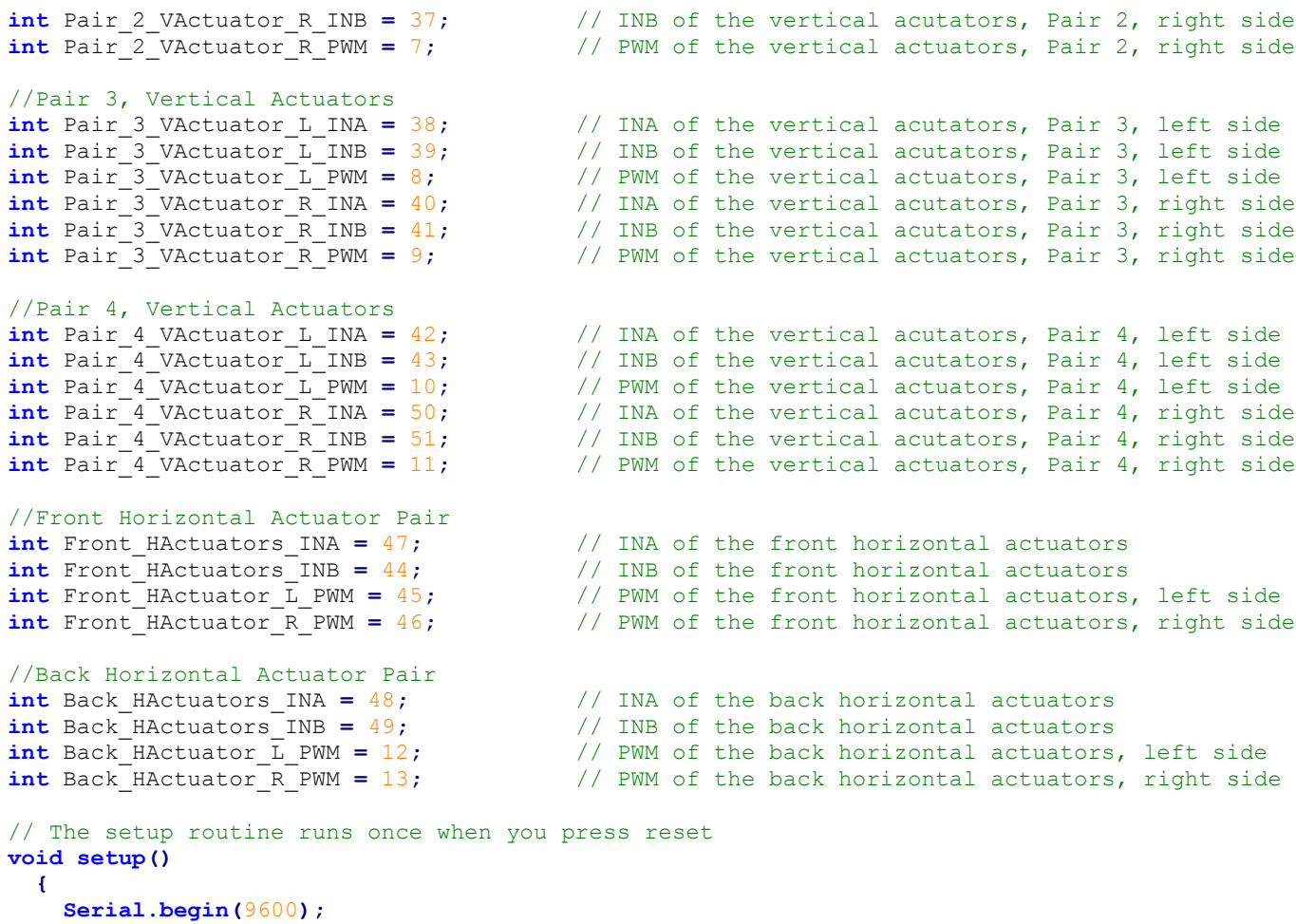

// Declares Actuator pins as outputs: pinMode(Pair 1 VActuator L INA, OUTPUT) : pinMode (Pair_1_VActuator_L_INB, OUTPUT); pinMode (Pair 1 - VActuator ${ }^{-}{ }^{-}$PWM, OUTPUT) ; pinMode (Pair 1 VActuator R INA, OUTPUT); pinMode (Pair 1 VActuator R INB, OUTPUT); pinMode (Pair_1_VActuator_R_PWM, OUTPUT);

pinMode(Pair 2 VActuator L INA, OUTPUT); pinMode (Pair_2_VActuator_L_INB, OUTPUT); pinMode (Pair_2_VActuator_L_PWM, OUTPUT); pinMode (Pair 2 VActuator R INA, OUTPUT); pinMode (Pair 2 VActuator R INB, OUTPUT); pinMode (Pair_2 ${ }^{-}$VActuator_R_PWM, OUTPUT) ;

pinMode (Pair 3 VActuator L INA, OUTPUT) pinMode (Pair 3 VActuator L INB, OUTPUT); pinMode (Pair_3_VActuator_L_PWM, OUTPUT); 
pinMode (Pair_3_VActuator_R_INA, OUTPUT); pinMode (Pair 3 -VActuator ${ }^{-}$INB, OUTPUT) ; pinMode (Pair_3_VActuator_R_PWM, OUTPUT) ;

pinMode (Pair 4 VActuator L INA, OUTPUT); pinMode (Pair 4 VActuator L INB, OUTPUT); pinMode (Pair_4_VActuator_L_PWM, OUTPUT) ; pinMode (Pair_4_VActuator_R_INA, OUTPUT); pinMode (Pair 4 VActuator R INB, OUTPUT); pinMode (Pair_4_VActuator_R_PWM, OUTPUT) ;

pinMode (Front_HActuators_INA, OUTPUT); pinMode (Front HActuators INB, OUTPUT); pinMode (Front_HActuator_L_PWM, OUTPUT) pinMode (Front_HActuator_R_PWM, OUTPUT) ;

pinMode (Back HActuators INA, OUTPUT); pinMode (Back_HActuators_INB, OUTPUT); pinMode (Back_HActuator_L_PWM, OUTPUT); pinMode (Back_HActuator_R_PWM, OUTPUT);

// Default all pin outputs to low analogWrite (SMotor_PWM, motor_off); analogWrite (DMotor_PWM, motor_off);

digitalWrite(Pair_2_SMotor_L_INA, LOW) ; digitalWrite (Pair_2_SMotor_L_INB, LOW); digitalWrite(Pair 2 DMotor L INA, LOW); digitalWrite(Pair_2_DMotor_L_INB, LOW) ;

digitalWrite(Pair_2_SMotor_R_INA, LOW) ; digitalWrite (Pair 2 SMotor R INB, LOW) digitalWrite (Pair_2_DMotor_R_INA, LOW); digitalWrite (Pair_2_DMotor_R_INB, LOW);

digitalWrite (Pair 4 SMotor L INA, LOW) digitalWrite (Pair_4_SMotor_L_INB, LOW); digitalWrite (Pair_4_DMotor_L_INA, LOW); digitalWrite(Pair_4_DMotor_L_INB, LOW);

digitalWrite(Pair_4_SMotor_R_INA, LOW) ; digitalWrite (Pair_4_SMotor_R_INB, LOW); digitalWrite (Pair 4 DMotor R INA, LOW); digitalWrite (Pair_4_DMotor_R_INB, LOW) ;

digitalWrite(Pair_1_VActuator_L_INA, LOW); digitalWrite (Pair 1 VActuator L INB, LOW);

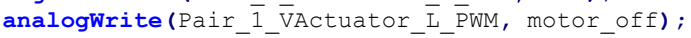
digitalWrite (Pair $\overline{1}_{-} \overline{1}_{\text {VActuato }} \bar{r}_{-} \bar{R}_{-}$INA, LOW) ; digitalWrite (Pair 1 VActuator $R$ INB, LOW); analogWrite (Pair_ $\overline{1}$ - VActuator $\bar{R}_{-} \bar{P} W M$, motor_off) ;

digitalWrite (Pair 2 VActuator L INA, LOW) ; digitalWrite (Pair 2 VActuator L INB, LOW); analogWrite (Pair_ 2 _V $A c t u a t o r \_\bar{L} \_\bar{P} W M$, motor_off); digitalWrite (Pai $\bar{r} \overline{2}_{2}$ VActuator_$\overline{\mathrm{R}}$ INA, LOW) ; digitalWrite (Pair 2 VActuator $\mathrm{R}^{-}$INB, LOW);

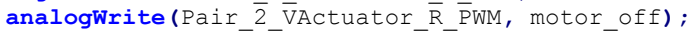

digitalWrite (Pair_3_VActuator_L_INA, LOW) ; digitalWrite (Pair 3 VActuator L INB, LOW) analogWrite (Pair $\overline{3}$ VActuator $\overline{\mathrm{L}} \overline{\mathrm{P}} W \mathrm{M}$, motor off); digitalWrite (Pai $\bar{r} \overline{3}_{3}$ VActuator_$\overline{\mathrm{R}}$ INA, LOW) ; digitalWrite (Pair 3 VActuator R INB, LOW); analogWrite (Pair $\overline{3}$ VActuator $\bar{R} \bar{P} W M$, motor off);

digitalWrite (Pair_4_VActuator_L_INA, LOW); digitalWrite (Pair 4 VActuator L INB, LOW): analogWrite (Pair 4 VActuator L PWM, motor off); digitalWrite (Pair $\overline{4}$ __VActuator_ $\bar{R}$ _INA, LOW) ; digitalWrite (Pair_4 VActuator_R_INB, LOW); analogWrite(Pair_ $\overline{4}$ - VActuator $\bar{R}_{-}{ }_{\text {PWM, }}$, motor_off);

digitalWrite (Front_HActuators_INA, LOW) ; digitalWrite (Front HActuators INB, LOW) ; analogWrite (Front HActuator L PWM, motor off); analogWrite (Front_HActuator_R_PWM, motor_off); 


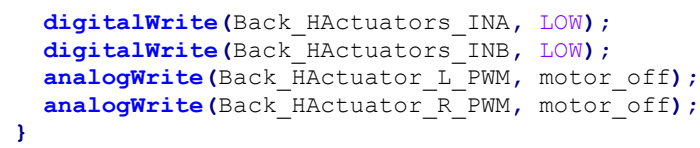




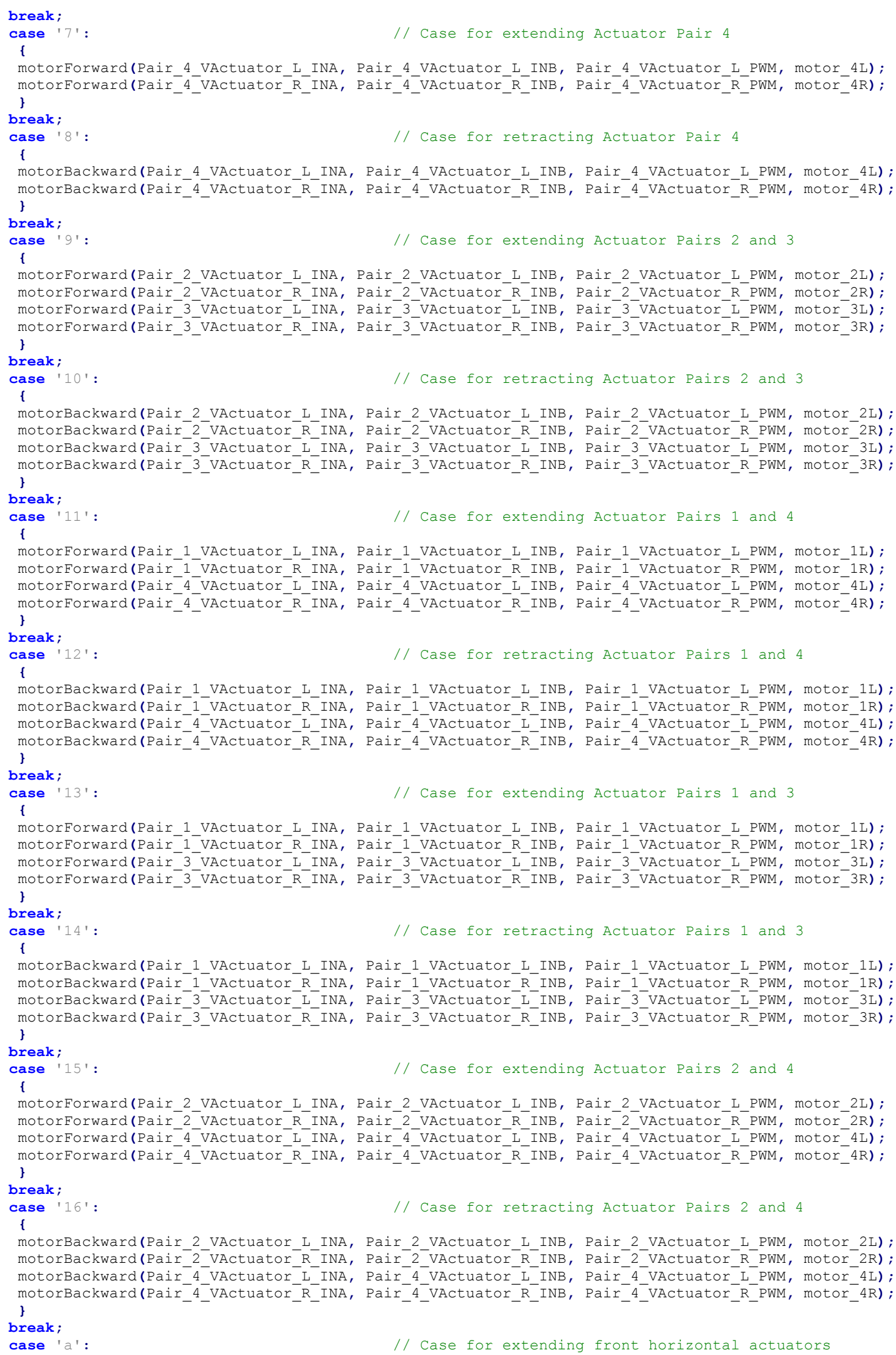




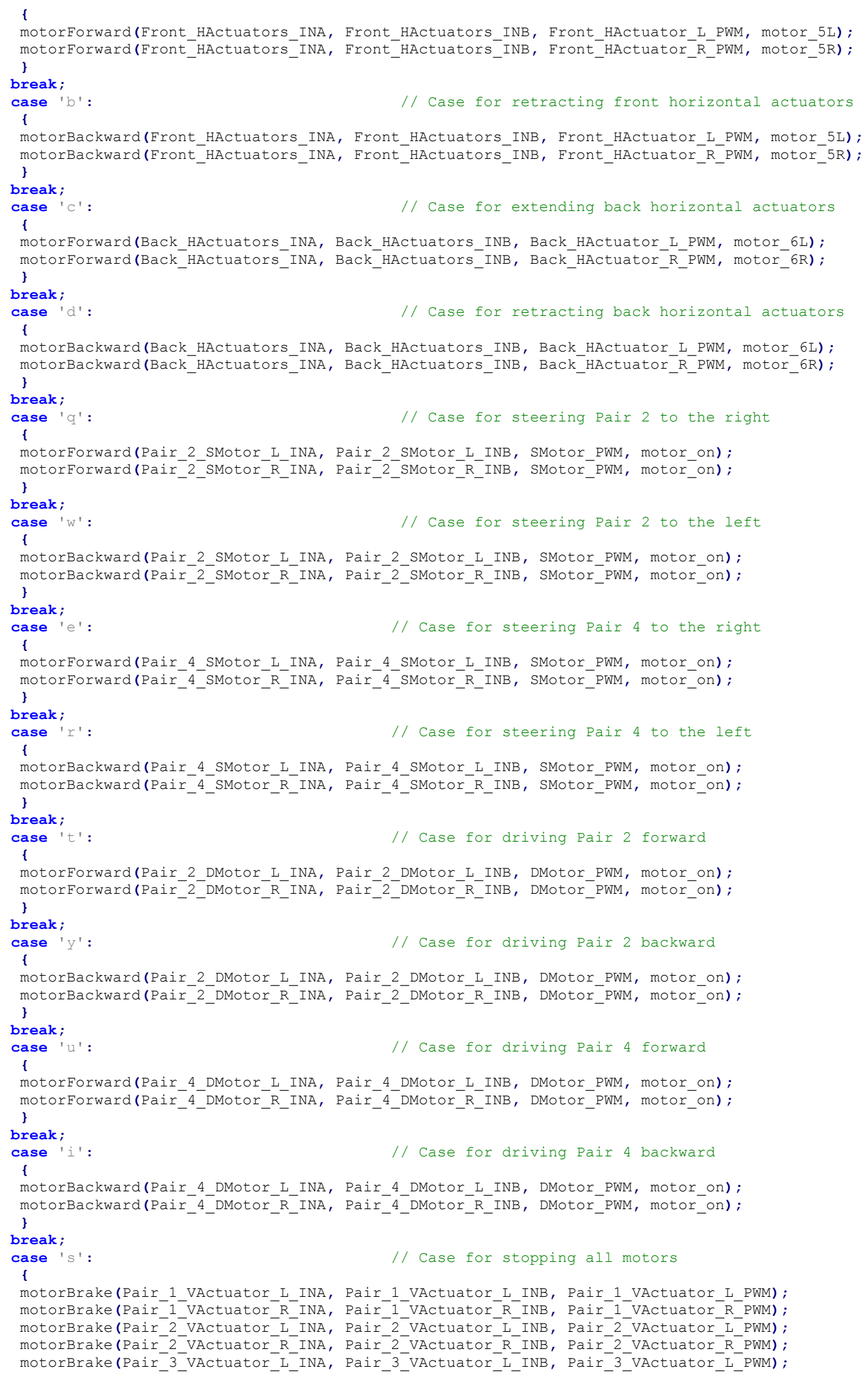


motorBrake (Pair_3_VActuator_R_INA, Pair_3_VActuator_R_INB, Pair_3_VActuator_R_PWM); motorBrake (Pair 4 VActuator L INA, Pair 4 VActuator L INB, Pair 4 VActuator L PWM):

motorBrake (Pair 4 VActuator $\mathrm{R}$ INA, Pair 4 VActuator $\mathrm{R}$ INB, Pair 4 VActuator $\mathrm{R}$ PWM).

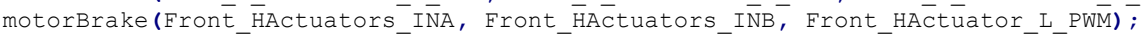

motorBrake (Front ${ }^{-}$HActuators ${ }^{-}$INA, Front ${ }^{-}$HActuators ${ }^{-}$INB, Front ${ }^{-}$HActuator ${ }^{-}{ }^{-}$PWM) ;

motorBrake (Back $\bar{H} A c t u a t o r s ~ \bar{I} N A$, Back HĀctuators I $\bar{N} B$, Back HActuator L $\overline{\mathrm{P}} W \overline{\mathrm{M}}$ ) ;

motorBrake(Back_HActuators_INA, Back_HActuators_INB, Back_HActuator_R_PWM);

motorBrake(Pair_2_DMotor_L_INA, Pair_2_DMotor_L_INB, DMotor_PWM);

motorBrake (Pair_2_DMotor_R_INA, Pair_2_DMotor_R_INB, DMotor_PWM);

motorBrake (Pair 4 DMotor L INA, Pair 4 DMotor L INB, DMotor PWM);

motorBrake(Pair_4_DMotor_R_INA, Pair_4_DMotor_R_INB, DMotor_PWM);

motorBrake(Pair_2-SMotor_L_INA, Pair_2_SMotor_L_INB, SMotor_PWM);

motorBrake (Pair 2 SMotor ${ }^{-}$INA, Pair 2 SMotor ${ }^{-}$INB, SMotor $P W M$ )

motorBrake (Pair_4_SMotor_L_INA, Pair_4_SMotor_L_INB, SMotor_PWM);

motorBrake(Pair_4_SMotor_R_INA, Pair_4_SMotor_R_INB, SMotor_PWM) ;

\}

break；

default:

Serial.print("Not a valid command.");

\}

\} 